Florida International University FIU Digital Commons

4-12-2004

\title{
Design and analysis of micro-channel heat- exchanger embedded in Low Temperature Co-fire Ceramic (LTCC)
}

Hari Kishore Adluru

Florida International University, hadlu001@fiu.edu

DOI: $10.25148 /$ etd.FI13101532

Follow this and additional works at: https://digitalcommons.fiu.edu/etd

Part of the Mechanical Engineering Commons

\section{Recommended Citation}

Adluru, Hari Kishore, "Design and analysis of micro-channel heat-exchanger embedded in Low Temperature Co-fire Ceramic (LTCC)" (2004). FIU Electronic Theses and Dissertations. 1160.

https://digitalcommons.fiu.edu/etd/1160 
FLORID A INTERNATIONAL UNIVERSITY

Miami, Florida

DESIGN AND ANALYSIS OF MICRO-CHANNEL HEAT-EXCHANGER EMBEDDED IN LOW TEMPERATURE CO-FIRE CERAMIC (LTCC)

A thesis submitted in partial fulfillment of the requirements for the degree of MASTER OF SCIENCE in MECHANIC AL ENGINEERING by

Hari Kishore Adluru 
To: Dean Vish Prasad

College of Engineering

This thesis, written by Hari Kishore Adluru, and entitled Design and Analysis of Microchannel Heat-exchanger Embedded in Low Temperature Co-fire Ceramic (LTCC), having been approved in respect to style and intellectual content, is referred to you for judgment.

We have read this thesis and recommend that it be approved.

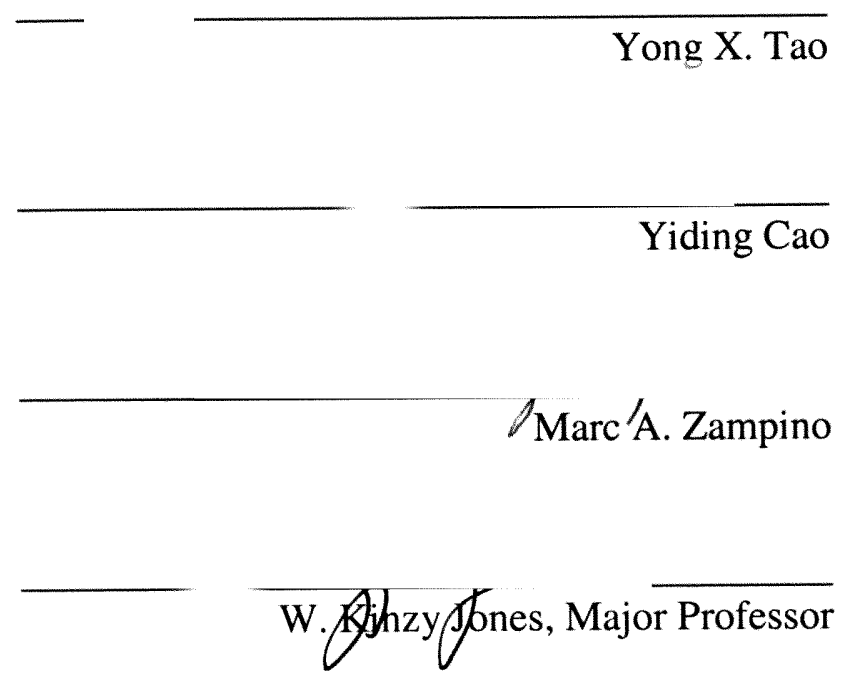

Date of Defense: April 12, 2004

The thesis of Hari Kishore Adluru is approved.

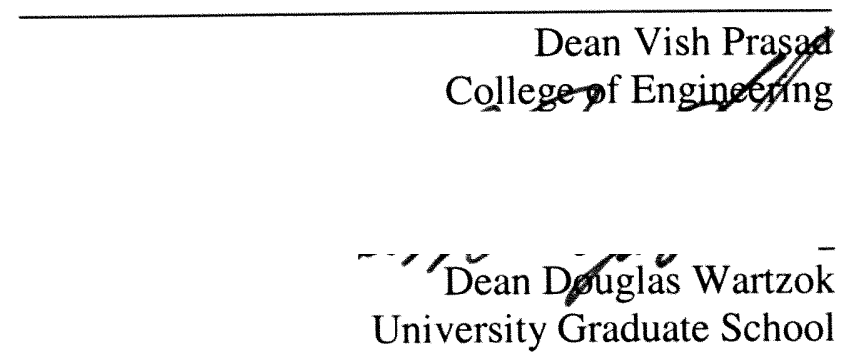

Florida International University, 2004 
(C) Copyright 2004 by Hari Kishore Adluru All rights reserved. 


\section{DEDICATION}

I dedicate this thesis to my parents and to my sister and brother for their love and support throughout my life. 


\section{ACKNOWLEDGMENTS}

I wish to thank all the committee members for their support, patience and comments. In particular, I would like to thank my Major Professor Dr. W. Kinzy Jones for giving me an opportunity to work on this project in my fashion and my co-advisor, Dr Marc A. Zampino for his patience, support and suggestions from the beginning of this work. I would like to thank Dr. Yanquin Liu and Mrs. Jain for their help in preparing the samples. My special thanks to the employees of Applica Consumer Products Inc., Mr. Leslie Campbell, Mr. Chuck Weyant, Mr. Walter Yap, Mr. Richard Rogistar and Mr. Zac Smith for their valuable support. I would like to thank the technical support of CFDesign by Blue Ridge Numerics Inc. - Dr. Peggy Menzies, Mr. Jason and Mr. Ken Smith for reviewing the analysis. I would like to thank my colleagues and my friends, with special thanks to Roshan, Raghu, Prasanth, Kiran, Vishnuvardhan and Aparna for their help in several ways with my work. 


\begin{abstract}
OF THE THESIS
DESIGN AND ANALYSIS OF MICRO-CHANNEL HEAT-EXCHANGER

EMBEDDED IN LOW TEMPERATURE CO-FIRE CERAMIC (LTCC)
\end{abstract}

by

Hari Kishore Adluru

Florida International University, 2004

Miami, Florida

Professor W. Kinzy Jones, Major Professor

Increased device density, switching speeds of integrated circuits and decrease in package size is placing new demands for high power thermal-management. The convectional method of forced air cooling with passive heat sink can handle heat fluxes up-to $3-5 \mathrm{~W} / \mathrm{cm}^{2}$; however current microprocessors are operating at levels of $100 \mathrm{~W} / \mathrm{cm}^{2}$. This demands the usage of novel thermal-management systems. In this work, water-cooling systems with active heat sink are embedded in the substrate.

The research involved fabricating LTCC substrates of various configurations - an open-duct substrate, the second with thermal vias and the third with thermal vias and free-standing metal columns and metal foil. Thermal testing was performed experimentally and these results are compared with CFD results. An overall thermal resistance for the base substrate is demonstrated to be $3.4^{\circ} \mathrm{C} / \mathrm{W}-\mathrm{cm}^{2}$. Addition of thermal vias reduces the effective resistance of the system by 7 times and further addition of free standing columns reduced it by 20 times. 


\section{TABLE OF CONTENTS}

CHAPTER

PAGE

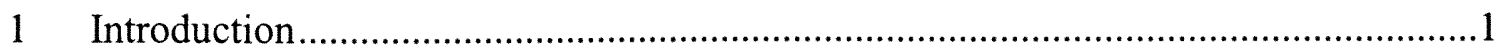

1.1 An overview of Low Temperature Co-fire Ceramic Technology ...................... 1

1.2 Need for thermal management........................................................................ 2

1.3 Classical cooling techniques in electronic components .................................... 3

1.4 Other non-conventional cooling techniques ..................................................... 5

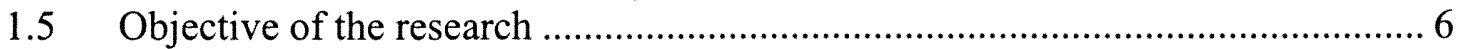

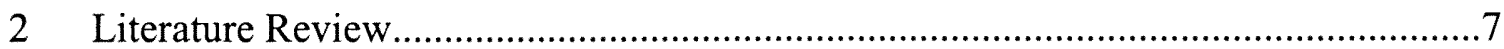

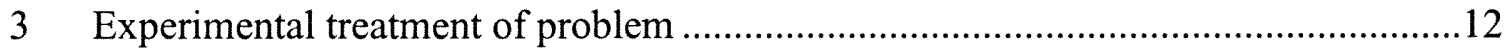

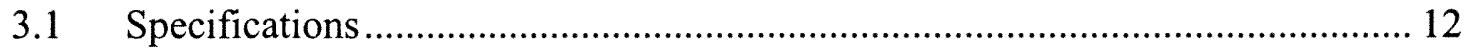

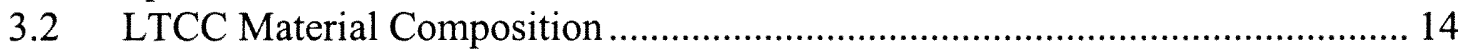

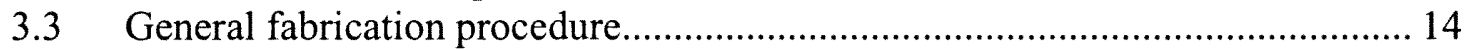

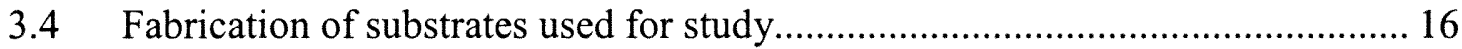

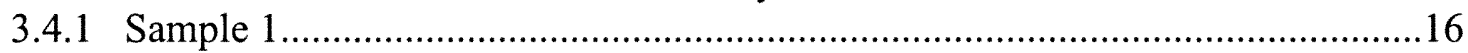

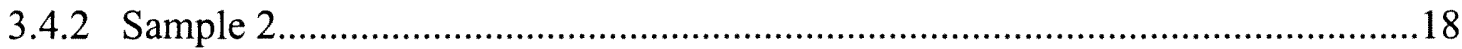

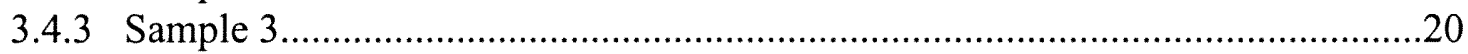

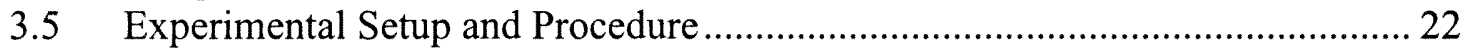

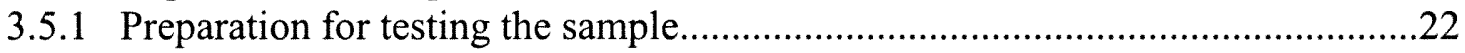

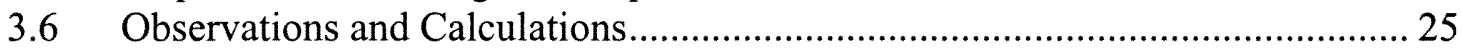

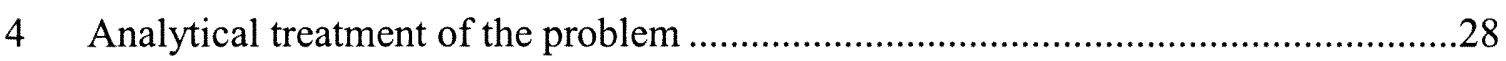

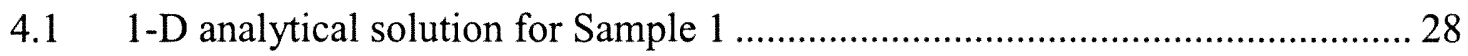

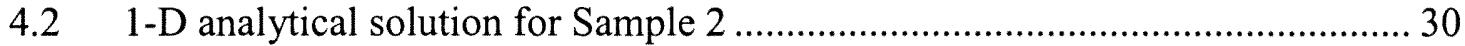

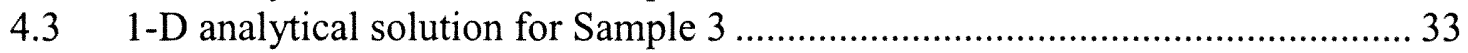

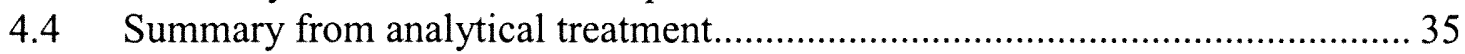

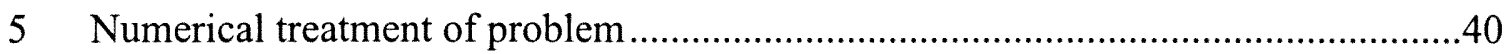

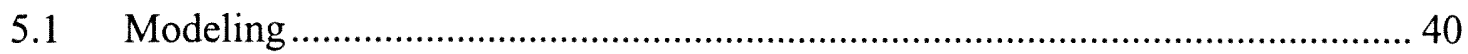

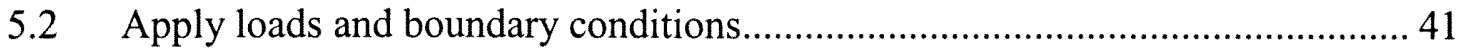

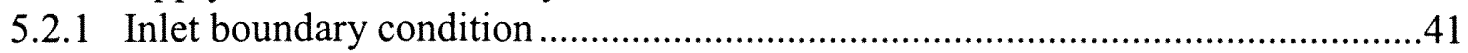

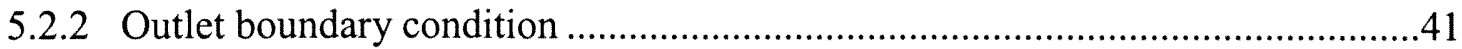

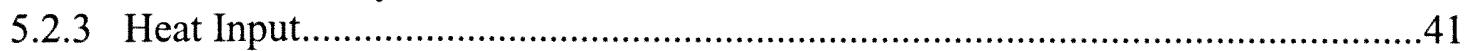

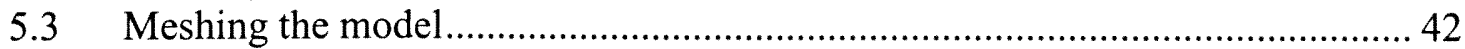

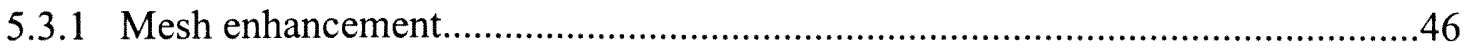

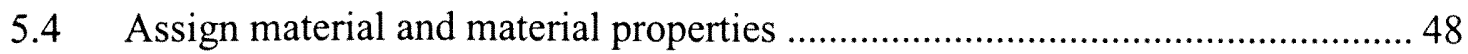

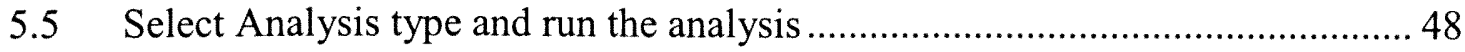




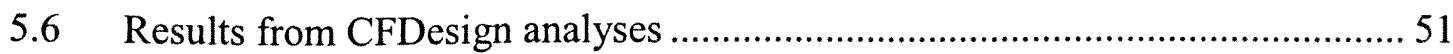

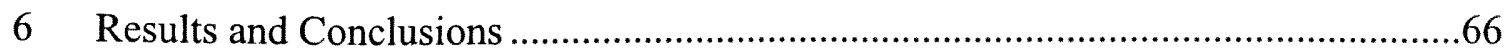

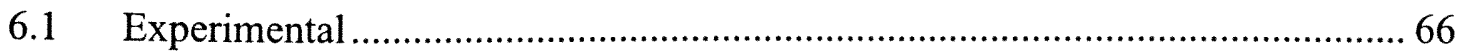

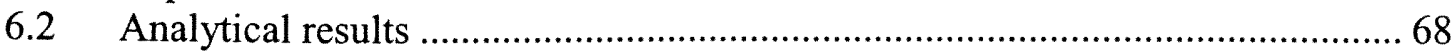

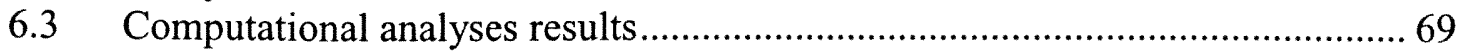

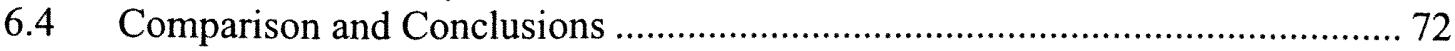

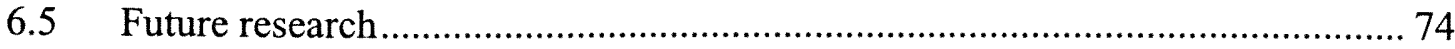

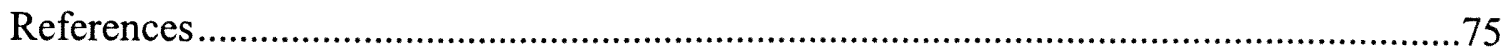

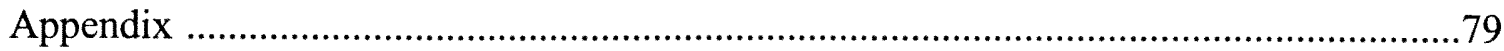


Table 3-1 Specifications of Samples used for testing. .12

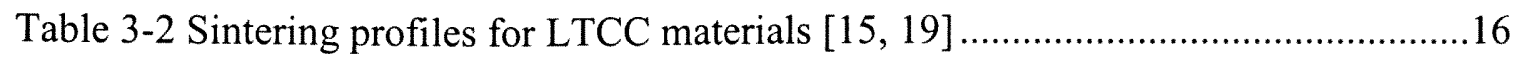

Table 4-1 Effective overall thermal resistance of the system using 1-D analytical approach.

Table 5-1 Finite element summary.

Table 5-2 Mesh enhancement details.

Table 5-3 Material properties.

Table 6-1 Effective overall thermal resistance $\left(\right.$ in ${ }^{\circ} \mathrm{C} / \mathrm{W}-\mathrm{cm}^{2}$ ) using different techniques

Table 1 Observations and calculations of various test substrates at constant flow rate.

Table 2 Observations and Calculations of various test substrates at constant power.

Table 3 Observations and Calculations of various test substrates at constant power. 


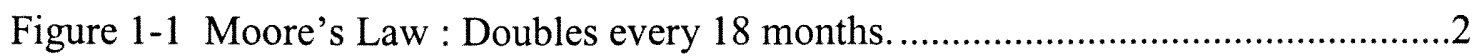

Figure 2-1 Schematic of rectangular micro-channel heat sinks and unit cell [36]. 8

Figure 2-2 Structure under investigation with its packaging and microchannels [38].

Figure 3-1 Outline of Samples fabricated 12

Figure 3-2 Test sample with embedded cooling system and ......................................13

Figure 3-3 Detail view of $1 \mathrm{~cm}^{2}$ thermal via array on test samples.............................13

Figure 3-4 Cross-sectional view of Ag columns in Sample 3 ......................................14

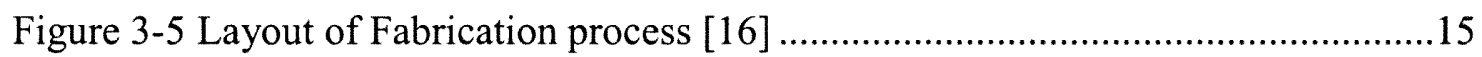

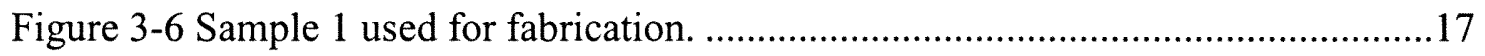

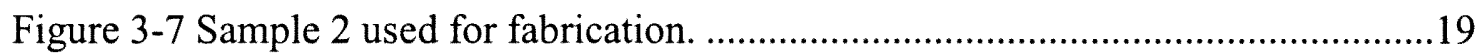

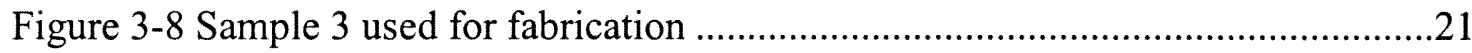

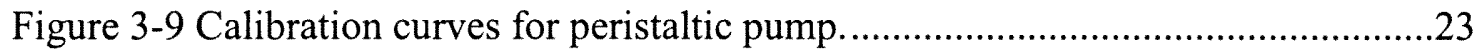

Figure 3-10 Substrate rise in temperature and effective overall thermal resistance of the system for all test configurations: $\mathrm{C}$ - channel only; $\mathrm{V}-$ thermal vias; F-pin fins.

Figure 3-11 Effective thermal resistance of the system with varying power

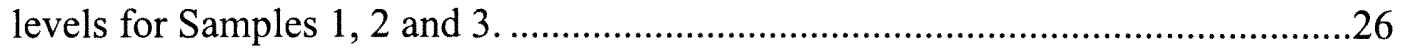

Figure 3-12 Effective thermal resistance of the system with varying flow rates for Samples 1, 2 and 3, three power levels $10 \mathrm{~W}, 20 \mathrm{~W}$ and $30 \mathrm{~W}$ shown for Samples 2 and 3; and $10 \mathrm{~W}$ for Sample 1.

Figure 4-1 Equivalent thermal resistance circuit diagram for Sample 1. ......................29

Figure 4-2 Equivalent thermal resistance circuit diagram for Sample 2 ......................31

Figure 4-3 Equivalent thermal resistance circuit diagram for Sample 3 ........................33 
Figure 4-4 Description of pitch along and across the flow for (A) In-line (B) Staggered array [32]

Figure 4-5 Substrate rise in temperature and effective overall thermal resistance of the system for all test configurations: $\mathrm{C}$ - channel only; $\mathrm{V}$ thermal vias; F-pin fins.

Figure 4-6 Effective thermal resistance of the system with varying power levels for Samples 1, 2 and 3 (logarithmic graph).

Figure 4-7 Effective thermal resistance of the system with varying flow rates for Samples 1, 2 and 3 at $30 \mathrm{~W}$ power input (logarithmic graph). 38

Figure 5-1 Boundary conditions with heat source as total heat generation. 42

Figure 5-2 Meshing for sample 1 (shows LTCC substrate, flow volume and $\mathrm{Cu}$ shim)...... 43

Figure 5-3 Meshing for sample 2 (shows LTCC substrate, vias, Ag pad and $\mathrm{Cu}$ shim). .43

Figure 5-4 Detailed meshing of thermal vias in samples 2 and 3 .44

Figure 5-5 Plot showing percentage error in Q w.r.t. element size of water. 46

Figure 5-6 Mesh enhancement in fluid near the wall and fluid interface. 47

Figure 5-7 The norm of mean residual at each iteration for Sample 1. 50

Figure 5-8 The norm of mean residual at each iteration for Sample 2........................50

Figure 5-9 The norm of mean residual at each iteration for Sample 3. 51

Figure 5-10 Iso-velocities for Sample1 at $294 \mathrm{~mL} / \mathrm{min}$ flow rate and $50 \mathrm{~W} / 80^{\circ} \mathrm{C}$ power source.

Figure 5-11 Iso-velocities for Sample2 at $294 \mathrm{~mL} / \mathrm{min}$ flow rate and $50 \mathrm{~W} / 80^{\circ} \mathrm{C}$ power source.

Figure 5-12 Iso-velocities along 010 for Sample 3 at $294 \mathrm{~mL} / \mathrm{min}$ flow rate and $50 \mathrm{~W} / 80^{\circ} \mathrm{C}$ power source.

Figure 5-13 Iso-velocities for Sample3 at $1230 \mathrm{~mL} / \mathrm{min}$ flow rate and $50 \mathrm{~W}$ power input. 
Figure 5-14 Velocity of water down-stream for Samples 1, 2 and 3 at 293 $\mathrm{ml} / \mathrm{min}$ flow rate.

Figure 5-15 Velocity of water down-stream for Samples 1, 2 and 3 at 1230 $\mathrm{ml} / \mathrm{min}$ flow rate. 55

Figure 5-16 Isotherms for Sample1 at $294 \mathrm{~mL} / \mathrm{min}$ flow rate and $50 \mathrm{~W}$ power input (shows full model including $\mathrm{Cu}$ shim).

Figure 5-17 Isotherms for Sample2 at $294 \mathrm{~mL} / \mathrm{min}$ flow rate and $50 \mathrm{~W}$ power input (shows full model including $\mathrm{Cu}$ shim).

Figure 5-18 Isotherms for Sample3 at $294 \mathrm{~mL} / \mathrm{min}$ flow rate and $50 \mathrm{~W}$ power input (shows full model including $\mathrm{Cu}$ shim)

Figure 5-19 Isotherms for Sample3 at $294 \mathrm{~mL} / \mathrm{min}$ flow rate and $50 \mathrm{~W}$ power input (shows $\mathrm{Cu}$ shim, vias, $\mathrm{Ag}$ pad and $\mathrm{Ag}$ columns).

Figure 5-20 Isotherms for Sample3 along (010) at $294 \mathrm{~mL} / \mathrm{min}$ flow rate and $50 \mathrm{~W}$ power input.

Figure 5-21 Isotherms for Sample3 along (100) at $294 \mathrm{~mL} / \mathrm{min}$ flow rate and $50 \mathrm{~W}$ power input.

Figure 5-22 Temperature of water down-stream for Samples 1, 2 and 3 at 294 $\mathrm{ml} / \mathrm{min}$ flow rate and $50 \mathrm{~W}$ power input along the center line duct.

Figure 5-23 Temperature of the system along the thickness of the substrate (logarithmic plot).

Figure 5-24 Isotherms for Sample1 at $1230 \mathrm{~mL} / \mathrm{min}$ flow rate and $50 \mathrm{~W}$ power input (shows full model including $\mathrm{Cu}$ shim)

Figure 5-25 Isotherms for Sample2 at $1230 \mathrm{~mL} / \mathrm{min}$ flow rate and $50 \mathrm{~W}$ power input (shows full model including $\mathrm{Cu}$ shim)...

Figure 5-26 Isotherms for Sample3 at $1230 \mathrm{~mL} / \mathrm{min}$ flow rate and $50 \mathrm{~W}$ power input (shows full model including $\mathrm{Cu}$ shim)...

Figure 5-27 Temperature of water down-stream for Samples 1, 2 and 3 at $1230 \mathrm{ml} / \mathrm{min}$ flow rate and $50 \mathrm{~W}$ power input along the center and at a distance of $0.6 \mathrm{~mm}$ away from the center line of the duct. 
Figure 6-1 Substrate rise in temperature and effective overall thermal resistance of the system for all test configurations: $\mathrm{C}$ - channel; $\mathrm{V}$ thermal vias; $\mathrm{F}$ - pin fins.

Figure 6-2 Effect of variation in flow rate and addition of pin fins in the duct on the system's thermal resistance.

Figure 6-3 Substrate rise in temperature and effective overall thermal resistance of the system for all test configurations: $\mathrm{C}$ - channel; $\mathrm{V}$ thermal vias; $\mathrm{F}$ - pin fins 70

Figure 6-4 Effect of variation in flow rate on system's overall thermal resistance

Figure 6-5 Effect of variation in flow rate on convective thermal resistance 72 


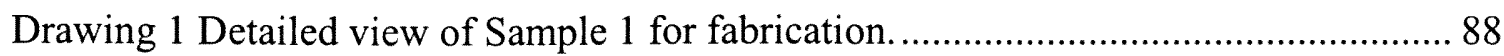

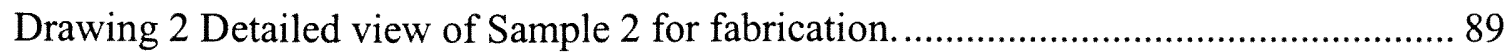

Drawing 3 Detailed view of Sample 3 for fabrication.............................................. 90

Drawing 4 Detailed view of Sample 1 for analysis. .................................................... 91

Drawing 5 Detailed view of Sample 2 for analysis. ................................................. 92

Drawing 6 Detailed view of Sample 3 for analysis. ....................................................... 93 


\section{Introduction}

\subsection{An overview of Low Temperature Co-fire Ceramic Technology}

LTCC is an acronym for Low Temperature Co-fired Ceramic. It is a multilayer ceramic technology, which possesses the ability to embed passive elements, such as resistors, capacitors and inductors into a ceramic interconnect package while the active elements are mounted on the top layer. This tape is so named because of several material properties including firing cycle, firing capabilities and composition. It is considered to be a low temperature material because it is fired at a temperature below $1000{ }^{\circ} \mathrm{C}$. Since the tape and all passive elements that may be embedded in it can be fired at the same temperature, it is said to be co-fireable. It is a ceramic because the major components are oxides.

LTCC provides an electrical interconnect, made from multi-layered ceramic dielectric tape and thick film conducting materials. LTCC systems offer high performance packaging solutions for high-frequency devices in a wide variety of wireless and telecommunication, microwave and automotive applications. LTCC technology provides a promising way to realize high quality multi-chip modules (MCM), which have huge market prospects. The major RF opportunities are in the fields of mobile telecommunication devices; wireless local networks such as Blue-tooth, geographical positioning such as GPS and in broadband access connection systems.

LTCC technology possesses several advantages making it suitable for mass production in telecommunication applications. The process itself enables high yield, fast turn around and reduced cost of devices. This combination together with the possibility of 
fabricating fine conductive lines and spaces, small interconnect vias and high dielectric constant layers are necessary for high-density packaging. Also, once fired, the tapes are thermally stable compared to silicon devices, which generally work best at or near room temperature, $22{ }^{\circ} \mathrm{C}$. LTCC devices have been shown to work in temperatures exceeding $150^{\circ} \mathrm{C}$.

The last decade has seen the appearance of many commercial LTCC material systems including ceramic tapes, suitable conductors and resistor pastes (DuPont 951 and 943, Ferro A6-5-M-13, Heraeus CT700 and CT2000) and their electrical and thermomechanical properties have been well reported $[1,2,3]$. This development has accelerated their utilization in microwave technologies and also commercially available mobile phones in transmit and receive modules (T/R) $[4,5,6]$.

\subsection{Need for thermal management}

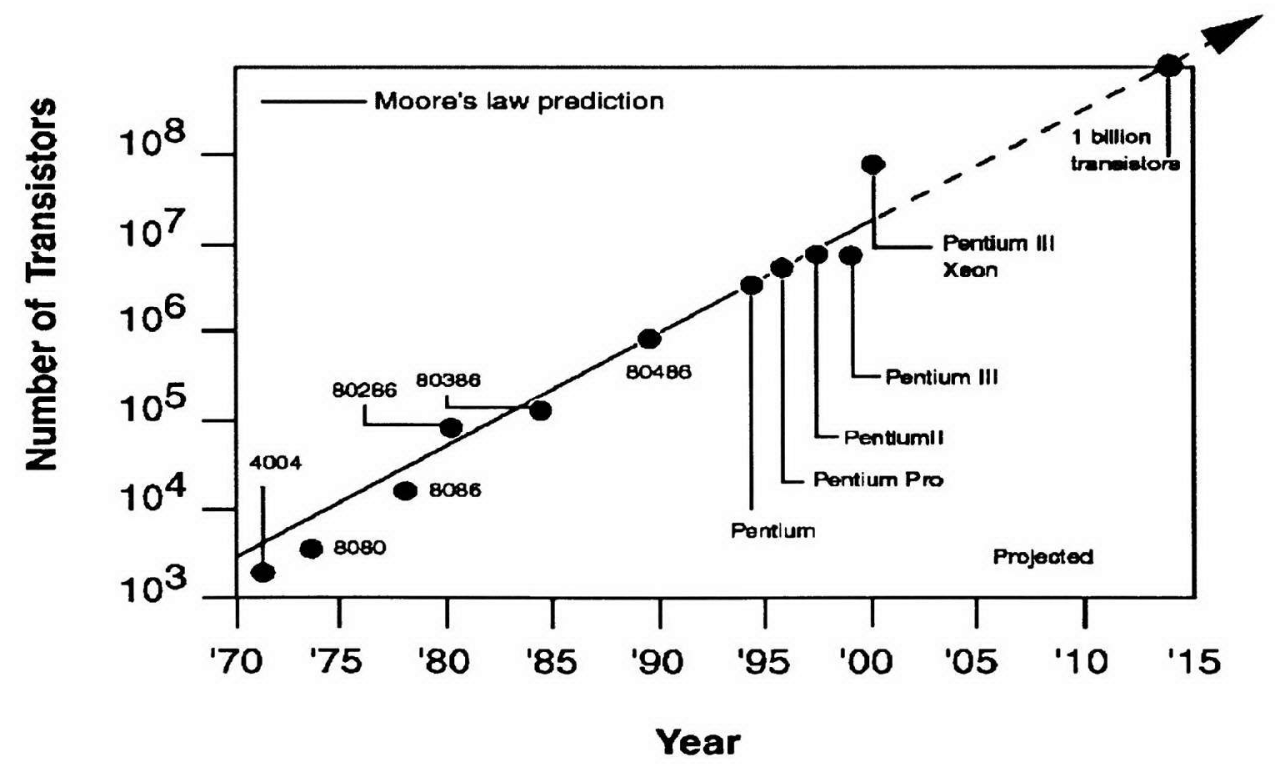

Figure 1-1 Moore's Law : Doubles every 18 months. 
Moore's law states that the number of transistors per square inch on integrated circuits doubled in every 18 months. The transistor densities and operational frequencies continue to increase especially in $\mathrm{RF} /$ microwave systems. This in return increases the operating power densities, which are expected to exceed $1000 \mathrm{~W} / \mathrm{cm}^{2}$ over small die area. In spite of the vast developments in science, an unavoidable residue produced in integrated circuits is heat. The amount of residual heat produced is directly proportional to the power densities used. It was estimated about $70 \%$ of the failures in integrated circuits are due to thermal failures. Also, the failure rate doubles for every $20{ }^{\circ} \mathrm{C}$ temperature rise in the substrate. Due to increase in transistor density and switching speed of integrated circuits and a decrease in package size, the emerging generation of highpower IC's requires high performance thermal management.

The thermal management system must consider the complete thermal path from heat source to the heat sink; therefore, the entire system must be considered. The thermal management requires optimization of the heat removal by conduction and convection with the lowest possible thermal resistance at all levels of assembly. Depending on the application, a wide range of cooling methods are in use, which includes - forced air convection, external heat pipes, water cooled heat sinks, immersion cooling, refrigeration cycles, etc.

\subsection{Classical cooling techniques in electronic components}

The most common approach to thermal management is the use of a heat sink. The choice of the material is one of the main factors that affect the heat sink efficiency. Aluminum's lightweight and low cost make it a widely used material for convection 
cooling. The highly conductive nature and significant low-spreading resistance of copper, enable heat sinks produced from this material to efficiently spread heat along the base. This provides exceptional cooling for hot devices with high power densities. Copper heat sinks can increase heat dissipation from devices with heavy thermal loads by $10 \%$ to $20 \%$ compared to aluminum heat sinks, but at the expense of cost and weight.

Reducing thermal resistance for heat-sink optimization is becoming a critical task for engineers because of the increasing heat flux in high-performance IC devices. Another alternative is liquid cooling, in which heat is removed by the flow of a liquid usually water. A liquid cooling system is more efficient than an air-cooling system because of the main resistance factors, caloric effect, and rise in the fluid temperature are much lower in a liquid cooling system.

A liquid cooling system acts as a heat exchanger where the heat output from the device is extracted at a rate proportional to the specific heat and mass flow rate of the fluid. Water has an intrinsically higher thermal energy than air, and the mass flow rate of water can be easily controlled. A liquid cooling system yields a lower thermal resistance than an air cooling system, making it more efficient for thermal management.

A liquid cooling system, however, does have limitations. The effective temperature range for a water medium is limited to approximately $5^{\circ} \mathrm{C}$ to $95^{\circ} \mathrm{C}$, the dynamic response is relatively slow, and temperature stability is low. There also can be condensation problems, especially in high humidity environments. But compared to forced air-cooling, liquid cooling is relatively inexpensive method of thermal management. 


\subsection{Other non-conventional cooling techniques}

A thermoelectric cooler (TEC) integrated with liquid cooling has evolved in recent years as a thermal management technique for various applications. TEC uses Peltier effect to convert electricity to temperature differential. Its main advantages over air and liquid cooling are its wide temperature range of $-100^{\circ} \mathrm{C}$ to $+200^{\circ} \mathrm{C}$ and its capability to double as a heat pump and a cooler. Other TEC attributes include high reliability, rapid dynamic response, precise and stable temperature, small size, light weight, and relatively low cost.

A major limitation on the use of TEC alone arises from the amount of external power or supplement heat required to extract the heat from the device. The low efficiency of TEC can be overcome by integrating it with an efficient heat sink such as liquid cooling systems. The result of combining TEC with liquid cooling is a thermal management system that combines the wide range, fast response, accuracy, and stability of the former with the efficiency of the later.

Another alternative technique that provides the fastest response and greatest accuracy and stability for cooling is a refrigeration system. There are three drawbacks to widespread use of refrigeration systems for thermal management: they are expensive and large in size and have environmental issues because of the use of Freon for cooling. The system is also limited to cooling applications, and a secondary heating circuit must be added for most test applications.

These traditional ways of conduction cooling and using passive heat sinks, surface mounted forced convection, and immersion cooling will not adequately cool the devices at the projected power densities. Also these methods are limited by the large thermal 
resistance in the entire thermal path, from component to heat sink. This drives us to build an in-built heat sink in the substrate with vertical free standing silver columns acting as pin fins - the first of its kind.

\subsection{Objective of the research}

The main objectives of this research are to fabricate a heat exchanger embedded an LTCC substrate and characterize its performance in cooling a device mounted on the substrate. In this research, a liquid cooling system will be integrated directly into the interconnect substrate. Additionally, a high performance heat exchanger will be demonstrated and its performance is characterized. These experimental results are then compared with one-dimensional analytical and CFD results.

Four major aspects of the research are:

1. To determine the impact of fluid cooling over only conductive cooling.

2. To determine if it is possible to improve heat transfer over that of just an internal coolant duct in LTCC substrate.

3. Fabricate the high performance heat exchangers and test them experimentally.

4. To perform a numerical simulation of all tested configurations and compare it with experimental and one-dimensional analytical results. 


\section{Literature Review}

A lot of research is going on, in the field of thermal management since early 70 's due to tremendous growth in electronic field with increased transistor densities (following Moore's law), decrease in package size and increased power densities. In the initial stages, heat was removed using classical techniques such as surface mounted heat sinks, forced air convection cooling etc., Due to the high power density usage, these classical ways of cooling doesn't meet the requirements and so new methods of thermal management are employed.

A review of the literature related to this type of work is presented, to get a historical background of work done in this thesis. Even though lot of work existed in the microchannel heat sinks field, a brief review shows that no such work existed especially to integrate a micro heat exchanger in the substrate itself.

A study in three-dimensional fluid flows and heat transfer in a rectangular microchannel heat sink are analyzed numerically using water as coolant, was done by Issam Mudawar et al (2002) [36]. In this, the heat sink was made of a $1-\mathrm{cm}^{2}$ silicon wafer with micro-channels of width $57 \mu \mathrm{m}$ and a depth of $180 \mu \mathrm{m}$ and is separated by a $43-\mu \mathrm{m}$ wall. A large number of flow channels with characteristic dimensions ranging from 10 to $1000 \mu \mathrm{m}$ are fabricated in a solid substrate, which usually has high thermal conductivity such as silicon or copper. Figure 2-1 shows the schematic of micro-channel heat sink used and its unit cell. An electronic component is then mounted on the base surface of the heat sink. The heat generated by the component is first transferred to the channels by heat 
conduction through the solid, and removed by the cooling fluid, which is forced to flow through the channels.

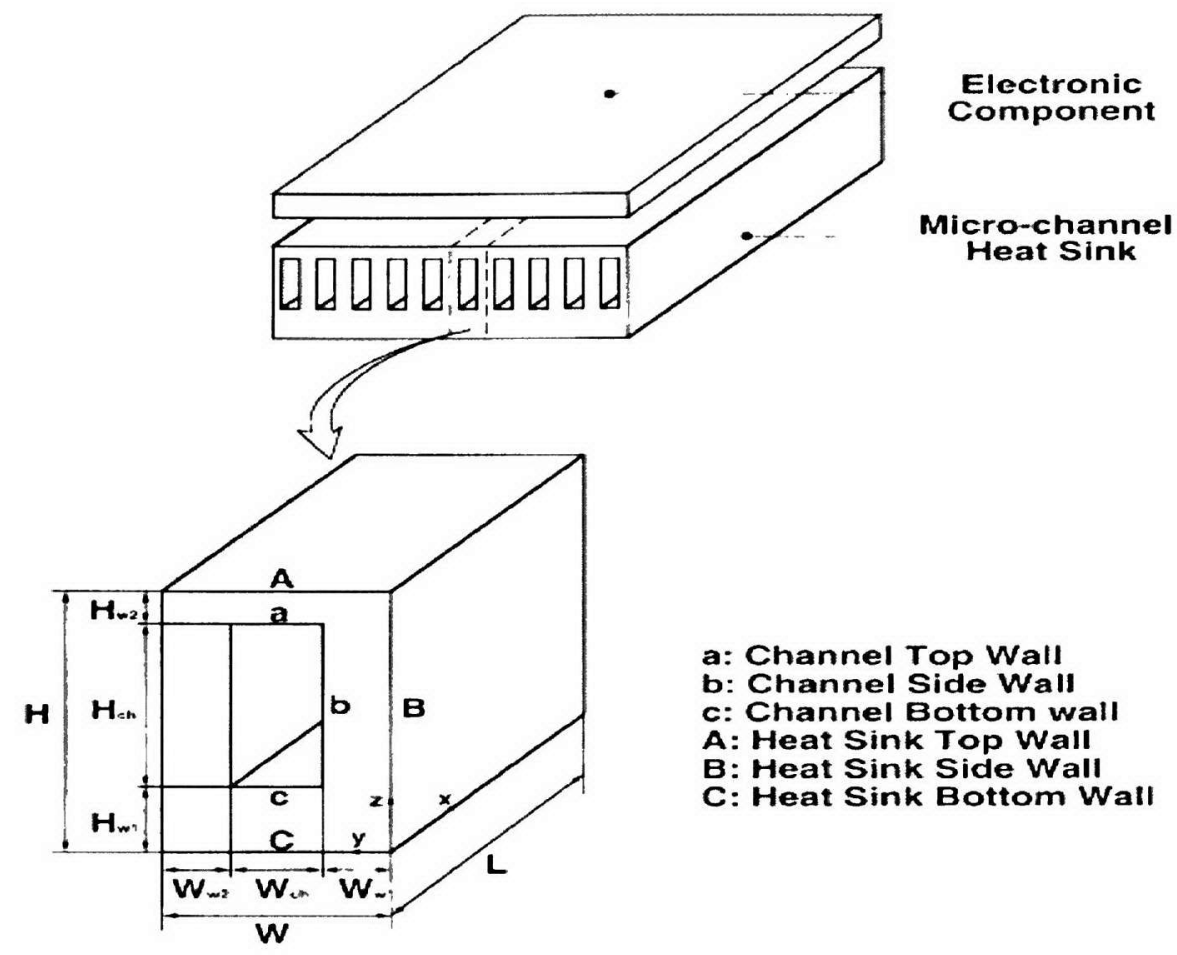

Figure 2-1 Schematic of rectangular micro-channel heat sinks and unit cell [36].

Micro heat pipe heat spreaders (MHPHS) with three copper foil layers was studied by Shung-Wen Kang et al (2003) [37], to allow liquid and vapor flow separation to reduce viscous shear force. Two wick designs, one using $200 \mu \mathrm{m}$ wide etched radial groves and other with 100 mesh screens was investigated. The foils were vacuum diffusion bonded to form $31 \times 31 \times 2.7 \mathrm{~mm}^{3}$ heat spreader. Thermal performance of the MHPHS was evaluated experimentally in a fan-heat sink CPU test apparatus with a heating area of $13.97 \mathrm{~mm} \times 13.97 \mathrm{~mm}$. 
Another study of using micro channels to cool microprocessors by TransmissionLine-Matrix (TLM) technique was done by A. Saidane et al. (2003) [38]. The Figure 2-2 shows the packaging structure for heat removal considered in this work. In this structure, the primary mode of heat removal is from the back surface of the silicon die. The die is attached to a heat spreader through an interfacial material, which is either thermal conductive gel or epoxy.

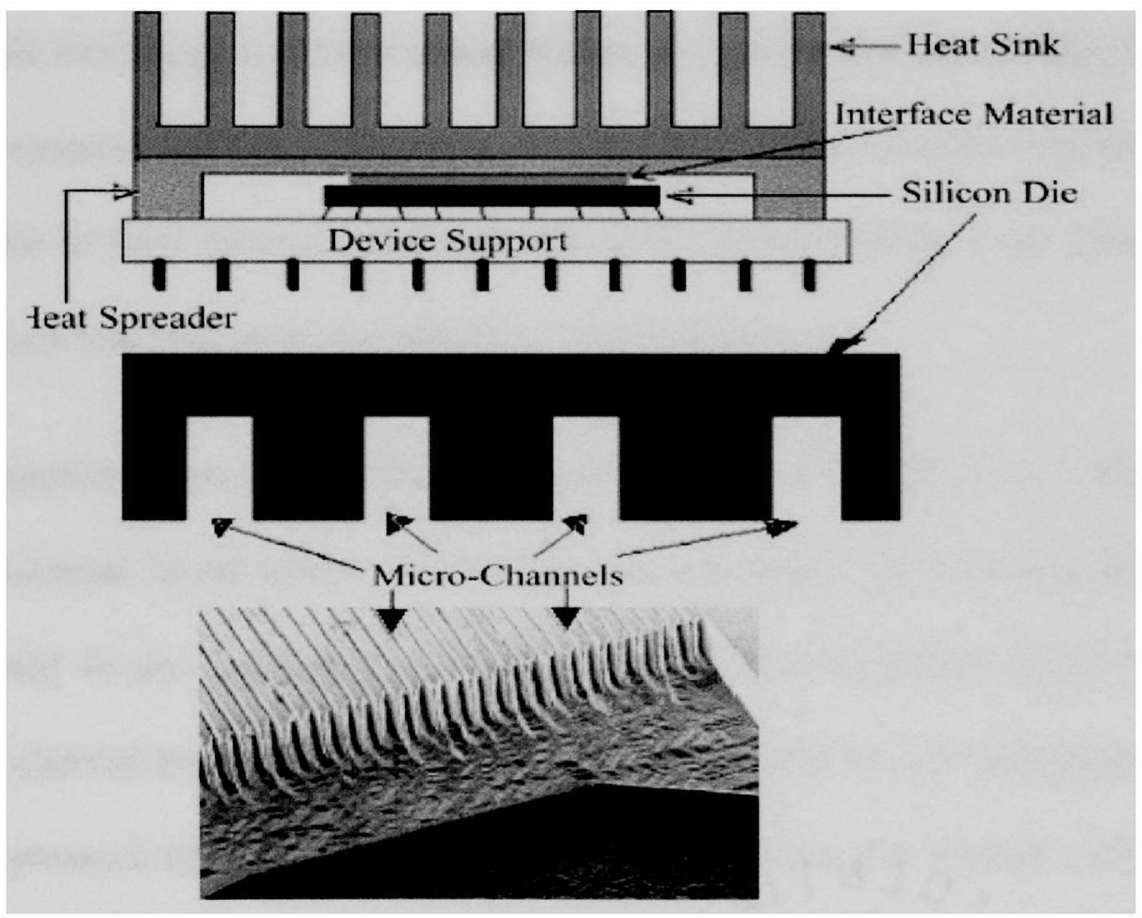

Figure 2-2 Structure under investigation with its packaging and micro-channels [38].

The geometry considered was silicon die $2 \mathrm{~mm}$ thick with a surface of $20 \times 20 \mathrm{~mm}^{2}$. Micro-channels of various depths and widths are introduced on the backside of the microprocessor silicon die. These micro channels are micro-machined in the silicon substrate using MEMS technology. In this study, the TLM technique was used to 
simulate the effect of micro-channels on the temperature distribution in the active region. To minimize the interface heat resistance various micro-channel and patterns are examined. In this part of work, the micro channels are filled with the heat spreader material copper or aluminum.

Another similar type of work was done by E. W. Kreutz et al. (2000) [39], on Simulation of micro-channel heat sinks for Optoelectronic Microsystems. Water cooled heat sinks are investigated both experimentally and theoretically as model systems to simulate the energy and mass transportation in devices used for cooling of Optoelectronic micro-systems such as diode lasers. The design of micro-channel heat sinks resulted in a decrease of their thermal resistance and of the pressure drop of the coolant allowing an increased heat load of an optoelectronic micro-system.

Another interesting study was done by Seok Pil Jang et al. (2003) [40] named Experimental Investigation of thermal characteristics for a micro-channel heat sink subjected to an impinging jet, using a micro-thermal sensor array. In this study, a micro-channel heat sink was introduced which is subject to an impinging jet, which has a small pressure drop. It experimentally investigated the heat transfer enhancement of the micro-channel heat sink subject to jet impingement. Temperature distributions at the base of the micro-channel heat sink are measured for evaluating the thermal resistance by using a micro-thermal sensor array.

Zampino (2001) [8], developed the heat pipes embedded into the ceramic substrates that provide a thermal transport mechanism capable of transporting heat over the length of the substrate at an effective thermal conductivity at least ten times higher than typical 
metals and over 100 times that of the substrate material. The heat pipes described serve to spread heat over a large area, utilizing more of the heat sink if the substrate is bonded to a heat sink material resulting in smaller temperature rise across the substrate. The most powerful use of heat pipe described is in applications where cooling can only be provided along an edge of the substrate [19].

Ravindra (2002) [15, 19], developed a high density thermal vias in Low Temperature Co-fired Ceramics. His work shows that denser thermal vias can be fabricated in the substrates thus reducing the in line resistance of the substrate. These vias also help in efficiently carrying heat on to the surface of the substrate, which can be further removed by a passive heat sink.

From the literature review, it can be concluded that even though lot of research was done and going on in the design of micro-channel heat exchangers, most of them are surface mounted on the substrate, which means another passive heat sink. Since the thermally management requires the optimization of the heat removal by conduction and convection with the lowest possible thermal resistance at all levels of assembly, first it is required to minimize the thermal resistance of the substrate itself. Even though the passive heat sinks are efficient, the resistance of the system increases due to the use of thermal glues or epoxies. Also most of the heat exchangers were tested for silicon devices, which are costly when, compared to LTCC substrates. Further more it can be concluded from the literature review that fabricating an integrated micro-channel heat-exchanger with freestanding Ag columns in it, was the first of its kind. 


\section{Experimental treatment of problem}

\subsection{Specifications}

The specifications of the three samples after sintering are tabulated in the table below with reference to the diagram. The fabricated samples with embedded cooling channels are shown in Figures 3-2; 3-3 and 3-4. Figure 3-2 shows the isometric view of the entire sample after fabrication. Figure 3-3 shows the layout of via array, which extends further into the duct area in sample 3. Figure 3-4 shows the cross section of $\mathrm{Ag}$ columns, which act as pin fins or as a heat exchanger and enhance the performance of the substrate.

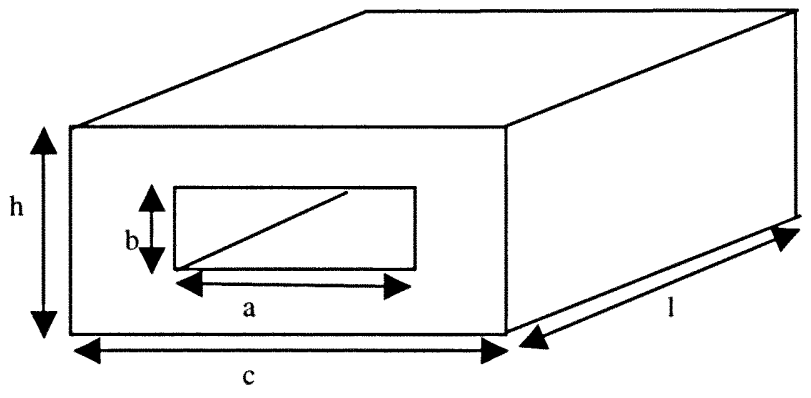

Figure 3-1 Outline of Samples fabricated

\begin{tabular}{|c|c|c|c|c|c|}
\hline $\begin{array}{c}\text { Sample } \\
\text { Number }\end{array}$ & $\begin{array}{c}\mathrm{a} \\
(\mathrm{mm})\end{array}$ & $\begin{array}{c}\mathrm{b} \\
(\mathrm{mm})\end{array}$ & $\begin{array}{c}\mathrm{h} \\
(\mathrm{mm})\end{array}$ & $\begin{array}{c}\mathrm{c} \\
(\mathrm{mm})\end{array}$ & $\begin{array}{c}\mathrm{l} \\
(\mathrm{mm})\end{array}$ \\
\hline 1 & 7.46 & 1.8 & 4.65 & 30.5 & 69 \\
\hline 2 & 8.49 & 1.7 & 4.55 & 32.8 & 68 \\
\hline 3 & 8.88 & 1.9 & 4.41 & 31.3 & 65 \\
\hline
\end{tabular}

Table 3-1 Specifications of Samples used for testing. 


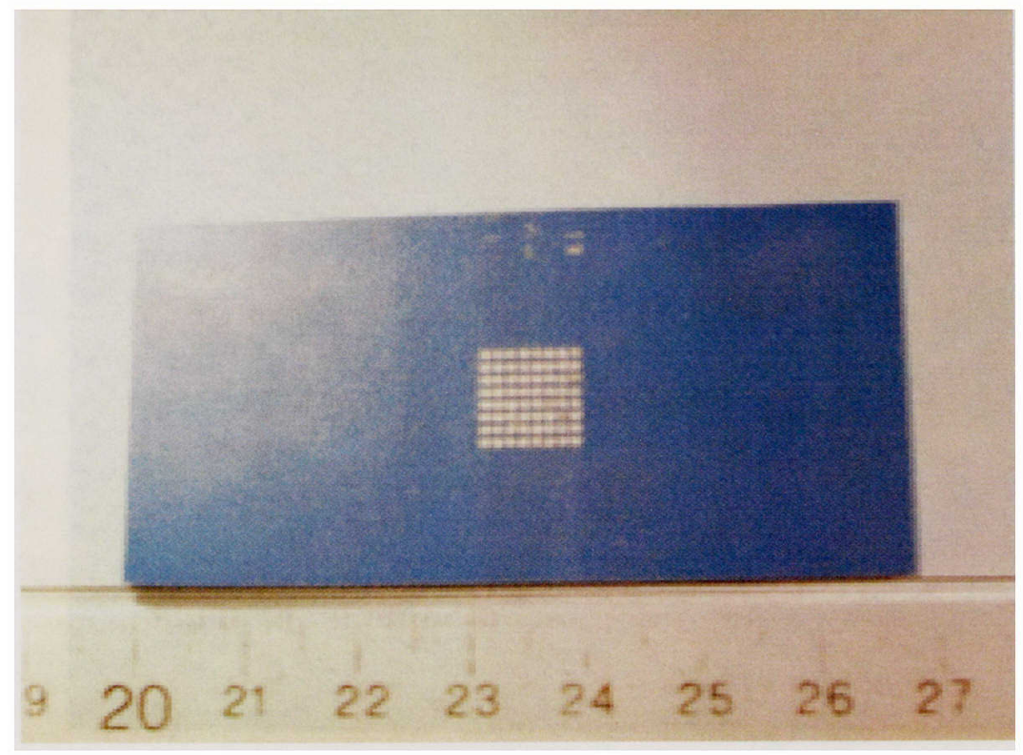

Figure 3-2 Test sample with embedded cooling system and thermal via array (center of top surface).

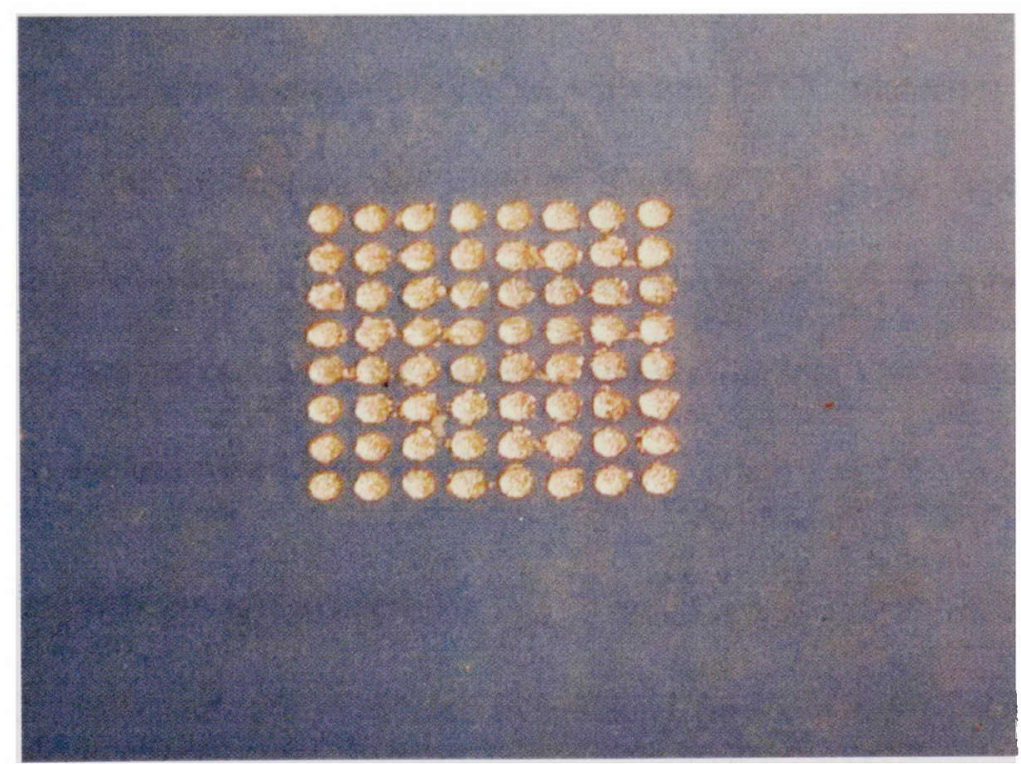

Figure 3-3 Detail view of $1 \mathrm{~cm}^{2}$ thermal via array on test samples. 
used to fill the vias for $\mathrm{Z}$-axis interconnection or for thermal vias. The process is shown in Figure 3-5.

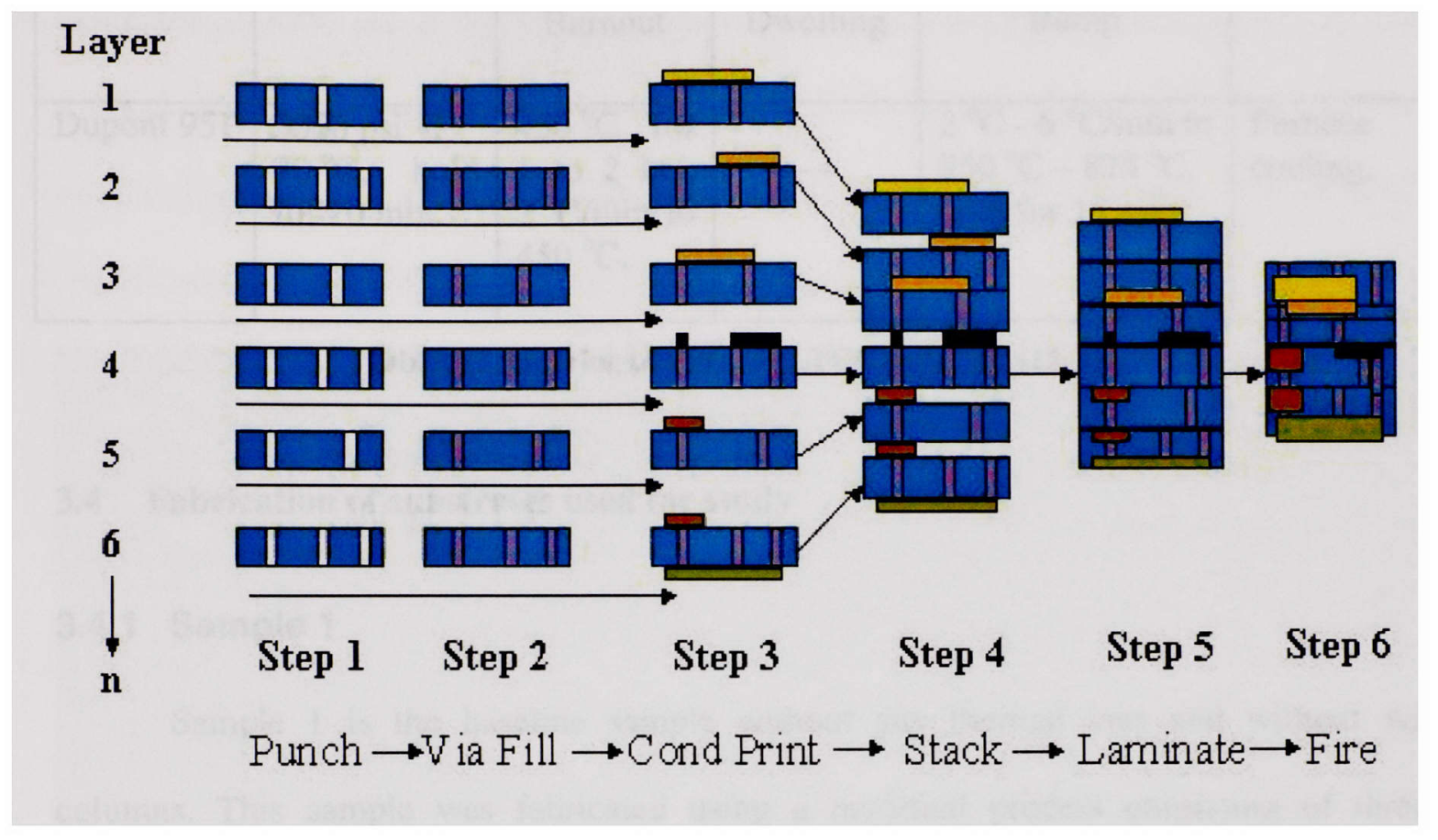

Figure 3-5 Layout of Fabrication process [16]

Even though the process works with any LTCC tapes, DuPont 951, a cofireable green tape was used for this study. This green tape is commercially available and is also $\mathrm{Ag}$ and/or Au compatible. The green tape is cut to the desired shape and size and sintered in a furnace following the manufacturer's desired firing profile. The dimensions are made 13 to $14 \%$ more than the desired final dimensions to account for shrinkage during sintering. The firing profile for Dupont 951 is given in Table 3-2. 


\begin{tabular}{|c|c|c|c|c|c|}
\hline Material & \multirow{2}{*}{$\begin{array}{c}\text { Lamination } \\
\text { Pressure }\end{array}$} & \multicolumn{2}{|c|}{ Burnout } & Sinter & Cooling \\
\cline { 3 - 6 } & & Burnout & Dwelling & Ramp & \\
\hline Dupont 951 & $\begin{array}{l}3000 \text { psi @ } \\
70{ }^{\circ} \mathrm{C}, \text { hold } \\
\text { for } 10 \text { min. }\end{array}$ & $\begin{array}{l}450^{\circ} \mathrm{C} \text { for } \\
1 \text { to } 2 \text { hrs, } \\
2{ }^{\circ} \mathrm{C} / \mathrm{min} \text { to } \\
450^{\circ} \mathrm{C} .\end{array}$ & -- & $\begin{array}{l}2{ }^{\circ} \mathrm{C}-6{ }^{\circ} \mathrm{C} / \mathrm{min} \text { to } \\
850{ }^{\circ} \mathrm{C}-875^{\circ} \mathrm{C}, \\
\text { hold for } 15 \text { min. }\end{array}$ & $\begin{array}{l}\text { Furnace } \\
\text { cooling. }\end{array}$ \\
\end{tabular}

Table 3-2 Sintering profiles for LTCC materials [15, 19]

\subsection{Fabrication of substrates used for study}

\subsubsection{Sample 1}

Sample 1 is the baseline sample without any thermal vias and without $\mathrm{Ag}$ columns. This sample was fabricated using a modified process consisting of three sub-assemblies, which are pre-laminated separately and then stacked and laminated together and finally sintered. The substrates have an open duct inside which runs all through the length of the substrate. Pre-lamination of sub-assemblies individually and then laminating them together ensures a hermetic structure after fabrication. Also, since there is an open space, laminating the entire sample together at the designed pressure will develop a deformed structure especially near the open space. Taking these into consideration a modified process of lamination and fabrication are used.

The bottom sub-assembly is made by stacking 10 layers of $80 \mathrm{~mm} \times 35 \mathrm{~mm}$ cofireable green tape and is laminated at $3000 \mathrm{psi}$ at $70{ }^{\circ} \mathrm{C}$ for about 10 to $15 \mathrm{~min}$ on a Uniaxial laminator. The middle sub-assembly has two pieces of 15 layers stacked on each other of $80 \mathrm{~mm} \times 35 \mathrm{~mm}$ cofireable green tape and are laminated using a Uniaxial 
laminator at $3000 \mathrm{psi}$ at $70{ }^{\circ} \mathrm{C}$ for 10 to $15 \mathrm{~min}$. The top sub-assembly is made by stacking 10 layers of $80 \mathrm{~mm} \times 35 \mathrm{~mm}$ cofireable green tape and is laminated on a Uniaxial laminator at $3000 \mathrm{psi}$ at $70{ }^{\circ} \mathrm{C}$ for 10 to $15 \mathrm{~min}$. Now these three sub-assemblies are stacked one over the other as shown in the Figure 3-6, leaving a gap in the center of the middle layer which acts as a duct in the later stages of the testing. The detailed specifications are given in Appendix 2 in Drawing 1.

\section{Figure 3-6 Sample 1 used for fabrication.}


These three sub-assemblies are stacked together and laminated again on a Uniaxial laminator but at very low pressure of $300 \mathrm{psi}$ at $70{ }^{\circ} \mathrm{C}$, for $2 \mathrm{hrs}$. This method of laminating at low pressure and for longer time is used when the cofireable tape has cavities, so as to minimize sagging near the cavities.

The final laminated structure is sintered in a furnace following manufacturer's firing profile. The firing profile shows a ramp of $2{ }^{\circ} \mathrm{C} / \mathrm{min}$ from room temperature to $450{ }^{\circ} \mathrm{C}$, a hold of $2 \mathrm{hrs}$ at $450{ }^{\circ} \mathrm{C}$, to ensure proper organic binder burn out, a ramp of $2{ }^{\circ} \mathrm{C} / \mathrm{min}$ to a peak temperature of $850{ }^{\circ} \mathrm{C}$, a hold time of 10 to $15 \mathrm{~min}$ at this peak temperature. Afterwards, the furnace is turned off and allowed to cool-down. The substrate is to be cooled in the furnace itself to avoid thermal cracks due to large temperature gradient if removed from the furnace when it is hot. The entire sintering process takes around 10 to $14 \mathrm{hrs}$ depending on the tapes used, thickness of the structure which requires modification of the firing profile.

\subsubsection{Sample 2}

Sample 2 has the same internal channel as Sample 1 and also has thermal vias in the top sub-assembly. The bottom and middle sub-assemblies are laminated similar to that of Sample 1 .

The top sub-assembly is made by stacking 10 layers of $80 \mathrm{~mm} \times 35 \mathrm{~mm}$ cofireable green tape and is laminated in a Uniaxial laminator at $3000 \mathrm{psi}$ at $70^{\circ} \mathrm{C}$ for 10 to $15 \mathrm{~min}$. After laminating, vias are made in this layer, using a high-speed numerical controlled (NC) micro drilling/ micro-routing system. The holes are then filled with $\mathrm{Ag}$ via ink (a modified DuPont 6141 ink, with additional Ag added), by screen-printing the 
via ink into the vias with vacuum assist. For additional enhancement of heat transfer, a $10 \mathrm{~mm} \times 10 \mathrm{~mm}$ square pad of $\mathrm{Ag}$ ink $(0.1 \mathrm{~mm})$ thick was screened on the bottom side of the thermal via array inside the coolant channel. After screen-printing, this layer is dried in a furnace at 80 to $90{ }^{\circ} \mathrm{C}$ for about 8 to $10 \mathrm{hrs}$.

Ensuring proper drying of $\mathrm{Ag}$ ink, this sub-assembly along with the other two sub-assemblies are stacked one over the other as shown in Figure 3-7 with the detailed drawing in Appendix 2 - Drawing 2 and laminated on a Uniaxial laminator at 300 psi at $70{ }^{\circ} \mathrm{C}$ for about 2 to 3 hrs. After laminating, the structure is sintered in the furnace following manufacturer's desired profile and cooled in the furnace itself.

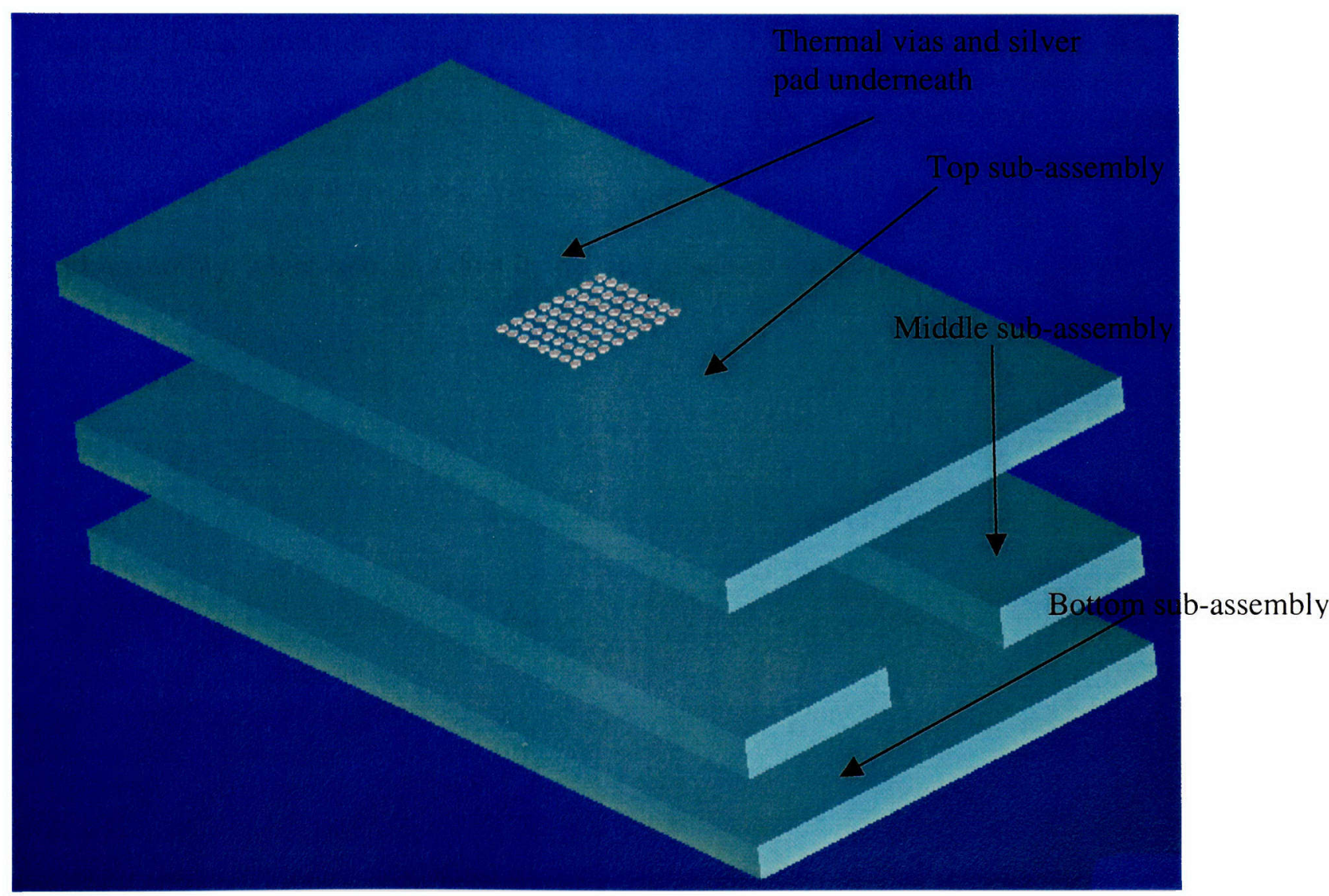

Figure 3-7 Sample 2 used for fabrication. 


\subsubsection{Sample 3}

Sample 3 is the substrate with both thermal vias and Ag columns. The top and bottom sub-assemblies are laminated similar to that of Sample 2. In this sample, the middle sub-assembly has free standing Ag columns which are extended from thermal vias into the duct space, acting as pin fins increasing the performance of heat transfer. The middle sub-assembly was made of two pieces of 15 layers each $80 \mathrm{~mm}$ × $35 \mathrm{~mm}$ cofireable green tape and is laminated on a Uniaxial laminator at $3000 \mathrm{psi}$ at $70{ }^{\circ} \mathrm{C}$ for 10 to $15 \mathrm{~min}$. To prepare freestanding columns, an $80 \mathrm{~mm} \times 9 \mathrm{~mm} \times 2 \mathrm{~mm}$ wax block is taken and holes are drilled into this using a high-speed NC micro-drilling/ micro-routing system. These holes are filled with Ag via ink (a modified Dupont 6141 ink, with additional $\mathrm{Ag}$ added) with vacuum assistance. This wax insert is dried in the furnace at $70{ }^{\circ} \mathrm{C}$ to $90{ }^{\circ} \mathrm{C}$ for 6 to $8 \mathrm{hrs}$. This wax insert is placed in the center of the middle sub-assembly, which acts as a duct in the later stages of the testing. 


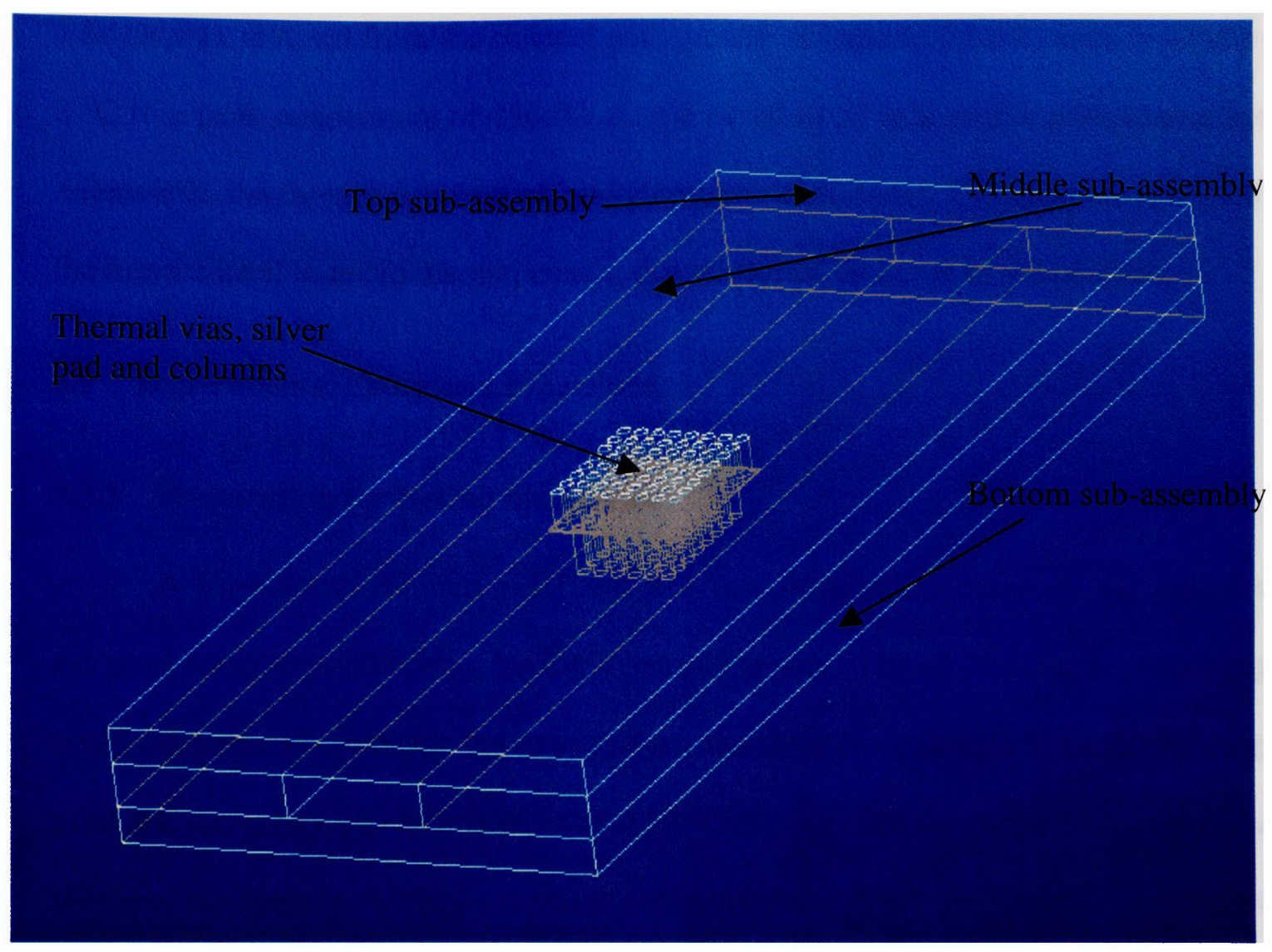

Figure 3-8 Sample 3 used for fabrication

All these three sub-assemblies along with the wax insert are stacked one over the other as shown in the Figure 3-8, the detailed view shown in Appendix 2- Drawing 3, and are laminated together on a Uniaxial laminator at 300 psi at $70{ }^{\circ} \mathrm{C}$ for about 4 to $5 \mathrm{hrs}$. Very low pressure is applied to prevent sagging of the green tape near the cavities. The wax insert acts as support for the free standing Ag columns and also prevents the green tape from sagging while laminating and acts as support in the initial stages of sintering.

This laminated structure is sintered in the furnace following manufacturer's desired profile. The firing profile shows a ramp of $2{ }^{\circ} \mathrm{C} / \mathrm{min}$ from room temperature to $450{ }^{\circ} \mathrm{C}$, a hold of $2 \mathrm{hrs}$ at $450{ }^{\circ} \mathrm{C}$. There is an intermediate temperature hold at $130{ }^{\circ} \mathrm{C}$ for 
$1 \mathrm{hr}$ for wax removal from the channel with gravity assistance. Further there is a ramp of $2{ }^{\circ} \mathrm{C}$ to a peak temperature of $850{ }^{\circ} \mathrm{C}$, a hold of 10 to $15 \mathrm{~min}$ at this peak temperature. Afterwards, the furnace is turned off and allowed to cool-down. The substrate is cooled in the furnace itself to avoid thermal cracks, due to sudden variation in temperature.

\subsection{Experimental Setup and Procedure}

\subsubsection{Preparation for testing the sample}

A Cu shim of $10 \mathrm{~mm} \times 10 \mathrm{~mm} \times 1 \mathrm{~mm}$ thickness is fixed on the top of the substrate using thermal epoxy, having a thermal conductivity of $29 \mathrm{~W} / \mathrm{m}-\mathrm{K}$. Assuming a cured thickness of $1 \mathrm{~mm}$ for the epoxy layer, the thermal resistance through the copper plate and the epoxy was estimated to be $0.37{ }^{\circ} \mathrm{C} / \mathrm{W}[11]$. The use of $\mathrm{Cu}$ shim reduces any localized hot spots in the heater element and facilitates uniform spreading of the heat over the substrate surface, and also allows for temperature measurement of the substrate surface. [11]

A small notch was made into the $\mathrm{Cu}$ shim and a thermocouple is fixed using thermal epoxy, which helps in measuring the substrate's surface temperature near the center of the heater [11]. A $0.5 \times 0.5$ inch foil heater was mounted on top of the $\mathrm{Cu}$ shim, which is powered by a regulated DC power supply. The dissipated power is found by directly measuring the potential drop across the foil heater and current drawn through the heater.

Water (coolant) is pumped into the test sample using a peristaltic pump through silicone tubing. The transition between the tubing and the substrate is achieved by affixing nylon barb fitting to the ends of the substrate using a two-part epoxy to 
permanently mount the barb fitting to the substrate. The peristaltic pump is calibrated using two different diameter tubes and the results are plotted in Figure 3-9. Also an approximate trend line is drawn, to determine the characteristic of the pump at various speeds. With these trend lines, the flow rate of the pump is determined accurately at a specified speed of the pump for a specific diameter of the tube. The flow rate of water is also measured using a stopwatch and a graduate cylinder.

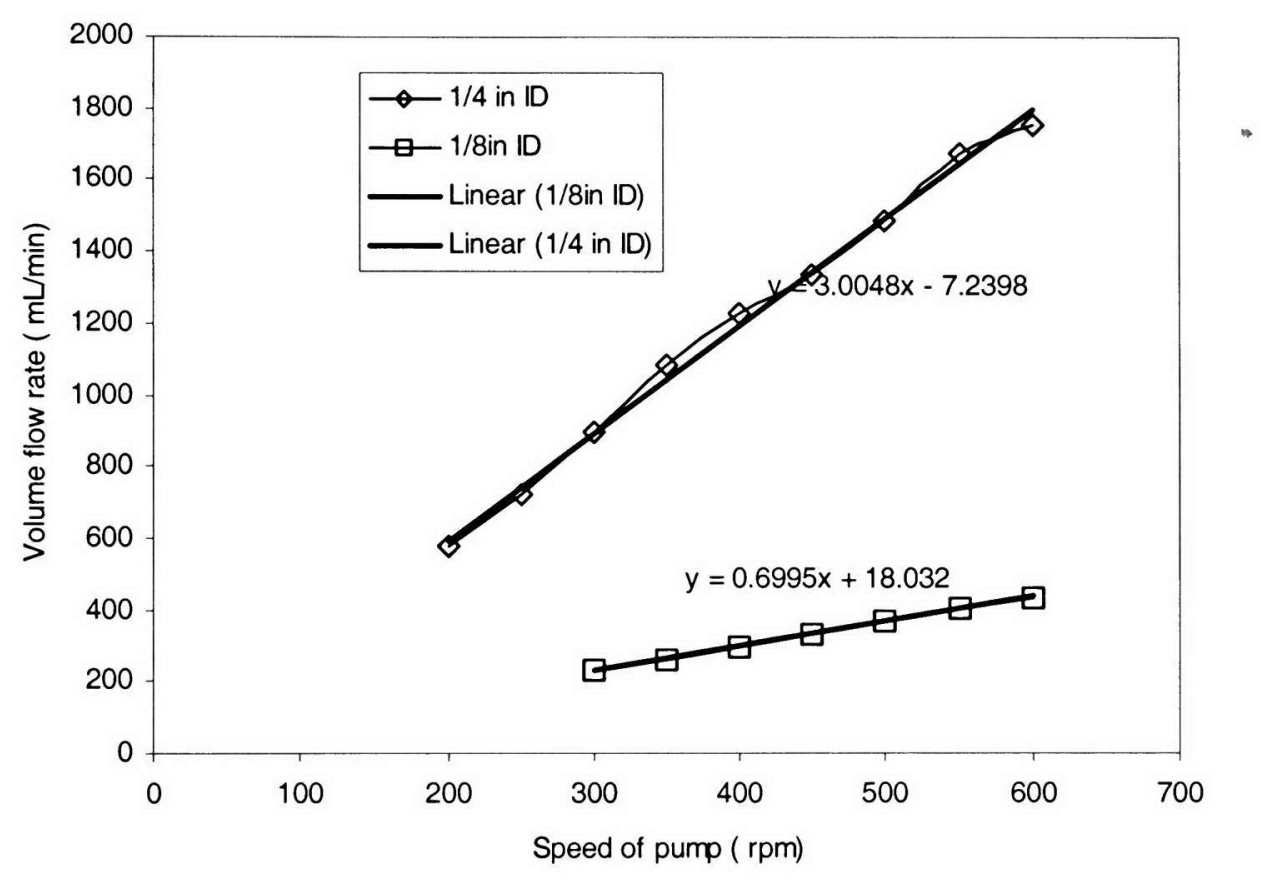

Figure 3-9 Calibration curves for peristaltic pump.

The temperature of the inlet water is maintained constant using a large temperature controlled water bath. The temperature of coolant at the inlet and outlet of the test sample are measured by inserting thermocouples directly into the flow regime by making small holes in the barb fittings. To prevent leaks, epoxy was used to seal the thermocouple wires. Care is taken to avoid getting epoxy on thermocouple bead, to 
position the thermocouple bead in the center of the flow channel and also avoid touching the bead to the surrounding walls. The entire test sample is wrapped in fiberglass foam of about 3" in thickness. This insulation is required to isolate the test sample from surrounding ambient air to minimize loss or gain of heat from the surroundings.

The testing starts by adjusting the volume flow to the desired flow rate and observing the temperature of the inlet and outlet of the test substrate and also the temperature below the heating coil or on the surface of $\mathrm{Cu}$ shim. Initially no power is given to monitor these temperatures to ensure steady state isothermal condition. The DC power supply is then adjusted to the desired power by observing the voltmeter and ammeter values. The temperatures at the inlet and exit and on the surface of the $\mathrm{Cu}$ shim are monitored until steady state condition is reached. Steady state is established when there is no change in temperature at the inlet and outlet continuously for 15 minutes. Several data points are measured, keeping the flow rate constant and changing the power levels. At each data point, potential difference across the heater, current in the circuit, temperatures of $\mathrm{Cu}$ shim, inlet and outlet temperatures of water and the volume flow rate are measured.

In the similar way, another set of steady state data points are measured by keeping the power constant and varying the volume flow rate of water. Each sample is tested following the same steps. 


\subsection{Observations and Calculations}

From the experimental testing, it was determined that the overall thermal resistance of the system is $4.9^{\circ} \mathrm{C} / \mathrm{W}$ for Sample $1,3.5{ }^{\circ} \mathrm{C} / \mathrm{W}$ for Sample 2 and $1.1{ }^{\circ} \mathrm{C} / \mathrm{W}$ for Sample 3 at $293 \mathrm{ml} / \mathrm{min}$ volume flow rate. The results from the experimental testing were tabulated in detail in Appendix 1.

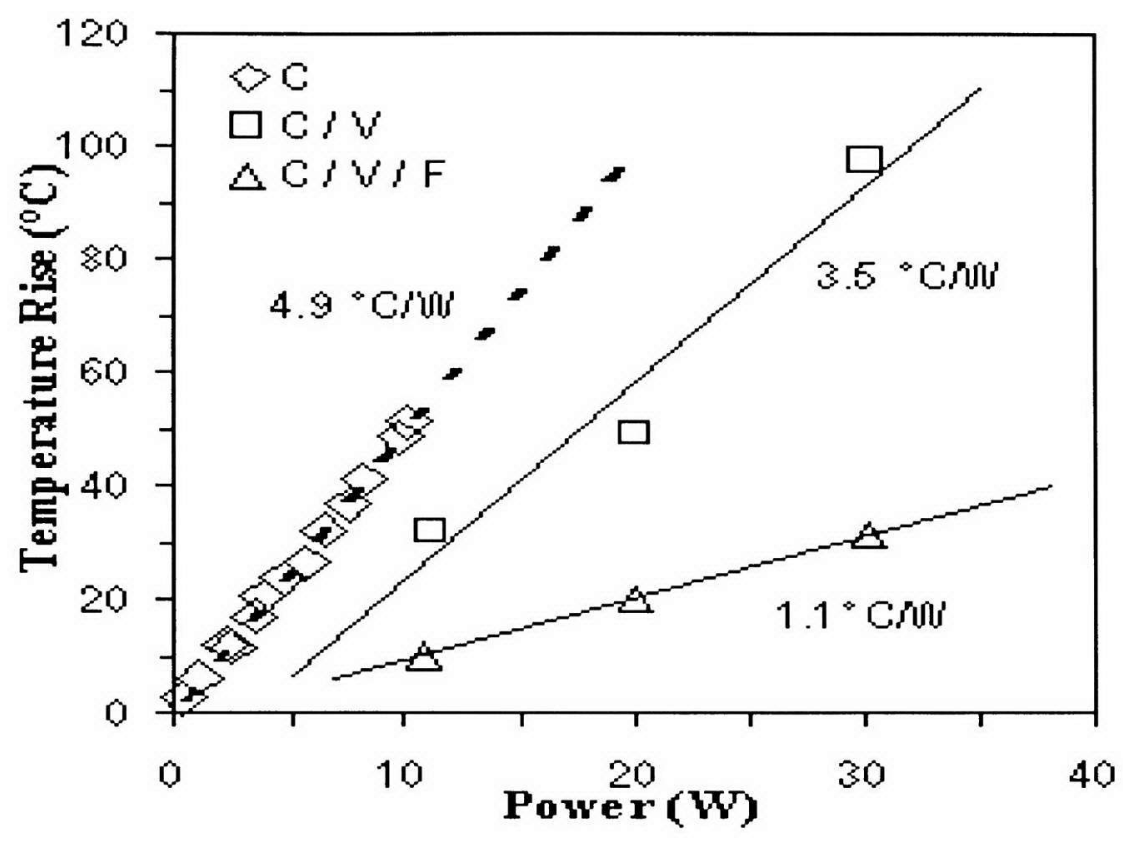

Figure 3-10 Substrate rise in temperature and effective overall thermal resistance of the system for all test configurations: $\mathrm{C}$ - channel only; $\mathrm{V}$ - thermal vias; F-pin fins. 


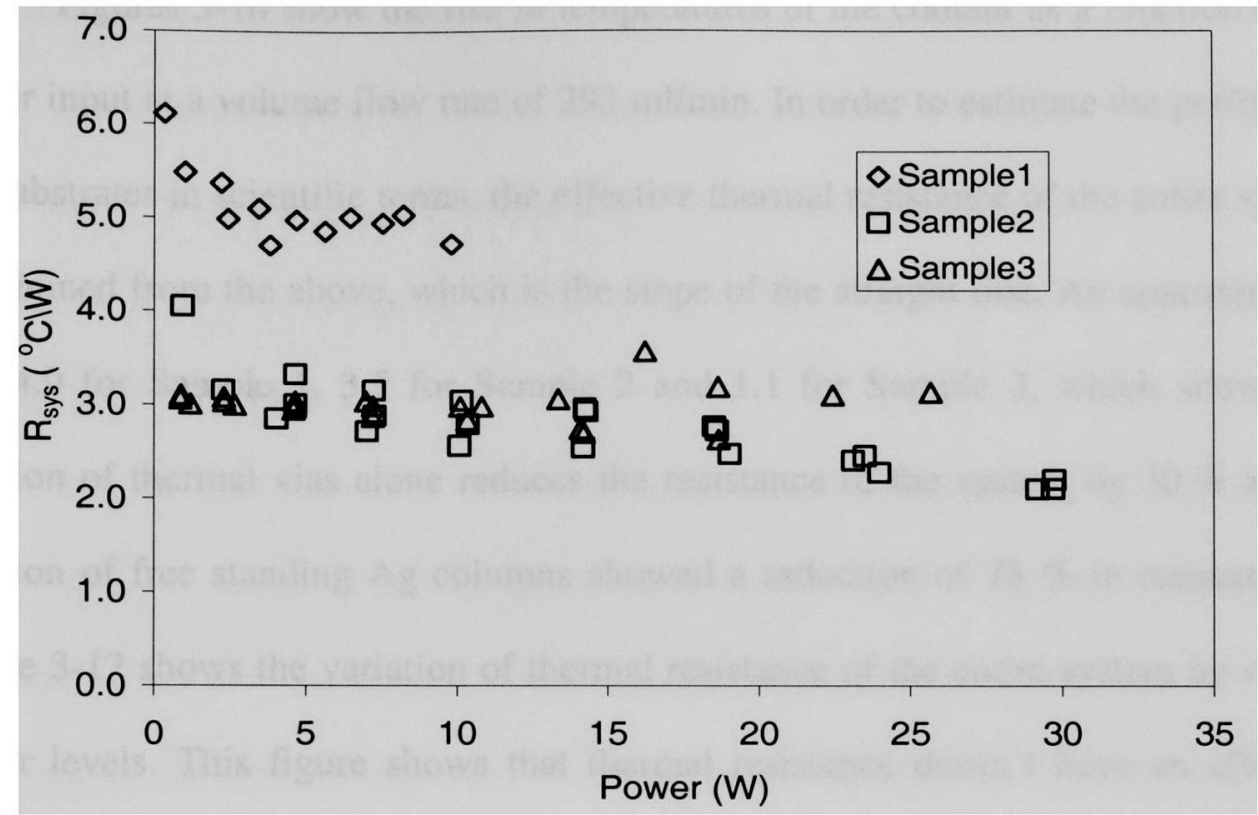

Figure 3-11 Effective thermal resistance of the system with varying power levels for Samples 1, 2 and 3.

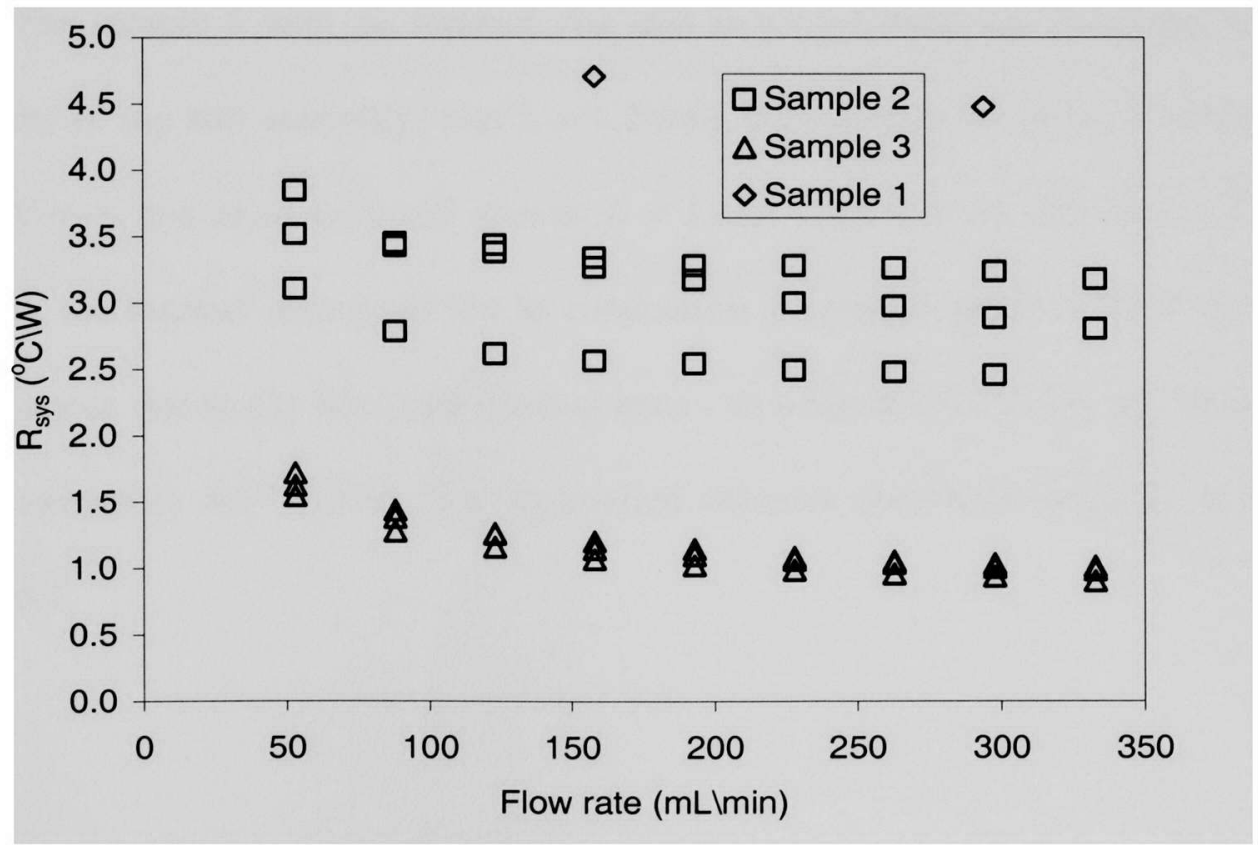

Figure 3-12 Effective thermal resistance of the system with varying flow rates for Samples 1, 2 and 3, three power levels $10 \mathrm{~W}, 20 \mathrm{~W}$ and $30 \mathrm{~W}$ shown for Samples 2 and 3; and $10 \mathrm{~W}$ for Sample 1. 
Figures 3-10 show the rise in temperatures of the coolant as a function of thermal power input at a volume flow rate of $293 \mathrm{ml} / \mathrm{min}$. In order to estimate the performance of the substrates in scientific terms, the effective thermal resistance of the entire system was determined from the above, which is the slope of the straight line. An approximate slope was 4.9 for Sample 1, 3.5 for Sample 2 and 1.1 for Sample 3, which shows that the addition of thermal vias alone reduces the resistance of the system by $30 \%$ and further addition of free standing $\mathrm{Ag}$ columns showed a reduction of $78 \%$ in resistance. Again Figure 3-12 shows the variation of thermal resistance of the entire system by varying the power levels. This figure shows that thermal resistance doesn't have an effect on the power input. 


\section{Analytical treatment of the problem}

The thermal efficiency of the substrate depends on the effective thermal resistance of the entire thermal path from heat source to heat sink. Even though the study doesn't fall into one-dimensional problem, it gives us an estimate of how heat is managed along the thru plane of the substrate.

The thermal resistance for conduction (in one-dimensional analysis) is defined as $\mathrm{L} / \mathrm{kA}$, where $\mathrm{L}$ is the length of the thermal path, $\mathrm{k}$ is the thermal conductivity of the material, $\mathrm{A}$ is the cross-sectional area through which heat is transferred. For convective heat transfer, the thermal resistance is defined as $1 / \mathrm{hA}$, where $\mathrm{h}$ is average convective heat transfer coefficient, and $\mathrm{A}$ is the surface area of heat transfer.

\subsection{1-D analytical solution for Sample 1}

For sample 1 with no thermal vias and silver columns, the thickness after firing (thickness of top sub-assembly) was $L=1.2 \mathrm{~mm}$, considering the thermal conductivity as $\mathrm{k}=3 \mathrm{~W} / \mathrm{m}-\mathrm{K}$ and cross-sectional area as $\mathrm{A}=1 \mathrm{~cm}^{2}$ (which is the area below the heating element), the thermal resistance due to conduction is approximately $4{ }^{\circ} \mathrm{C} / \mathrm{W}$. Considering the resistance due to $\mathrm{Cu}$ shim and thermal epoxy as well, the resistance due to conduction is approximately $4.37{ }^{\circ} \mathrm{C} / \mathrm{W}$. The equivalent thermal resistance diagram is shown in Figure 4-1. 


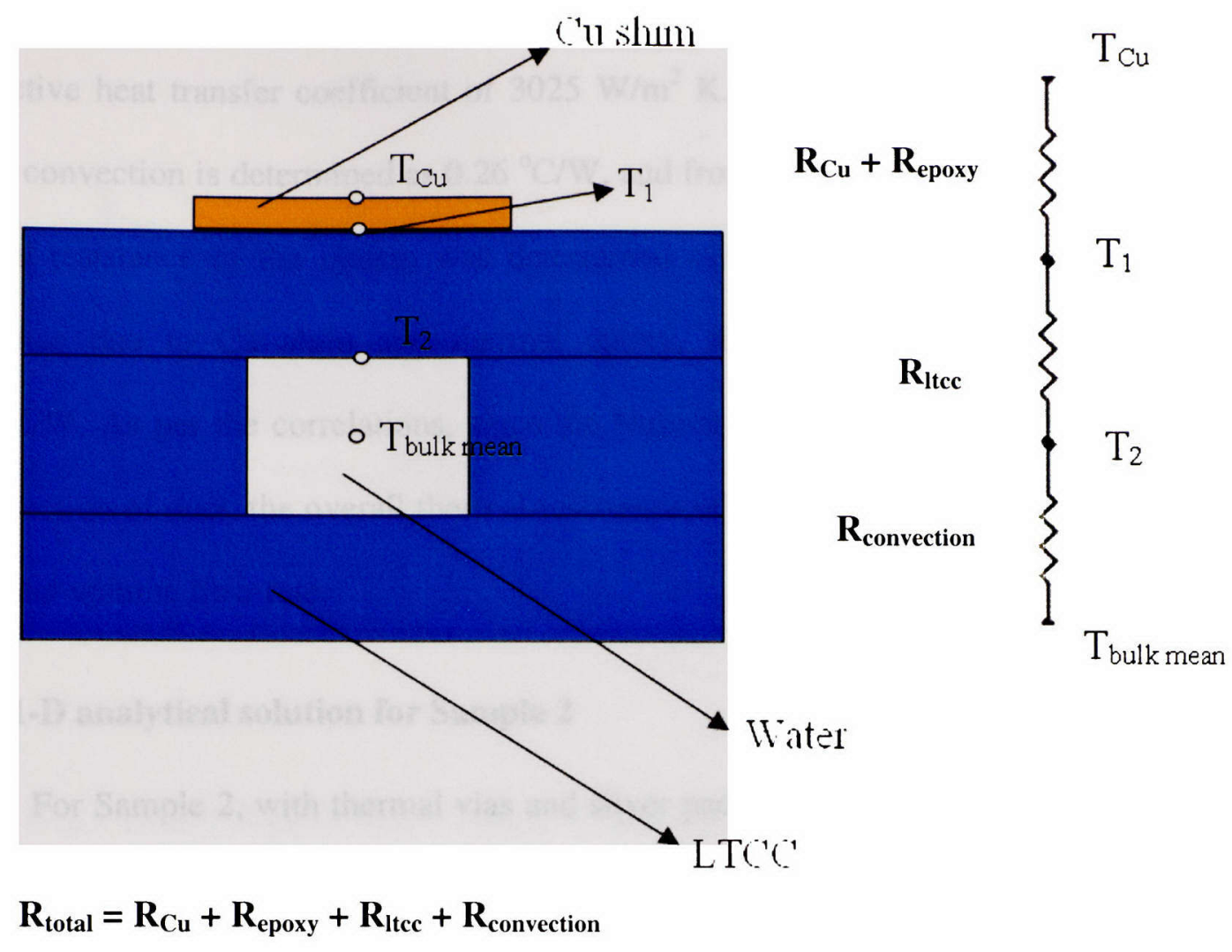

Figure 4-1 Equivalent thermal resistance circuit diagram for Sample 1.

To determine the resistance due to convection, no exact correlations were found for the cross-section and an approximation is made. For a rectangular cross-section, if the ratio of width to height of the duct is equal to 4 , the Nusselt number would be 3.66 for constant heat flux [32]. Since the ratio is equal to 4.1 , the Nusselt number can be assumed to be same as 3.66.

$$
\mathrm{Nu}=3.66=\frac{\mathrm{h} \mathrm{D}_{\mathrm{h}}}{\mathrm{k}}
$$

where $D_{h}$ is the hydraulic diameter, $\frac{A}{P}, A$ is the flow area, $\mathrm{P}$ is the wetted perimeter. 
Using the above relations and using $\mathrm{k}$ for water as $0.6 \mathrm{~W} / \mathrm{m}-\mathrm{K}$, it results in a convective heat transfer coefficient of $3025 \mathrm{~W} / \mathrm{m}^{2} \mathrm{~K}$. Using these values, the resistance due to convection is determined as $0.26{ }^{\circ} \mathrm{C} / \mathrm{W}$, and from these values, the overall effective thermal resistance of the system was determined as $4.26{ }^{\circ} \mathrm{C} / \mathrm{W}$. When considering the resistance due to $\mathrm{Cu}$ shim and thermal epoxy, the overall thermal resistance was $4.63{ }^{\circ} \mathrm{C} / \mathrm{W}$. As per the correlations, since the Nusselt number is constant for a particular cross-section of duct, the overall thermal resistance of the system is independent of power input and volume flow rate.

\subsection{1-D analytical solution for Sample 2}

For Sample 2, with thermal vias and silver pad and no silver columns, the thermal conductivity of fired via ink was determined from previous work using flash diffusivity giving a value of approximately $290 \mathrm{~W} / \mathrm{m}-\mathrm{K}[15,19]$. Since there is a $\mathrm{Cu}$ shim on the surface of the substrate and a silver pad below the vias, the temperature at these interfaces will be same, making a single node at these locations, thereby making the thermal path between these nodes as parallel and parallel law of resistance was used to determine the effective thermal resistance. The sectional view of the substrate, which indicates the heat flow path and its equivalent thermal resistance model are shown in the Figure 4-2 below. 

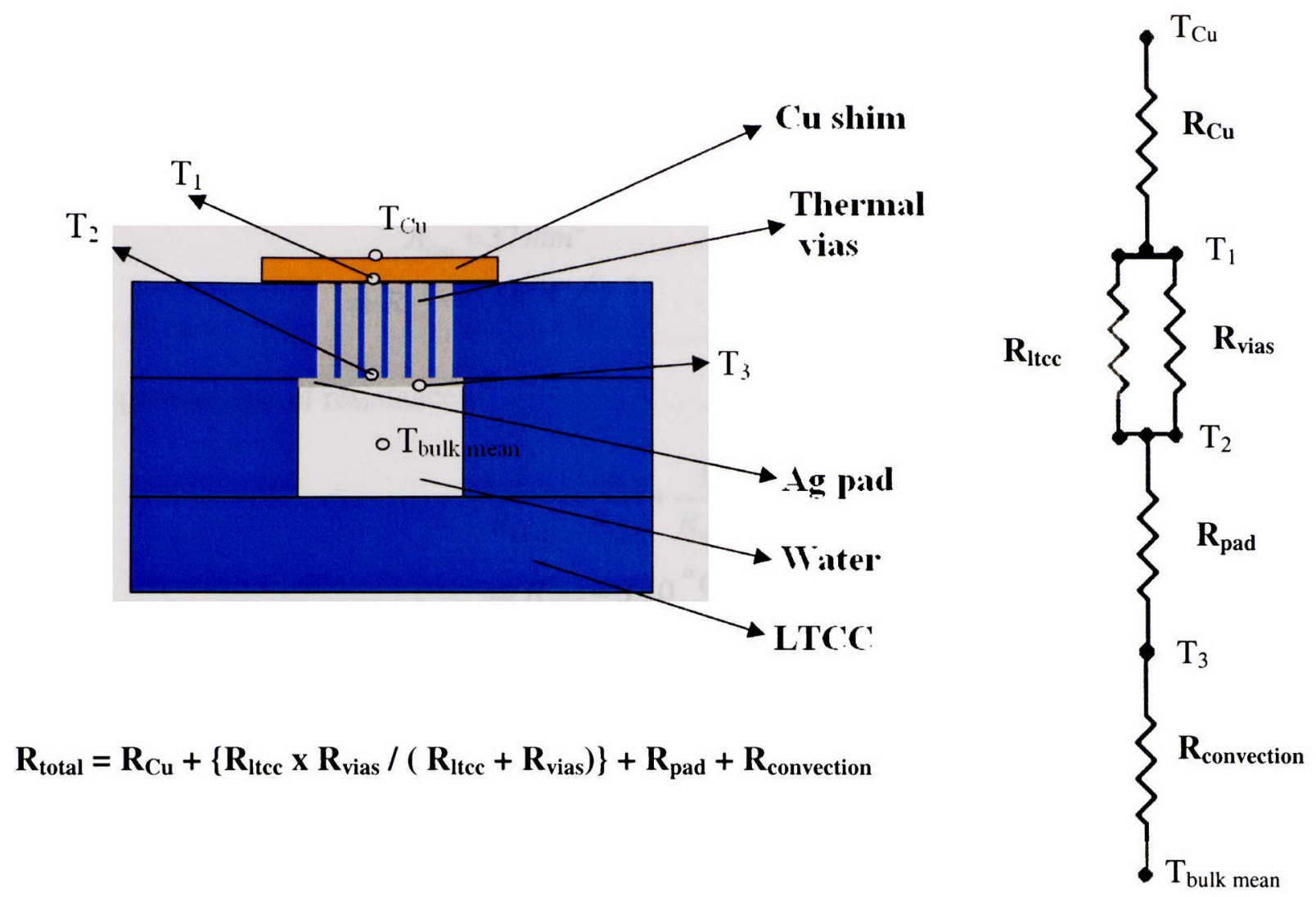

Figure 4-2 Equivalent thermal resistance circuit diagram for Sample 2

$$
\begin{aligned}
& \mathrm{R}_{\text {Itcc }}=\frac{\mathrm{L}_{\text {Itcc }}}{\mathrm{k}_{\text {Itcc }} \times \mathrm{A}_{\text {Itcc }}} \\
& \text { where } \mathrm{L}_{\text {Itcc }}=1.1 \mathrm{~mm}, \text { the length of the heat path } \\
& \mathrm{k}_{\text {Itcc }}=3 \mathrm{~W} / \mathrm{m} \mathrm{K} \\
& \mathrm{A}_{\text {Itcc }}=\mathrm{A}-\mathrm{A}_{\text {vias }} \\
& \Rightarrow \mathrm{A}_{\text {Itcc }}=100-8 \times 8 \times\left(\frac{\pi}{4}\right) \times 0.86^{2} \\
& =63 \mathrm{~mm}^{2} \\
& \therefore \mathrm{R}_{\text {Itcc }}=5.84^{\circ} \mathrm{C} / \mathrm{W}
\end{aligned}
$$




$$
\begin{aligned}
& R_{\text {vias }}=\frac{L_{\text {vias }}}{k_{\text {vias }} A_{\text {vias }}} \\
& \text { where } L_{\text {vias }}=1.1 \mathrm{~mm} \text {, thelength of the thermal vias } \\
& k_{\text {vias }}=290 \mathrm{~W} / \mathrm{m}-\mathrm{K} \\
& A_{\text {vias }}=37 \mathrm{~mm}^{2} \\
& \Rightarrow R_{\text {vias }}=0.10^{\circ} \mathrm{C} / \mathrm{W}
\end{aligned}
$$

Using parallel law of resistances,

$$
\begin{aligned}
& \frac{1}{R_{e q-1}}=\frac{1}{R_{\text {ltrc }}}+\frac{1}{R_{\text {vias }}} \\
& \Rightarrow R_{e q-1}=0.10^{\circ} \mathrm{C} / \mathrm{W} \\
& R_{\text {Ag pad }}=3.4 \times 10^{-3}{ }^{\circ} \mathrm{C} / \mathrm{W}
\end{aligned}
$$

Using the series law of resistances, the equivalent resistance due to conduction is

$$
\begin{aligned}
R_{\text {conduction }} & =R_{e q-1}+R_{A g \text { pad }} \\
& =0.10^{\circ} \mathrm{C} / \mathrm{W}
\end{aligned}
$$

The thermal resistance due to convection will be the same as that of Sample 1, since both have similar cross-section of duct, which will be $0.26{ }^{\circ} \mathrm{C} / \mathrm{W}$. This results in a total thermal resistance of the system to be approximately $0.36{ }^{\circ} \mathrm{C} / \mathrm{W}$. Considering the resistance due to conduction by $\mathrm{Cu}$ shim and thermal epoxy, the overall thermal resistance was approximately $0.73{ }^{\circ} \mathrm{C} / \mathrm{W}$. Even in this case since the Nusselt number is independent of flow rate, the overall thermal resistance is independent of the flow rate and power input. 


\subsection{1-D analytical solution for Sample 3}

For Sample 3, the thermal resistance due to conduction will be same as that of Sample 2 as both of them have identical structure in the top sub-assembly. Figure 4-3 shows the equivalent thermal resistance circuit diagram. In this substrate, the freestanding columns act as extended surfaces (pin fins). For the geometry in this study, the diameter of the column is about one half of the length of the column. Hence the heat flux will be assumed to be nearly uniform along the length of the fin. This assumption is further
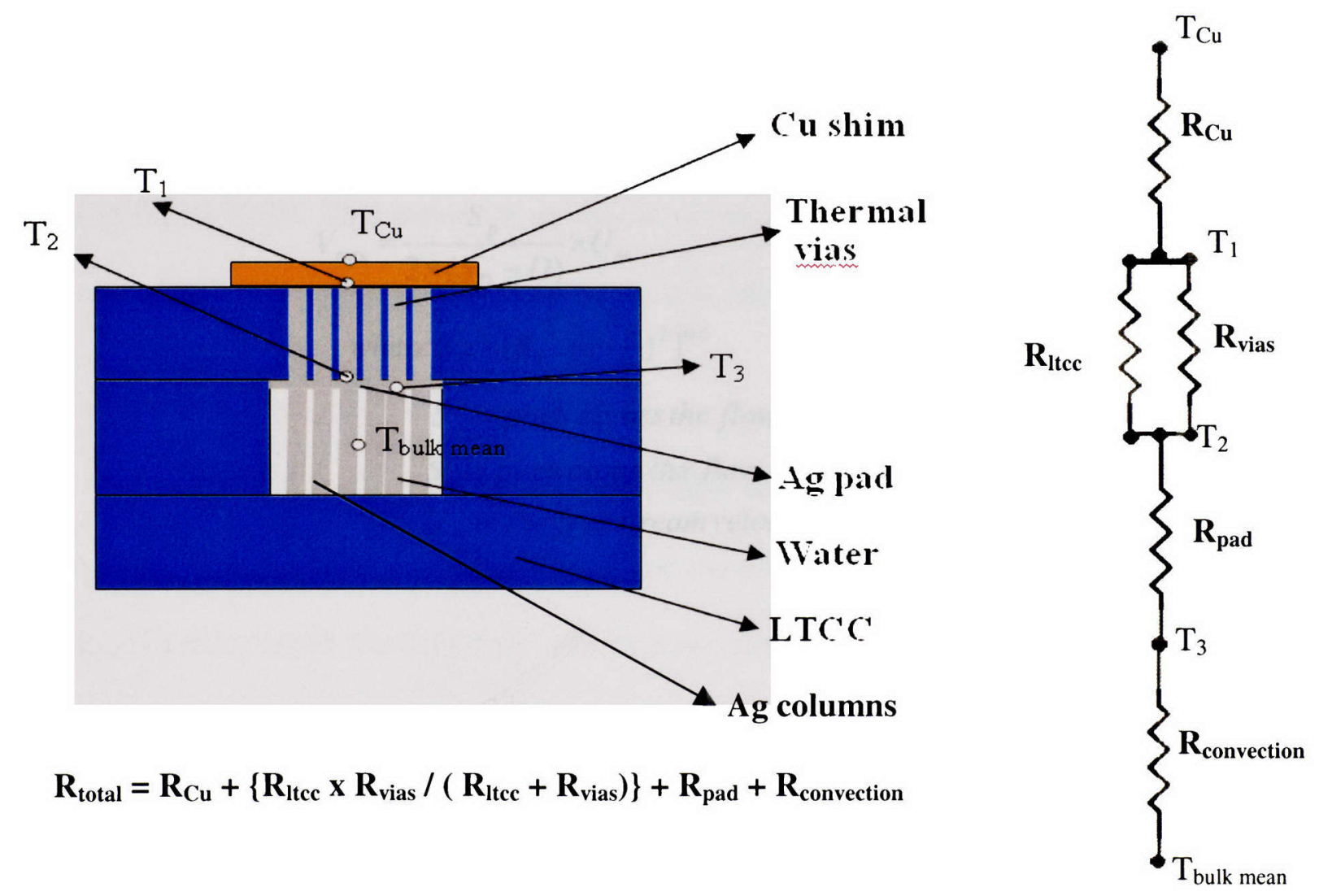

Figure 4-3 Equivalent thermal resistance circuit diagram for Sample 3

supported by the high thermal conductivity if the columns (over $350 \mathrm{~W} / \mathrm{m} \mathrm{K}$ ). Hence, the heat transfer for this geometry is very similar to that found in a conventional cross-flow 
heat exchanger with a bank of aligned tubes, for which empirical correlations and calculations are shown below.

$$
\begin{aligned}
& \operatorname{Re}=\frac{\rho \times V_{\max } \times D_{h}}{\mu} \\
& \text { where, } \operatorname{Re} \text { is the } \operatorname{Re} \text { ynolds Number } \\
& \\
& \rho \text { is the density } \\
& \mu \text { is kinematic vis cos ity } \\
& D_{h} \text { is hydraulic diameter } \\
& V_{\max } \text { is the max imum velocity [32] }
\end{aligned}
$$

For In line arrays (Figure 4-4(A))

$$
V_{\text {max }}=\frac{S_{p}}{\left(S_{p}-D\right)} \times U_{\infty}
$$

For Staggered arrays (Figure 4-4(B)) max imum of the above and

$$
\begin{gathered}
V_{\max }=\frac{S_{p}}{2 \times\left(S_{D}-D\right)} \times U_{\infty} \\
\text { where } S_{D}=\left[S_{n}^{2}+\left(\frac{S_{p}}{2}\right)^{2}\right]^{0.5} \\
\quad S_{p} \text { is pitch across the flow } \\
S_{n} \text { is pitch along the flow } \\
U_{\infty} \text { is the free stream velocity }[32]
\end{gathered}
$$

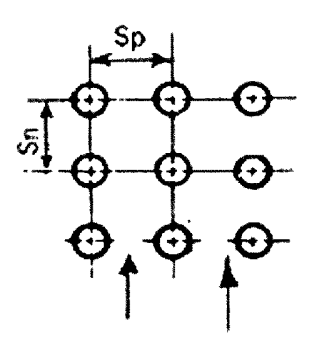

(A) In-line

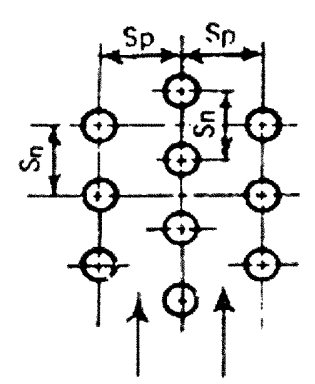

(B) Staggered

Figure 4-4 Description of pitch along and across the flow for (A) In-line (B) Staggered array [32]. 


$$
\begin{aligned}
& \text { Nu }=C_{1} \times C \times 1.13 \times \operatorname{Pr}^{0.33} \times \mathrm{Re}^{n} \\
& \text { where, } \text { Nu isNusseltNumber } \\
& \quad C_{1}, \text { C and nare cons tan ts } \\
& \text { Pr is } \operatorname{Pr} \text { andtl Number } \\
& \text { Re is } \operatorname{Re} \text { ynolds Number [32] }
\end{aligned}
$$

For an In-line array of 6 rows, $C_{1}=0.94, C=0.25$ and $n=0.620$ [32]

$$
\operatorname{Pr} \text { for water at } 20^{\circ} \mathrm{C} \text { is } 7.020[32]
$$

Using the above correlations, the convection coefficient was $27081 \mathrm{~W} / \mathrm{m}^{2}-\mathrm{K}$ for a flow rate of $293 \mathrm{ml} / \mathrm{min}$ and $65,910 \mathrm{~W} / \mathrm{m}^{2}-\mathrm{K}$ for a flow rate of $1230 \mathrm{ml} / \mathrm{min}$. Although these numbers may seem very large, consider that the surface area for heat transfer is very small, thus a thermal resistance for the convection component can be estimated to be from 0.029 to $0.012{ }^{\circ} \mathrm{C} / \mathrm{W}$. This results in an overall thermal resistance of $0.1326{ }^{\circ} \mathrm{C} / \mathrm{W}$ for a flow rate of $293 \mathrm{ml} / \mathrm{min}$ and $0.1048{ }^{\circ} \mathrm{C} / \mathrm{W}$ for a flow rate of $1230 \mathrm{ml} / \mathrm{min}$ of the system.

\subsection{Summary from analytical treatment}

The Figure 4-5 below shows the rise in temperature of the substrate with change in power. The data points here represent two-flow rates $293 \mathrm{ml} / \mathrm{min}$ and $1230 \mathrm{ml} / \mathrm{min}$. As mentioned earlier since the flow rate doesn't have any influence on the overall thermal resistance of the system in Sample 1 and 2, the data points overlap each other even at different flow rates. In the case of Sample 3, data points doesn't overlap for different flow rates but are close which cannot be noticed in this figure. To show this difference a logarithmic plot is drawn in Figure 4-6. An approximate trend line is drawn along the data points and the slope of this line represents the overall thermal resistance of the system. It is found that the approximate overall thermal resistance of the system was $4.25{ }^{\circ} \mathrm{C} / \mathrm{W}$ for 
Sample $1,0.36{ }^{\circ} \mathrm{C} / \mathrm{W}$ for Sample 2 and $0.11{ }^{\circ} \mathrm{C} / \mathrm{W}$ for Sample 3 at a flow rate of $293 \mathrm{ml} / \mathrm{min}$.

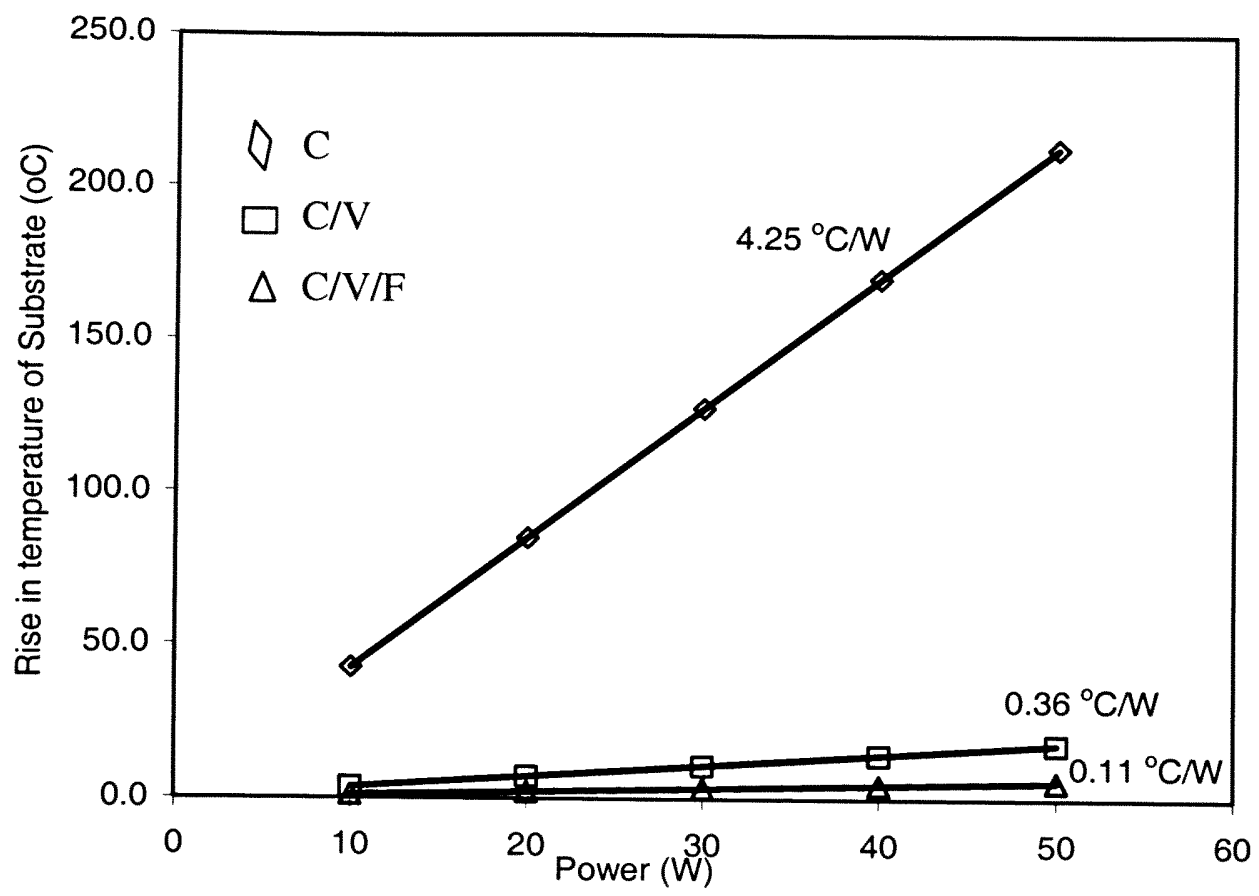

Figure 4-5 Substrate rise in temperature and effective overall thermal resistance of the system for all test configurations: $C$ - channel only; V - thermal vias; F-pin fins.

The Figure 4-6 shows the variation of the overall thermal resistance of the system with variation in power. Again in this two flow rates of $293 \mathrm{ml} / \mathrm{min}$ and $1230 \mathrm{ml} / \mathrm{min}$ are plotted. As discussed above, the thermal resistance doesn't have an effect with variation in power for Sample1 and 2. Also since flow rate doesn't have any influence, the data points of $293 \mathrm{ml} / \mathrm{min}$ flow rate coincide with $1230 \mathrm{ml} / \mathrm{min}$ for both these samples. For Sample 3, the thermal resistance doesn't vary with change in power levels. But since the flow rate has a slight influence of the thermal resistance, the curve shifts down (reduction in thermal resistance) with increase in flow rate. This is justified in the figure below for the two-flow rates $293 \mathrm{ml} / \mathrm{min}$ and $1230 \mathrm{ml} / \mathrm{min}$. 


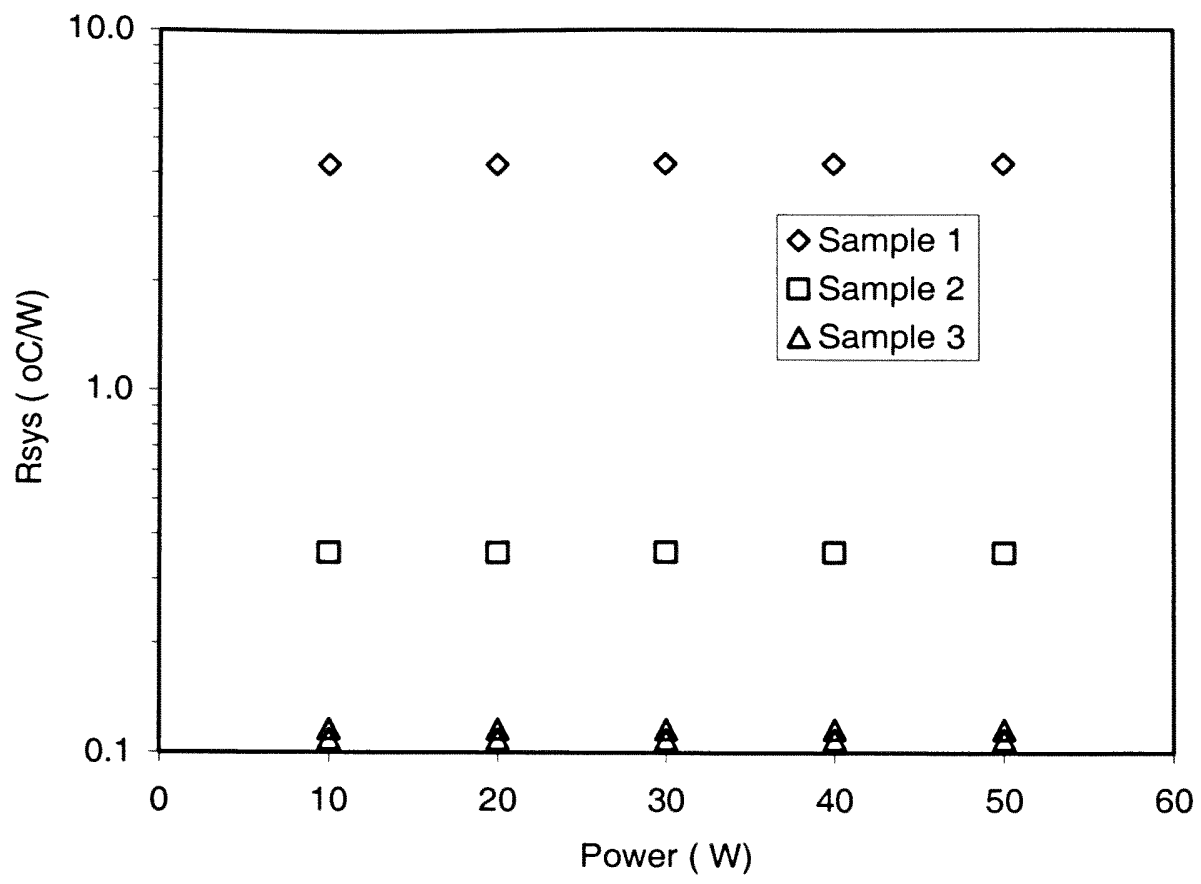

Figure 4-6 Effective thermal resistance of the system with varying power levels for Samples 1, 2 and 3 (logarithmic graph).

The Figure 4-7 shows the effect of thermal resistance with variation in flow rate at $30 \mathrm{~W}$ power input. It is observed from this figure that there is no change in the overall thermal resistance of the system for Samples 1 and 2 even though the flow rate is changed (already explained in the previous sections). For Sample 3 it shows that the overall thermal resistance reduces with the increase in flow rate. It is also noticed that the resistance decreases more up to a flow rate of $600 \mathrm{ml} / \mathrm{min}$ and after that it reaches a saturation point, which means even though the flow rate is increased very small decrease in resistance is noticed. 


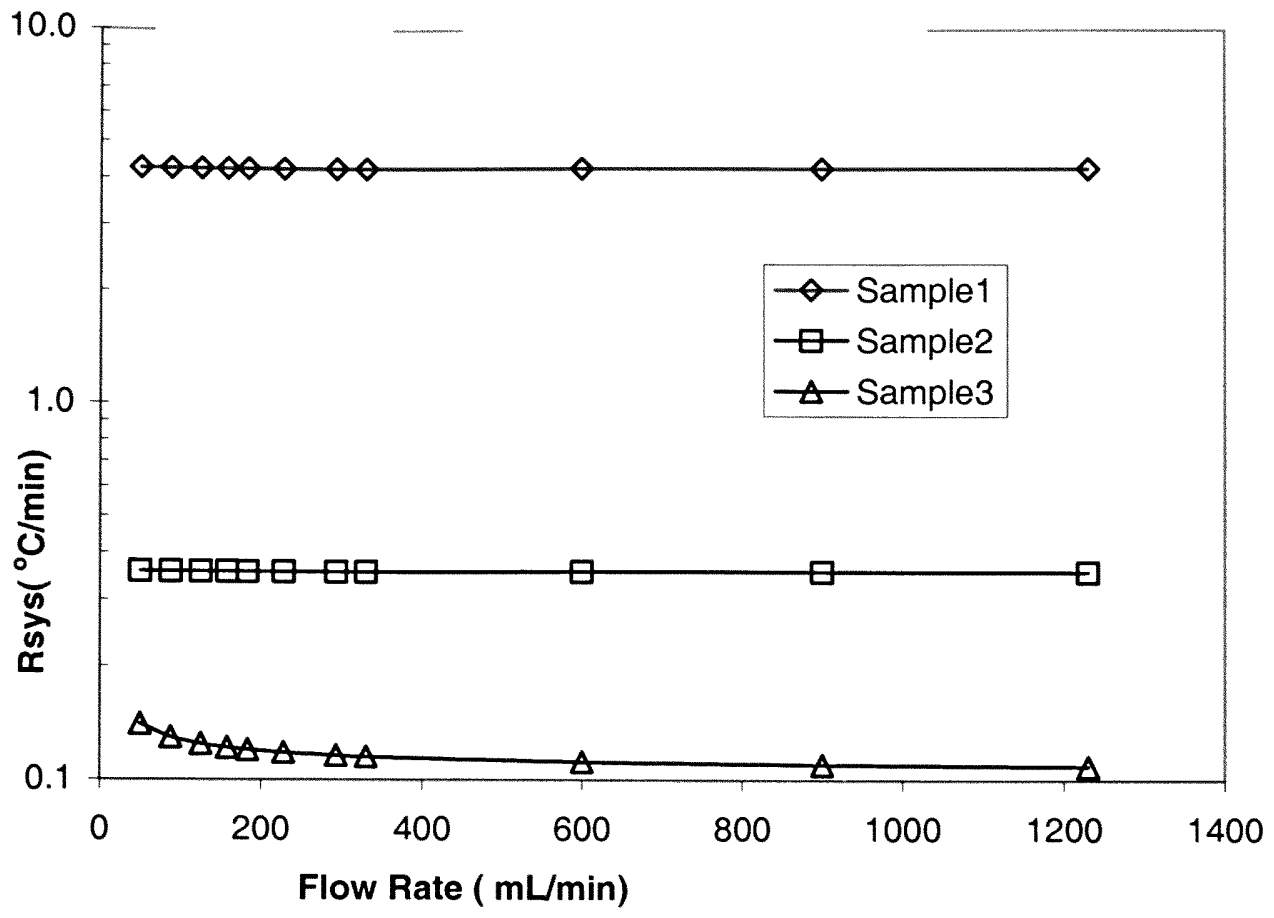

Figure 4-7 Effective thermal resistance of the system with varying flow rates for Samples 1, 2 and 3 at $30 \mathrm{~W}$ power input (logarithmic graph).

\begin{tabular}{|c|c|c|c|}
\hline Sample \# & $\begin{array}{c}\mathrm{Q} \\
(\mathrm{ml} / \mathrm{min})\end{array}$ & $\begin{array}{c}\text { Overall thermal } \\
\text { resistance } \\
\left({ }^{\circ} \mathrm{C} / \mathrm{W}\right)\end{array}$ & $\begin{array}{c}\text { Overall thermal } \\
\text { resistance } \\
\text { considering } \\
\text { resistance due to } \\
\text { Cu shim and epoxy } \\
\left({ }^{\circ} \mathrm{C} / \mathrm{W}\right)\end{array}$ \\
\hline \multirow{2}{*}{1} & 293 & 4.25 & 4.62 \\
\hline \multirow{2}{*}{2} & 1230 & 4.25 & 4.62 \\
\hline \multirow{2}{*}{3} & 293 & 0.36 & 0.73 \\
\hline & 1230 & 0.36 & 0.73 \\
\hline & 1230 & 0.12 & 0.49 \\
\hline
\end{tabular}

Table 4-1 Effective overall thermal resistance of the system using 1-D analytical approach.

The Table 4-1 above gives the overall thermal resistance of the three samples at different flow rates and at $30 \mathrm{~W}$ power input. Since for the experimental setup, the 
resistance due to $\mathrm{Cu}$ shim and thermal epoxy also come into account, the overall resistance considering the resistance due to $\mathrm{Cu}$ shim and epoxy is also specified. Since for the numerical analysis, the resistance due to thermal epoxy wasn't taken into account, the resistance without considering the $\mathrm{Cu}$ shim and epoxy was also tabulated. 


\section{$5 \quad$ Numerical treatment of problem}

In order to better understand the flow and heat transfer in the system, a numerical simulation, CFD was used to solve the fluid and thermal distributions for each of the three samples. The numerical simulation was performed using CFDesign (Version 6.0), a commercially available software package by Blue Ridge Numerics, Inc. three models were constructed, matching the geometries of the three tested samples. For the models, different flow rates of $50,88,125,158,183,228,293,330,600,900$ and $1230 \mathrm{ml} / \mathrm{min}$ and different power inputs varying from 10 to $50 \mathrm{~W}$ were simulated to compare the results from experimental data.

\subsection{Modeling}

As mentioned earlier, three models were made for simulation. The first model representing Sample 1, was made of LTCC substrate, flow volume and $\mathrm{Cu}$ shim according to the specifications. The second model representing Sample 2, was made of LTCC substrate (split into 3 layers for convince during assembling), the top layer of LTCC had thermal vias and $\mathrm{Ag}$ pad, flow volume and $\mathrm{Cu}$ shim. The third model representing Sample 3, was made of LTCC substrate (again split into 3 layers), the top layer of LTCC had thermal vias and Ag pad, the middle layer had free standing Ag columns, flow volume and $\mathrm{Cu}$ shim. The three assembled models used for analysis are shown in detail in drawings 4 , 5 and 6 in Appendix-2. 


\subsection{Apply loads and boundary conditions}

\subsubsection{Inlet boundary condition}

At the inlet, volume flow rate and inlet temperature of the fluid are specified. One of the flow rates among 50,88, 125, 158, 183, 228, 293, 330, 600, 900 and $1230 \mathrm{ml} / \mathrm{min}$ was used depending on the analysis and the inlet temperature is defined as either $20^{\circ} \mathrm{C}$ or $21.5^{\circ} \mathrm{C}$

\subsubsection{Outlet boundary condition}

For incompressible flows, the most robust condition for the pressure equation is to specify a value at the exit. Since CFDesign calculates only relative pressures, a value of zero is recommended at the exit. To obtain the absolute pressures in the solution domain, the absolute pressure at the exit should be added to the pressure values calculated by CFDesign. [20]

\subsubsection{Heat Input}

The thermal load was applied to the top surface of the Copper shim. A power source of total heat generation at various power levels from 10 to $50 \mathrm{~W}$ by copper shim is considered. The loads and boundary conditions assigned to the substrate are shown in the Figure 5-1. Figure 5-1 shows heat source boundary condition with total heat generation of $50 \mathrm{~W}$ and inlet $\mathrm{BC}$ 's volume flow rate as $1230 \mathrm{~mL} / \mathrm{min}$, temperature as $20^{\circ} \mathrm{C}$ and outlet pressure as $0 \mathrm{~Pa}$. This figure represents the sample without thermal vias and $\mathrm{Ag}$ columns (sample1). The BC's for other samples will also be similar. 


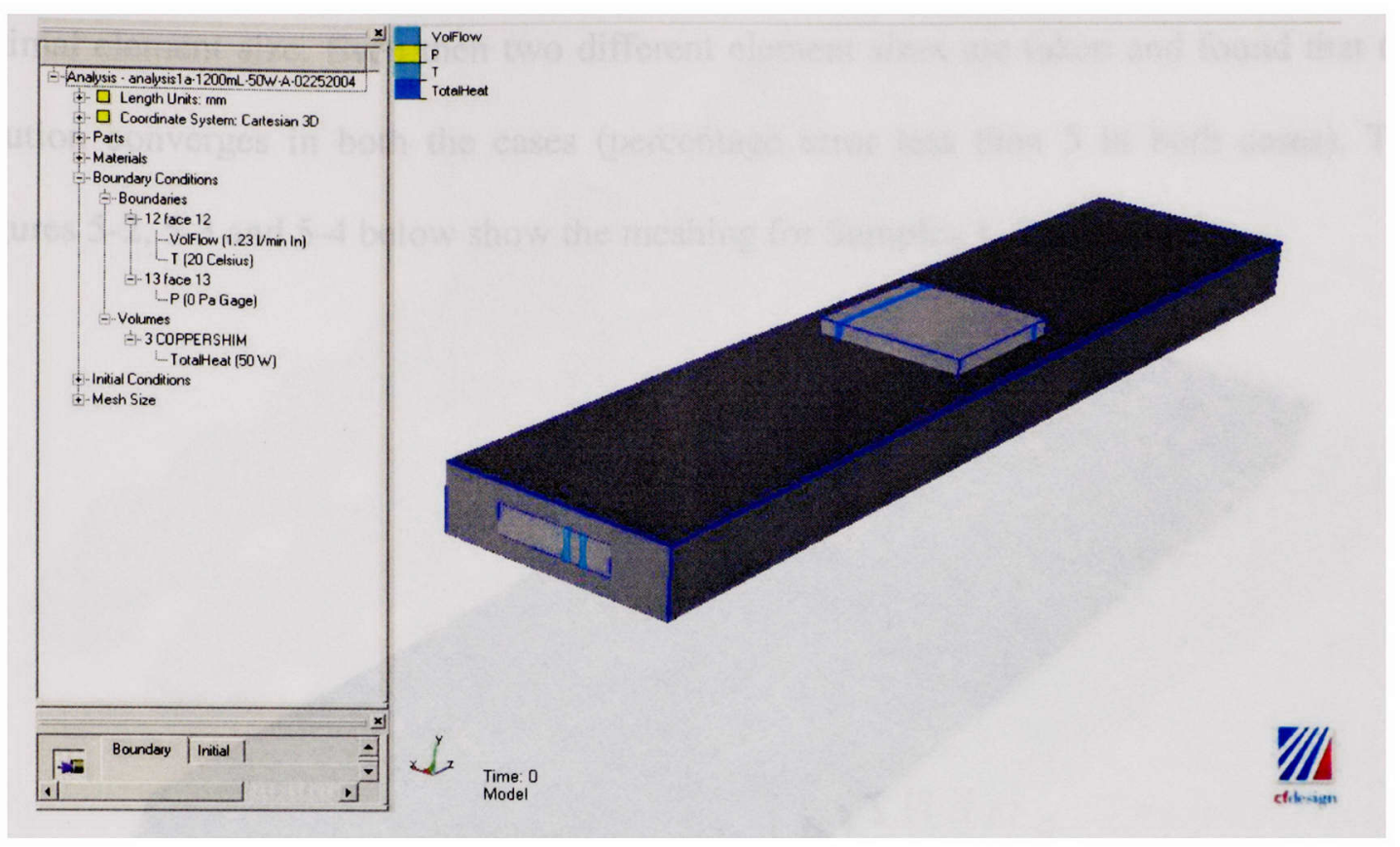

Figure 5-1 Boundary conditions with heat source as total heat generation.

In CFDesign, we need not specify the adiabatic surfaces and also the interface surfaces. CFDesign automatically detects the interface surfaces i.e., surface between two solids and interface surface between a solid and a liquid etc., and also when the surfaces are not in contact, by default it acts as an adiabatic surface.

\subsection{Meshing the model}

For the analysis of fluid flow and thermal problems, two types of elements are used - 3D, 4 node tetrahedral element for regular meshing and 3D, 6 node triangular prism or wedge element are used for mesh enhancement i.e., explained in detail in the coming sections.

For the first sample, the element size for LTCC and Copper shim are taken as $2 \mathrm{~mm}$ and for water (coolant) it was taken $1 \mathrm{~mm}$. Since sample 1 and 2 doesn't have complex shapes (i.e., silver columns in flow volume) it is not required to determine the 
optimal element size. Even then two different element sizes are taken and found that the solution converges in both the cases (percentage error less than 5 in both cases). The Figures 5-2, 5-3 and 5-4 below show the meshing for Samples 1, 2 and 3.

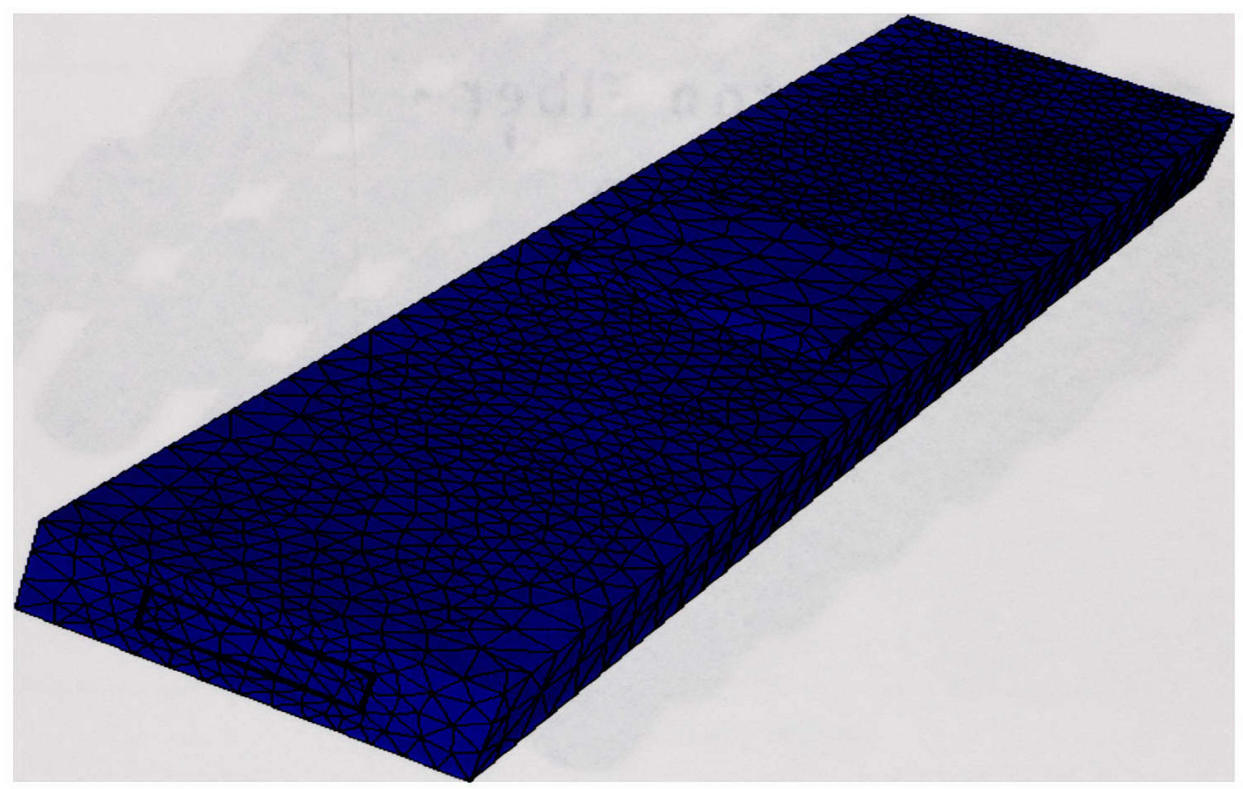

Figure 5-2 Meshing for sample 1 (shows LTCC substrate, flow volume and Cu shim)

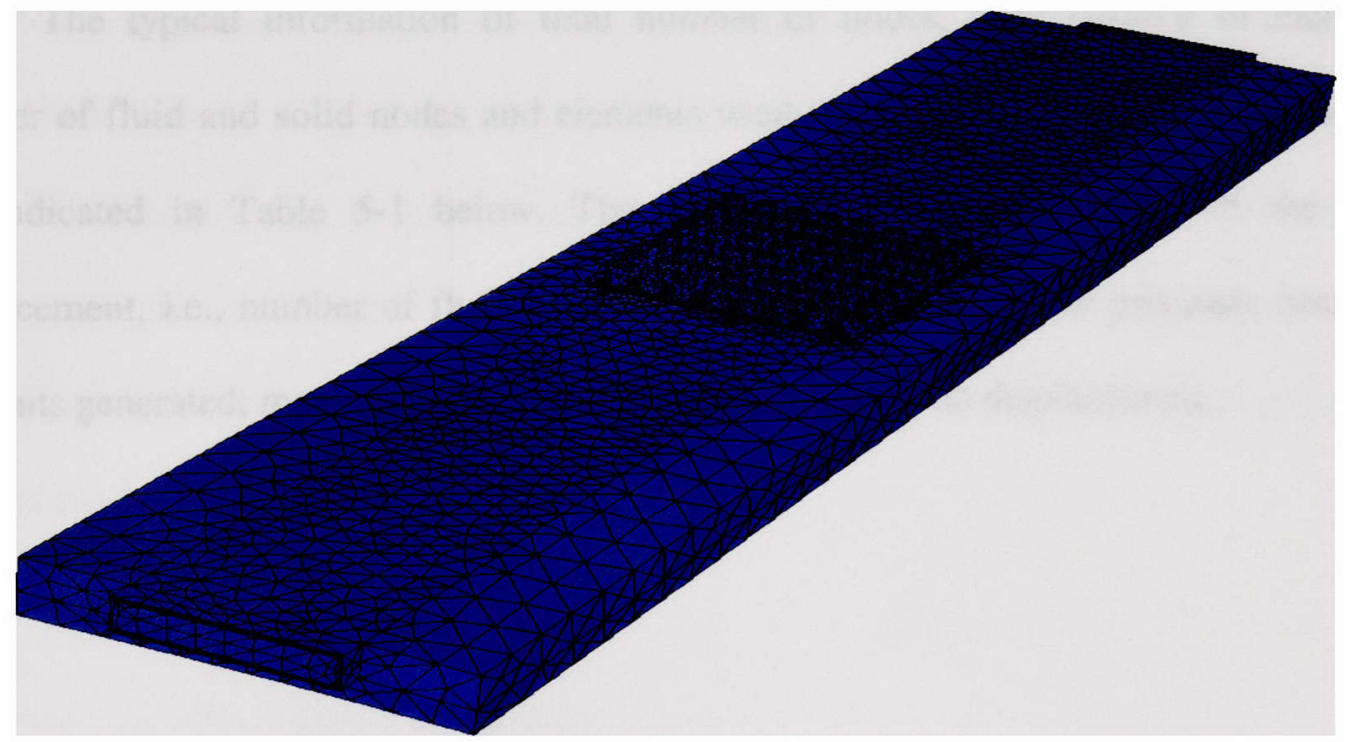

Figure 5-3 Meshing for sample 2 (shows LTCC substrate, vias, Ag pad and Cu shim) 


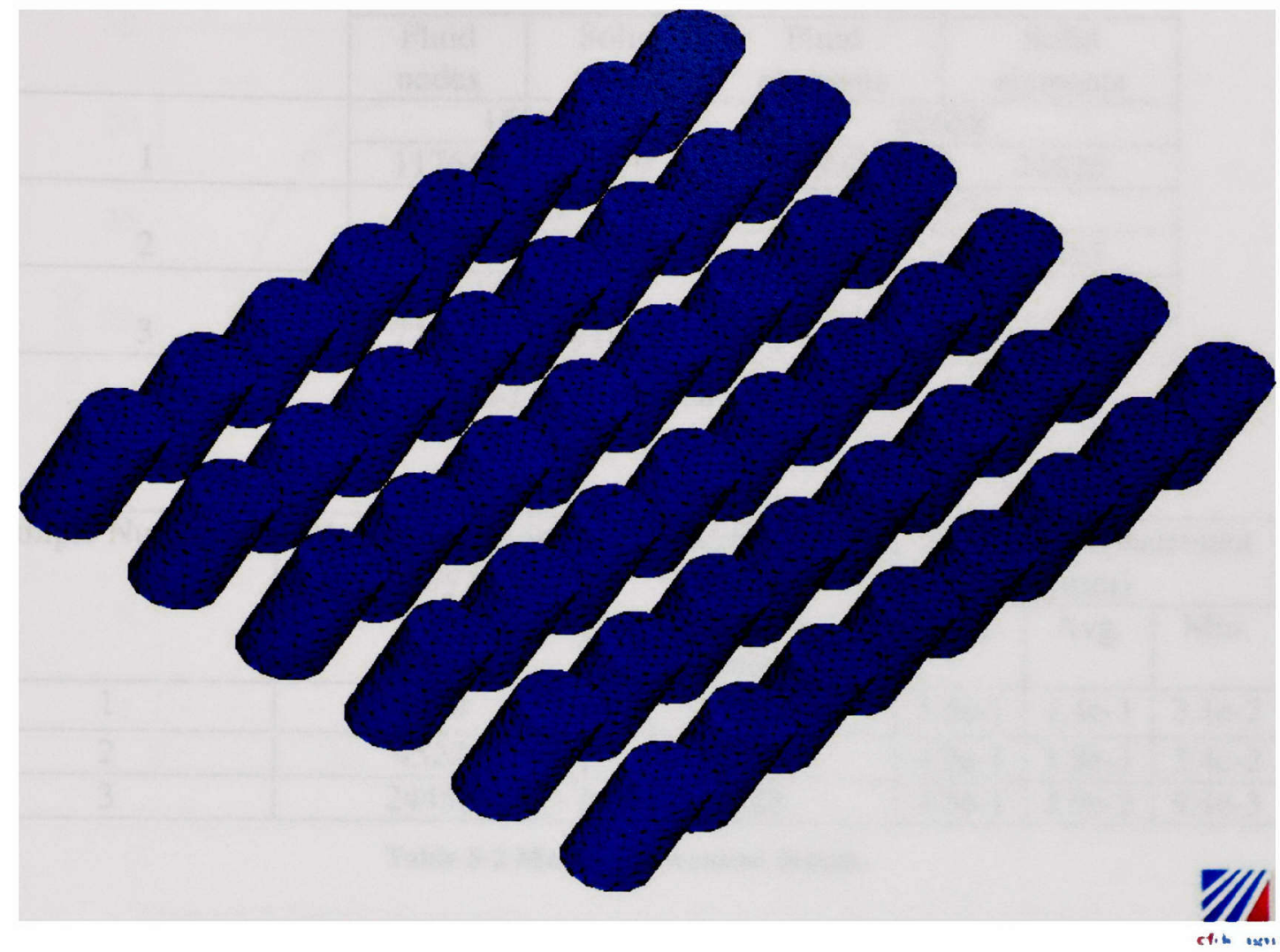

Figure 5-4 Detailed meshing of thermal vias in samples 2 and 3.

The typical information of total number of nodes, total number of elements, number of fluid and solid nodes and elements used for the analyses of the three samples are indicated in Table 5-1 below. The Table 5-2 shows the details of the mesh enhancement, i.e., number of fluid boundary faces found; number of prismatic boundary elements generated; maximum, average and minimum inflation displacement. 


\begin{tabular}{|c|c|c|c|c|}
\hline \multirow[t]{2}{*}{ Sample Number } & \multicolumn{2}{|c|}{ Total nodes } & \multicolumn{2}{|c|}{ Total elements } \\
\hline & $\begin{array}{l}\text { Fluid } \\
\text { nodes }\end{array}$ & $\begin{array}{l}\text { Solid } \\
\text { nodes }\end{array}$ & $\begin{array}{c}\text { Fluid } \\
\text { elements }\end{array}$ & $\begin{array}{c}\text { Solid } \\
\text { elements }\end{array}$ \\
\hline \multirow[b]{2}{*}{1} & \multicolumn{2}{|c|}{16143} & \multicolumn{2}{|c|}{60688} \\
\hline & 11764 & 4379 & 35862 & 24826 \\
\hline \multirow[b]{2}{*}{2} & \multicolumn{2}{|c|}{23512} & \multicolumn{2}{|c|}{102371} \\
\hline & 12257 & 11255 & 38606 & 63765 \\
\hline & \multicolumn{2}{|c|}{129122} & \multicolumn{2}{|c|}{552106} \\
\hline 3 & 77306 & 51816 & 232374 & 319732 \\
\hline
\end{tabular}

Table 5-1 Finite element summary.

\begin{tabular}{|c|c|c|c|c|c|}
\hline Sample Number & \multirow{2}{*}{$\begin{array}{c}\text { Number of Fluid } \\
\text { Boundary faces }\end{array}$} & \multirow{2}{*}{$\begin{array}{c}\text { Number of } \\
\text { Prismatic } \\
\text { boundary } \\
\end{array}$} & & \multicolumn{3}{|c|}{ Inflation displacement } \\
\cline { 4 - 6 } & & elements & Max. & Avg. & Min. \\
& 3520 & 13792 & $3.5 \mathrm{e}-1$ & $1.4 \mathrm{e}-1$ & $3.1 \mathrm{e}-2$ \\
\hline 1 & 4522 & 13538 & $4.9 \mathrm{e}-1$ & $1.9 \mathrm{e}-1$ & $3.4 \mathrm{e}-2$ \\
\hline 2 & 24458 & 97528 & $4.3 \mathrm{e}-1$ & $5.9 \mathrm{e}-2$ & $9.4 \mathrm{e}-3$ \\
\hline 3 & & &
\end{tabular}

Table 5-2 Mesh enhancement details.

But as the Sample 3 has complex geometries, the element size of flow volume and also the element size of LTCC are varied to determine an optimal element size. Due to these complex geometries, the flow volume is made into two parts -one named as inner water (flow volume defined across the Ag columns) and the other one named as outer water. The element size of inner water is varied from $0.1 \mathrm{~mm}$ to $1.2 \mathrm{~mm}$ with constant element size for outer water. Material properties are considered same as defined for the other analyses. A particular flow rate of $1230 \mathrm{ml} / \mathrm{min}, \mathrm{T}_{\text {inlet }}$ of $21.5^{\circ} \mathrm{C}$ and power input of $50 \mathrm{~W}$ is used. 


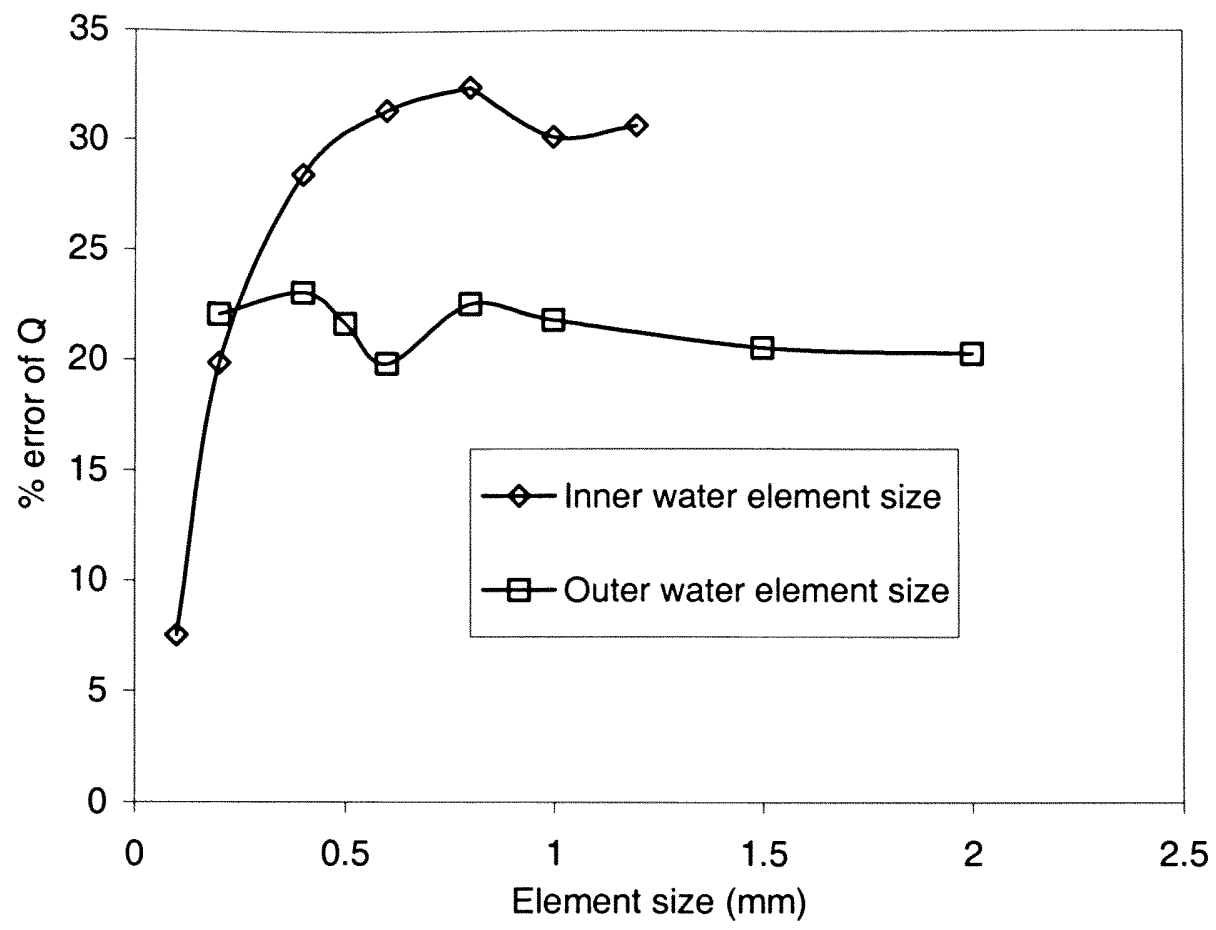

Figure 5-5 Plot showing percentage error in $Q$ w.r.t. element size of water.

In order to avoid colossal run time of analysis, LTCC, thermal vias and $\mathrm{Cu}$ shim are eliminated to determine the optimal element size and heat input is given through $\mathrm{Ag}$ pad. The results plotted in Figure 5-5, show that for an element size of $0.1 \mathrm{~mm}$ for inner water and $1 \mathrm{~mm}$ for outer water, the error is $7.53 \%$, which is below acceptable error of $10 \%$. Hence it was concluded that the optimal element size is $0.1 \mathrm{~mm}$ and $1 \mathrm{~mm}$ for inner and outer water respectively.

\subsubsection{Mesh enhancement}

Mesh enhancement is a great feature that considerably simplifies the mesh definition process. Mesh enhancement automatically constructs layers of prismatic 
elements along all walls and all fluid-solid interfaces in the model, based on the tetrahedral mesh that was defined. These additional elements serve two primary purposes:

The first is that the elements are concentrated in the boundary layer region, where high velocity, pressure and turbulence gradients most often occur.

The second benefit is that enough nodes are automatically placed in all gaps (area between walls) in the model. The two principal guidelines for meshing are to define shape and to allow/account for flow activity. Adequately meshing all of the small gaps and crevices in a complicated geometry is not an issue anymore, with mesh enhancement feature.

The mesh enhancement parameters are - number of element layers and boundary layer thickness factor. The default setting of 3 layers is satisfactory for most analyses. However when working with turbulent flows that are in the lower Reynolds number range, it may be necessary to reduce the number of layers to one. Boundary layer thickness factor controls the total height of the inflation layer relative to the original near-wall elements. The Figure 5-6 below shows the mesh enhancement near the wall and fluid interface.

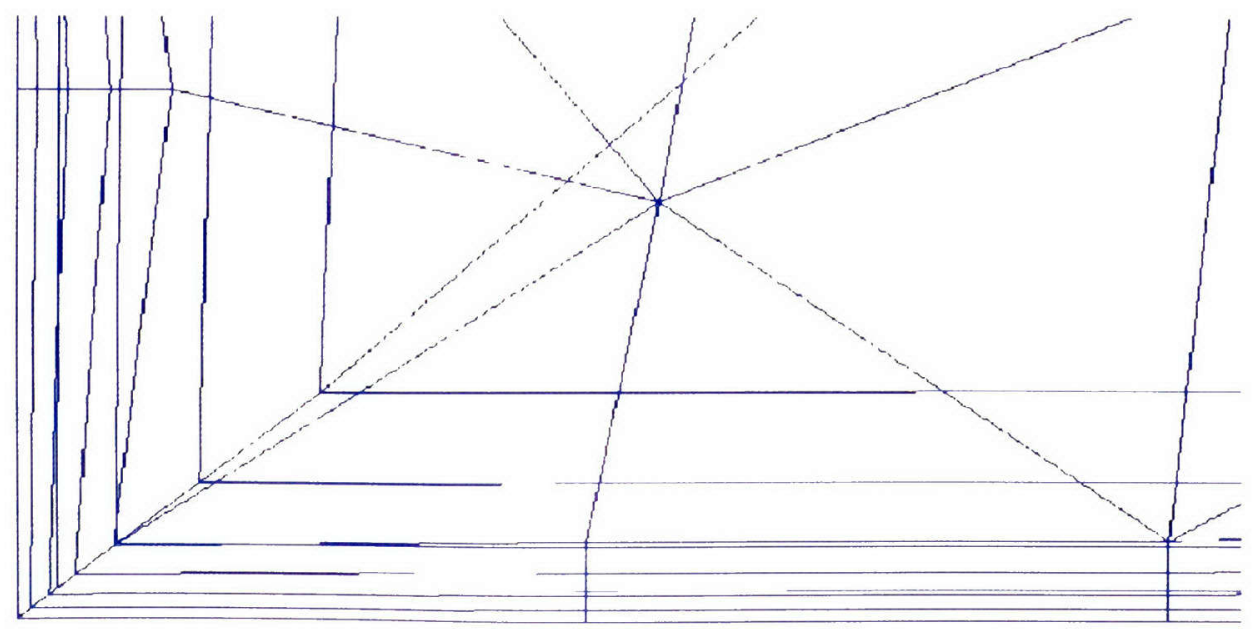

Figure 5-6 Mesh enhancement in fluid near the wall and fluid interface. 
The meshing discussed here is to define the mesh size and mesh enhancement in the geometry. The actual mesh generation is a part of analysis and is not a separate step.

\subsection{Assign material and material properties}

Materials are physical substances and are to be assigned to the parts (volumes for 3D models and surfaces for 2D models). The materials used in this analysis are LTCC, Silver (Ag), Copper variable and water. All the solid parts are defined as isotropic i.e., have same properties along $\mathrm{X}, \mathrm{Y}$ and $\mathrm{Z}$ directions.

Material properties used in the numerical analysis are given below in Table 5-3.

\begin{tabular}{|c|c|c|c|c|}
\hline & $\begin{array}{c}\mathrm{K} \\
\mathrm{W} / \mathrm{m}-\mathrm{K}\end{array}$ & $\begin{array}{c}\rho \\
\mathrm{kg} / \mathrm{m}^{3}\end{array}$ & $\begin{array}{c}\mathrm{C}_{\mathrm{p}} \\
\mathrm{J} / \mathrm{kg}-\mathrm{K}\end{array}$ & $\begin{array}{c}\mu \\
\mathrm{Pa}-\mathrm{s}\end{array}$ \\
\hline LTCC & 3 & 3100 & 837 & -- \\
\hline Silver paste & 290 & 10500 & 232 & -- \\
\hline Copper shim & 377 & 8900 & 380 & -- \\
\hline Water (at $\left.19.85^{\circ} \mathrm{C}\right)$ & 0.6 & 998 & 4182 & 0.001 \\
\hline
\end{tabular}

Table 5-3 Material properties.

\subsection{Select Analysis type and run the analysis}

Turbulent model:

Three turbulence models are available: constant eddy viscosity, k-epsilon and RNG turbulence model. These methods are discussed in detail in the last chapters. An auto start ON is selected which controls the automatic turbulent start-up (ATSU) algorithm. This algorithm goes through a number of steps to obtain turbulent flow solutions. The algorithm starts by running 10 iterations using a constant eddy viscosity model, so the kepsilon equations re not solved. With this solution as an initial guess, the two-equation turbulence model is started. At about 10 iterations, a spike in the convergence monitoring data will appear for the $\mathrm{k}$ and epsilon equations. Other steps are then taken gradually to 
arrive at the converged result. These steps may involve spikes in the convergence monitoring data at iterations 10,20 and 50 . After 50 iterations, the ATSU is turned off automatically. [20]

The final result of the analysis will be having fluid velocities, pressures and heat transfer. It is know from the basic convection heat transfer laws, that the solution of heat transfer is dependent on the fluid flow velocities. From this it was obvious that there is no point in solving the thermal analyses until a converging solution is found for fluid flow. Due to this reason, initially only fluid flow is solved. Once the analysis converged fluidically (the mean of the residual doesn't vary with number of iterations, which was approximately 250 iterations), then the solution to the flow field (i.e., velocity in all directions) was held constant and these results were used for the thermal analysis. In about 50 iterations for thermal analysis, it was found that mean residual for temperature stopped varying, showing the sign of convergence. The heat transfer cycle reached the convergence quicker than the fluid analysis since there is only one parameter. Figure 5-7 shows the mean of the residual of various parameters i.e., $\mathrm{U}, \mathrm{V}, \mathrm{W}, \mathrm{p}$ and $\mathrm{T}$ at different iterations for Sample 1. The plot is normalized in $y$-axis to closely monitor the convergence of each parameter. The plot shows that the temperature curve is flat until 200 iterations, which means the heat transfer equation is not solved for the first 200 iterations. Within these 200 iterations, it was noticed that the solution converges w.r.t U, V and $\mathrm{W}$ and also p. At the end of 200 iterations, only heat equations are solved turning off the fluid solver, which shows converges in $\mathrm{T}$ also in 50 iterations. Similar convergence plots are shown in Figure 5-8 and 5-9 for Samples 2 and 3 respectively. 


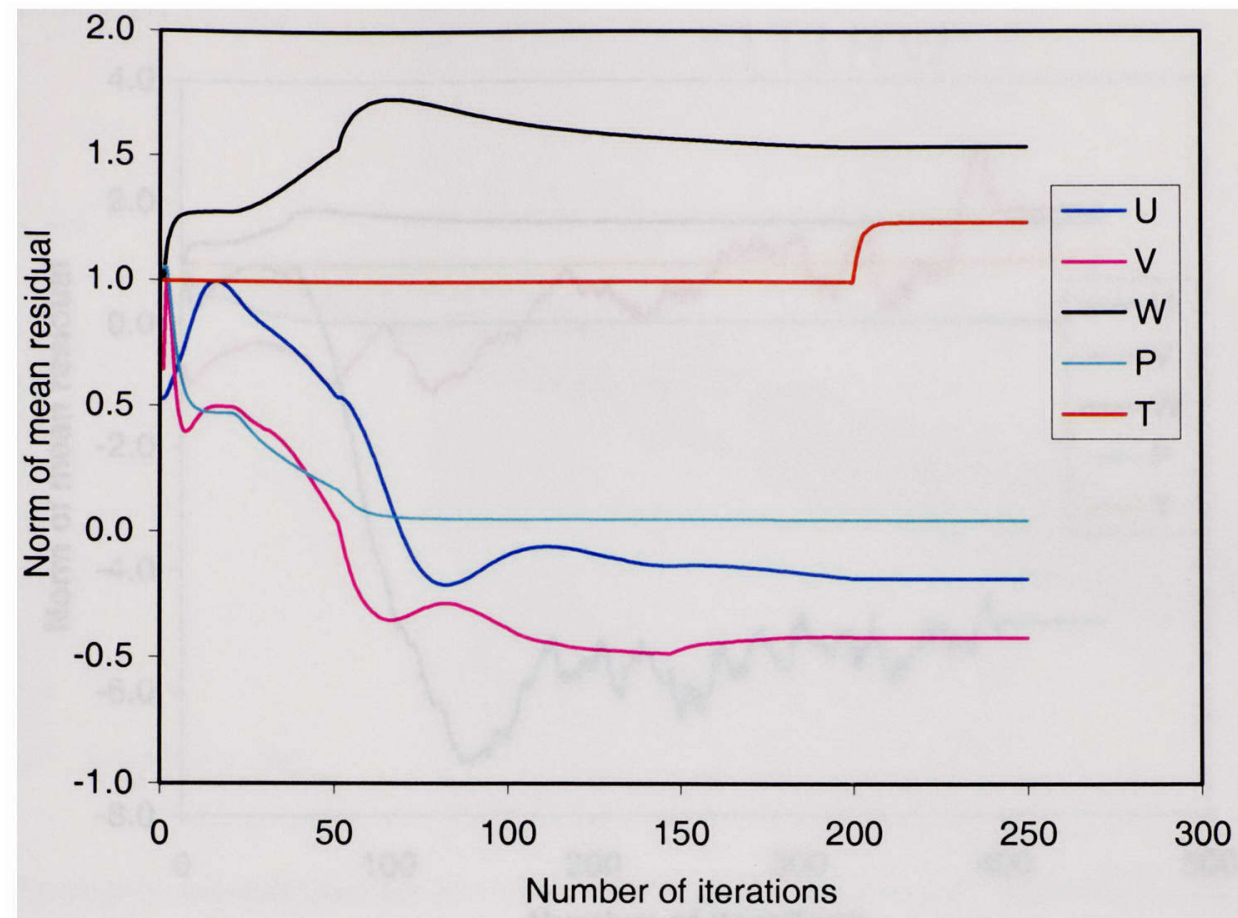

Figure 5-7 The norm of mean residual at each iteration for Sample 1.

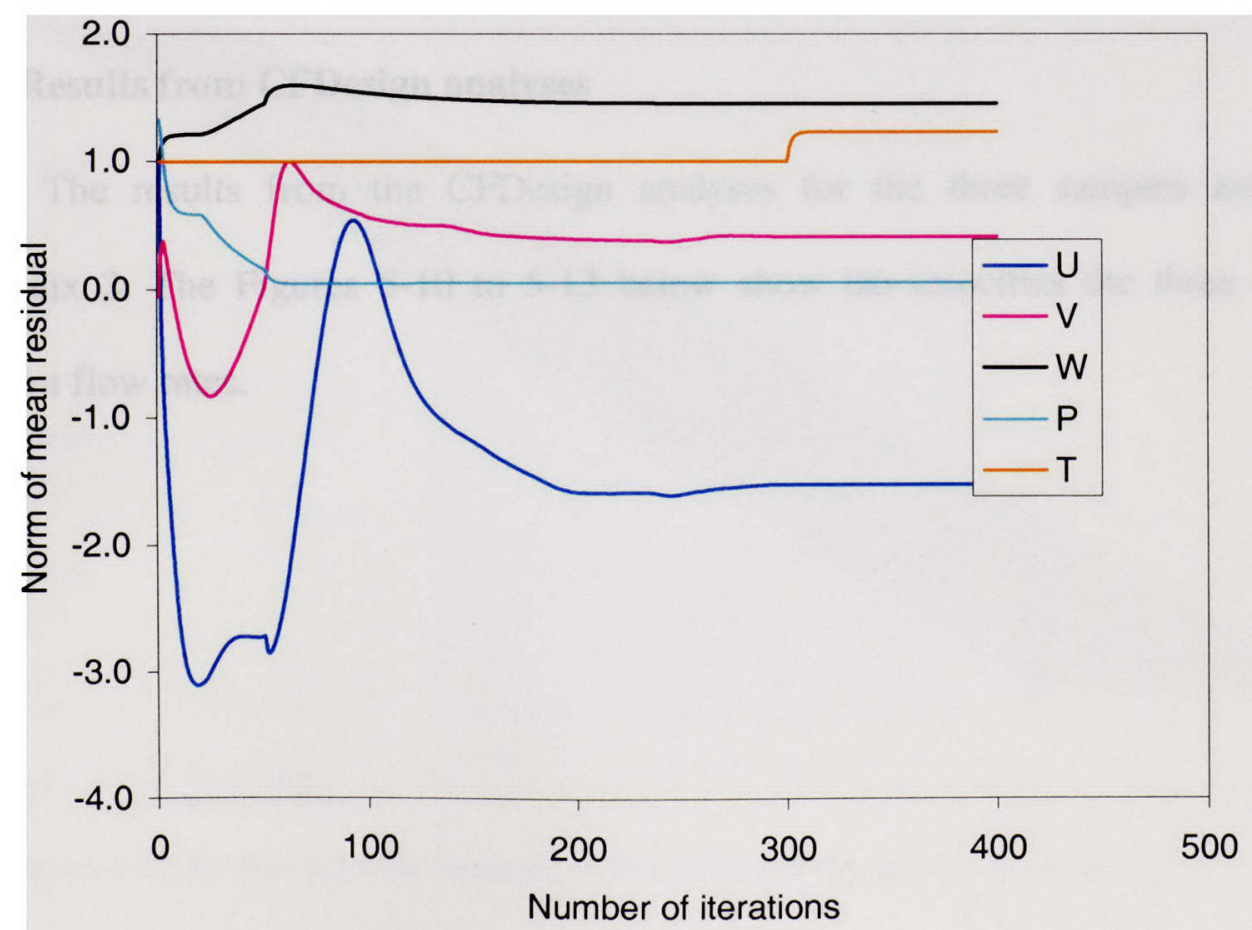

Figure 5-8 The norm of mean residual at each iteration for Sample 2. 


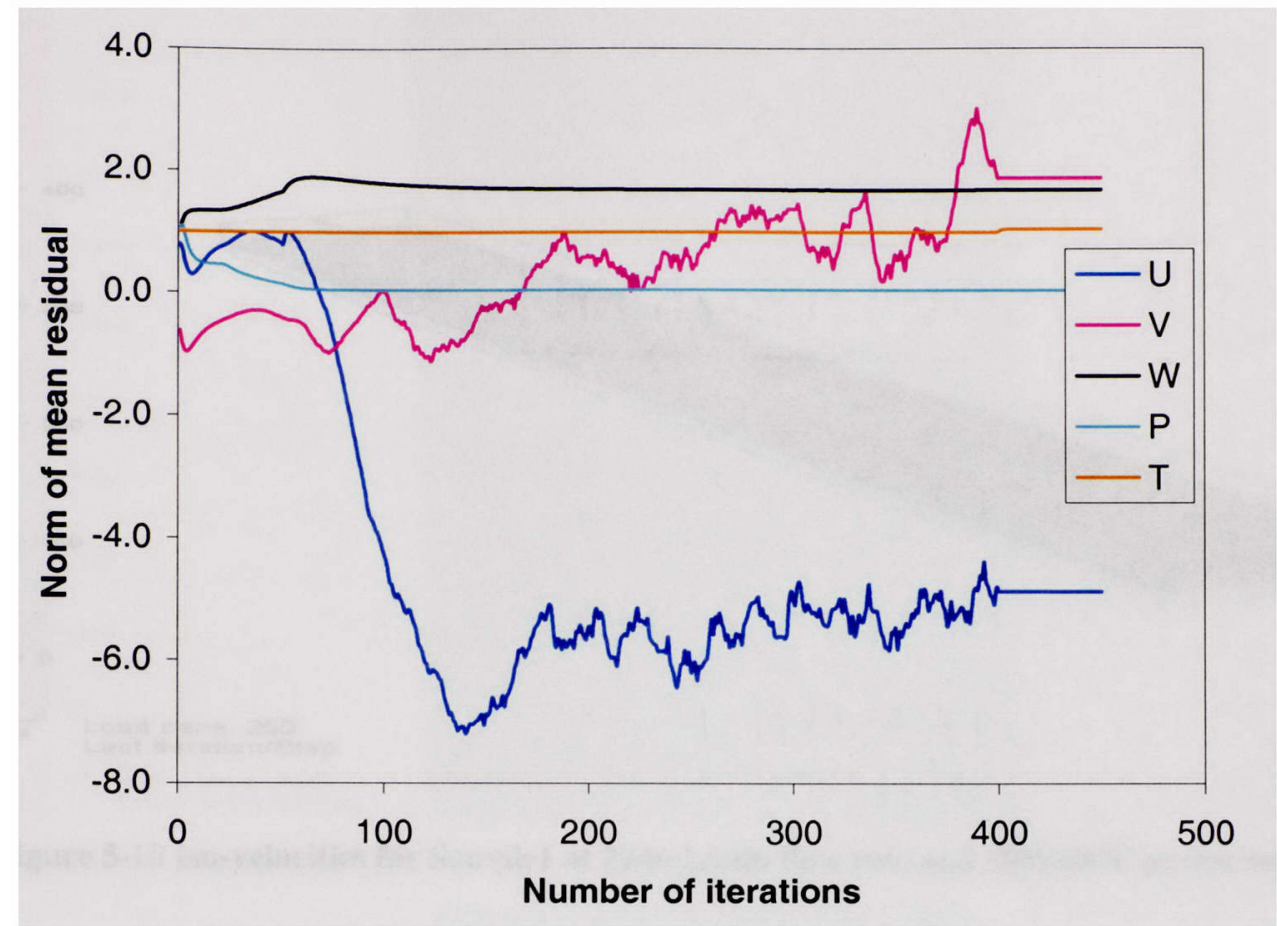

Figure 5-9 The norm of mean residual at each iteration for Sample 3.

\subsection{Results from CFDesign analyses}

The results from the CFDesign analyses for the three samples are given in Appendix 3. The Figures 5-10 to 5-13 below show iso-velocities the three samples at different flow rates. 


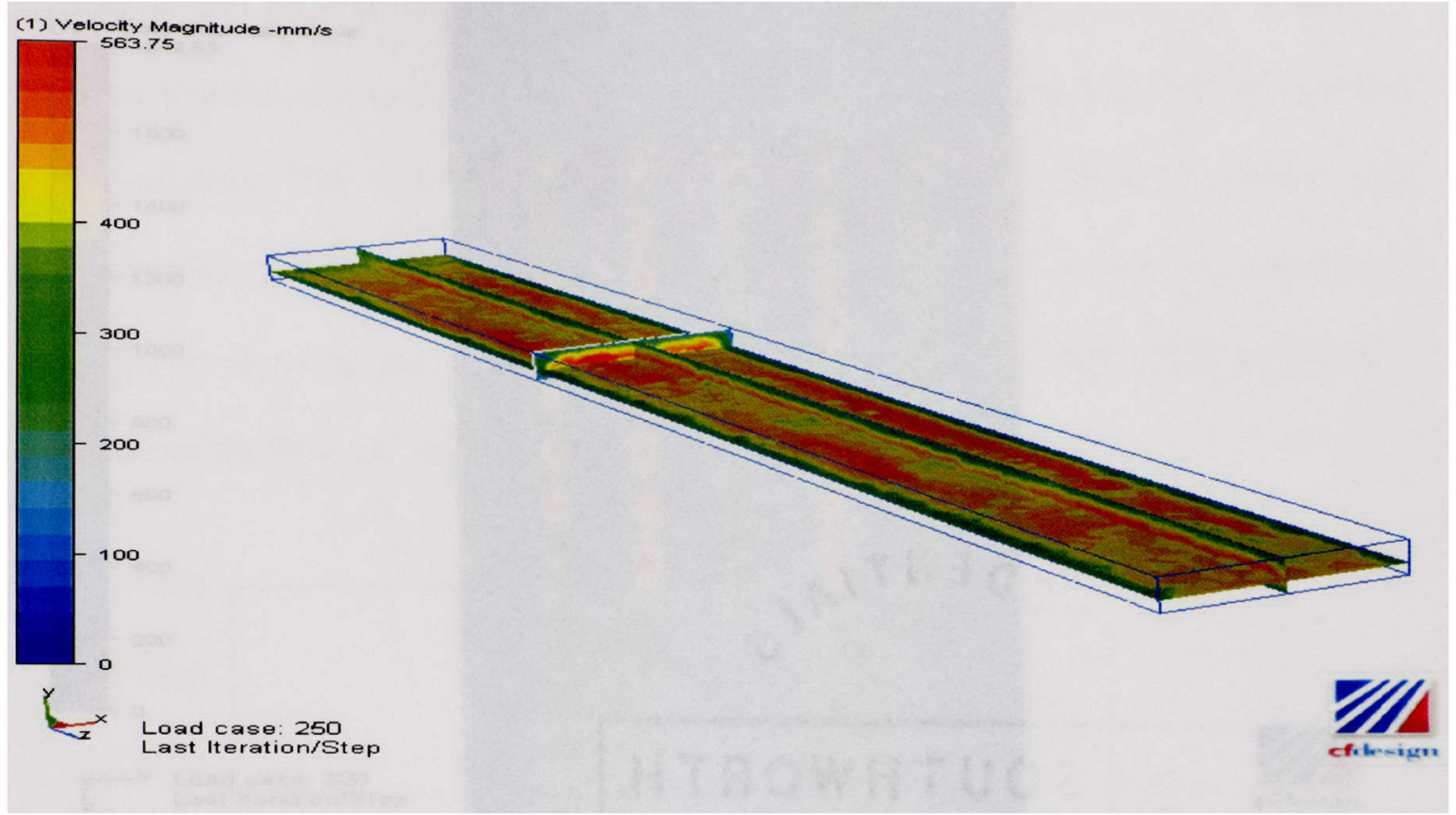

Figure 5-10 Iso-velocities for Sample1 at $294 \mathrm{~mL} / \mathrm{min}$ flow rate and $50 \mathrm{~W} / 80^{\circ} \mathrm{C}$ power source.

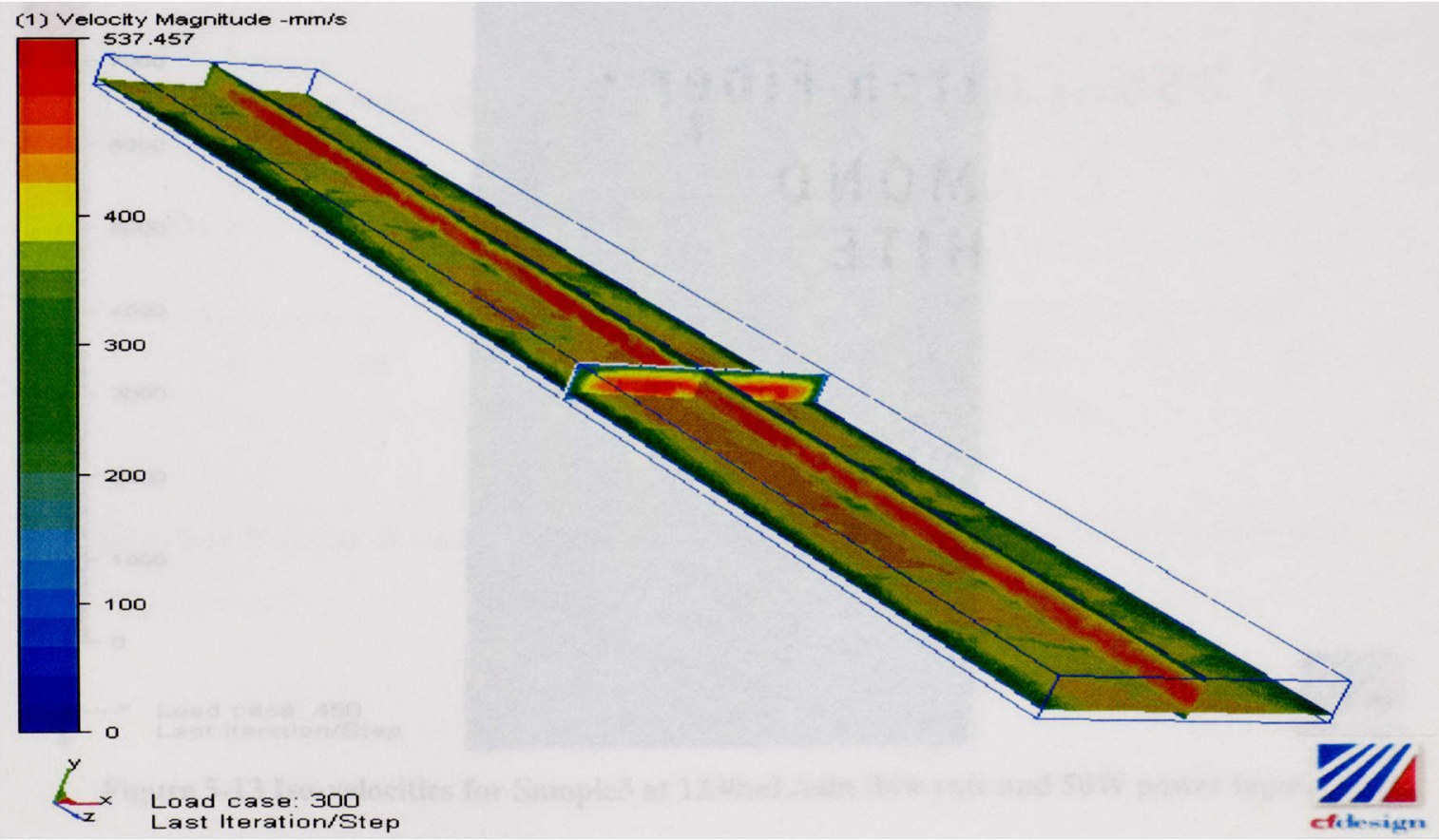

Figure 5-11 Iso-velocities for Sample2 at $294 \mathrm{~mL} / \mathrm{min}$ flow rate and $50 \mathrm{~W} / 80^{\circ} \mathrm{C}$ power source. 
more heat with it, which increases its temperature as we move down-stream. Since the heating element is near $35 \mathrm{~mm}$ to $45 \mathrm{~mm}$ along the length of the substrate, most of the heating takes place at that location, which indicates drastic rise in temperature and after that, it shows slight decrease in temperature which indicates that water slowly spreads this heat to the substrate. In the same manner, Figure 5-23 shows temperature of the system for a volume flow rate of $294 \mathrm{ml} / \mathrm{min}$ and $50 \mathrm{~W}$ power input, at the center of the system, as it is moved along the thickness of the substrate from the top of the $\mathrm{Cu}$ shim to LTCC top sub-assembly into water flow regime and further into the bottom sub-assembly. In this plot, the distance from $0 \mathrm{~mm}$ to $1 \mathrm{~mm}$ represents $\mathrm{Cu}$ shim, $1 \mathrm{~mm}$ to $2.5 \mathrm{~mm}$ represents LTCC top sub-assembly and $2.5 \mathrm{~mm}$ to $4 \mathrm{~mm}$ represents the water flow regime. Beyond 4 $\mathrm{mm}$ represents LTCC bottom sub-assembly. In this figure, the temperature remained constant from $0 \mathrm{~mm}$ to $1 \mathrm{~mm}$, in all the three samples, since this represents the $\mathrm{Cu}$ shim which is a good conducting material and has very low thermal resistance. This further indicates low temperature gradient in this section. In Sample 1, it is observed that from 1 $\mathrm{mm}$ to $2.5 \mathrm{~mm}$ high temperature gradient is noticed. This is due to the high thermal resistance offered by LTCC. In Sample 2 and 3, from $1 \mathrm{~mm}$ to $2.5 \mathrm{~mm}$ it is observed that the slope of temperature gradient remains constant and also less due to the presence of thermal vias. As we go further down into the flow regime slope for Sample 1 and 2 almost close, which indicates their resistance due to convection, would be close to each other. For Sample 3 in the flow regime, even though the temperature gradient is less when compared to other two samples. 


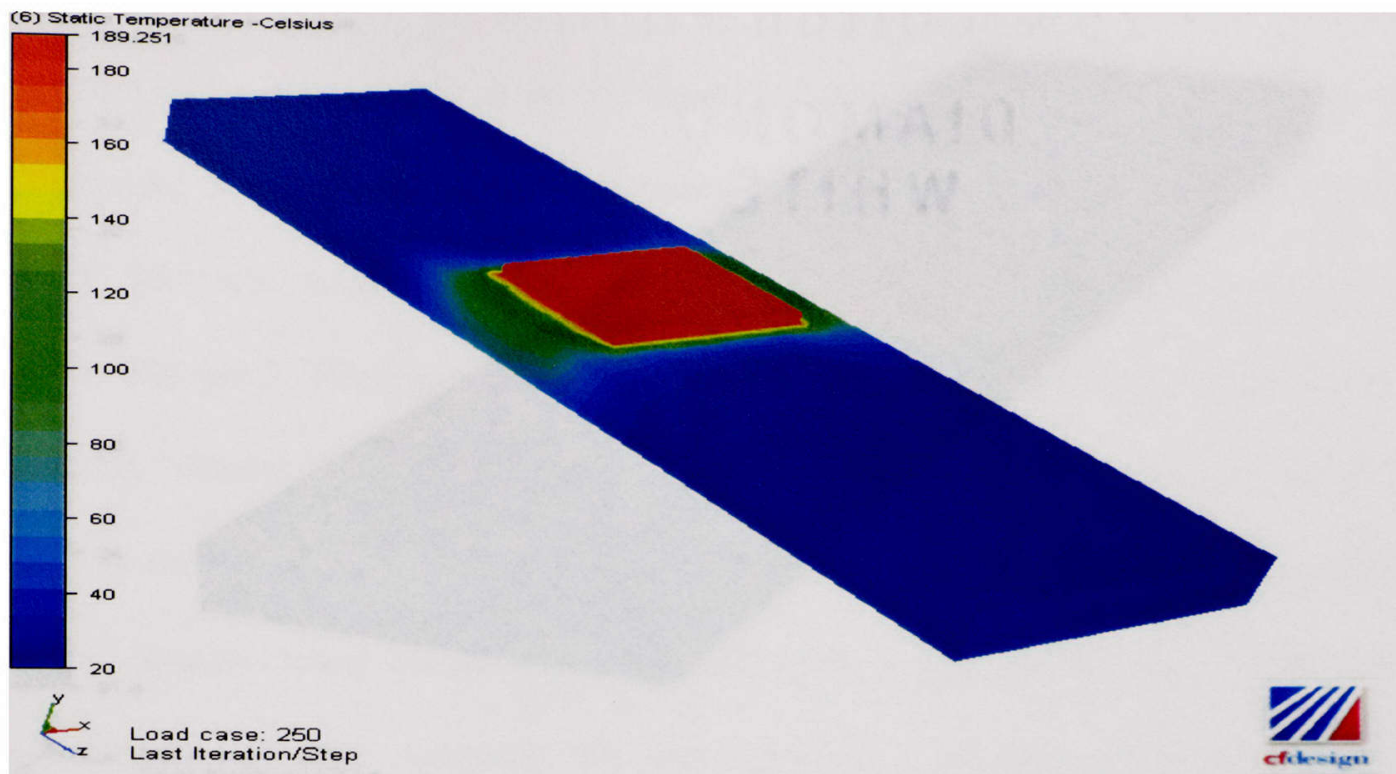

Figure 5-24 Isotherms for Sample1 at $1230 \mathrm{~mL} / \mathrm{min}$ flow rate and $50 \mathrm{~W}$ power input (shows full model including Cu shim).

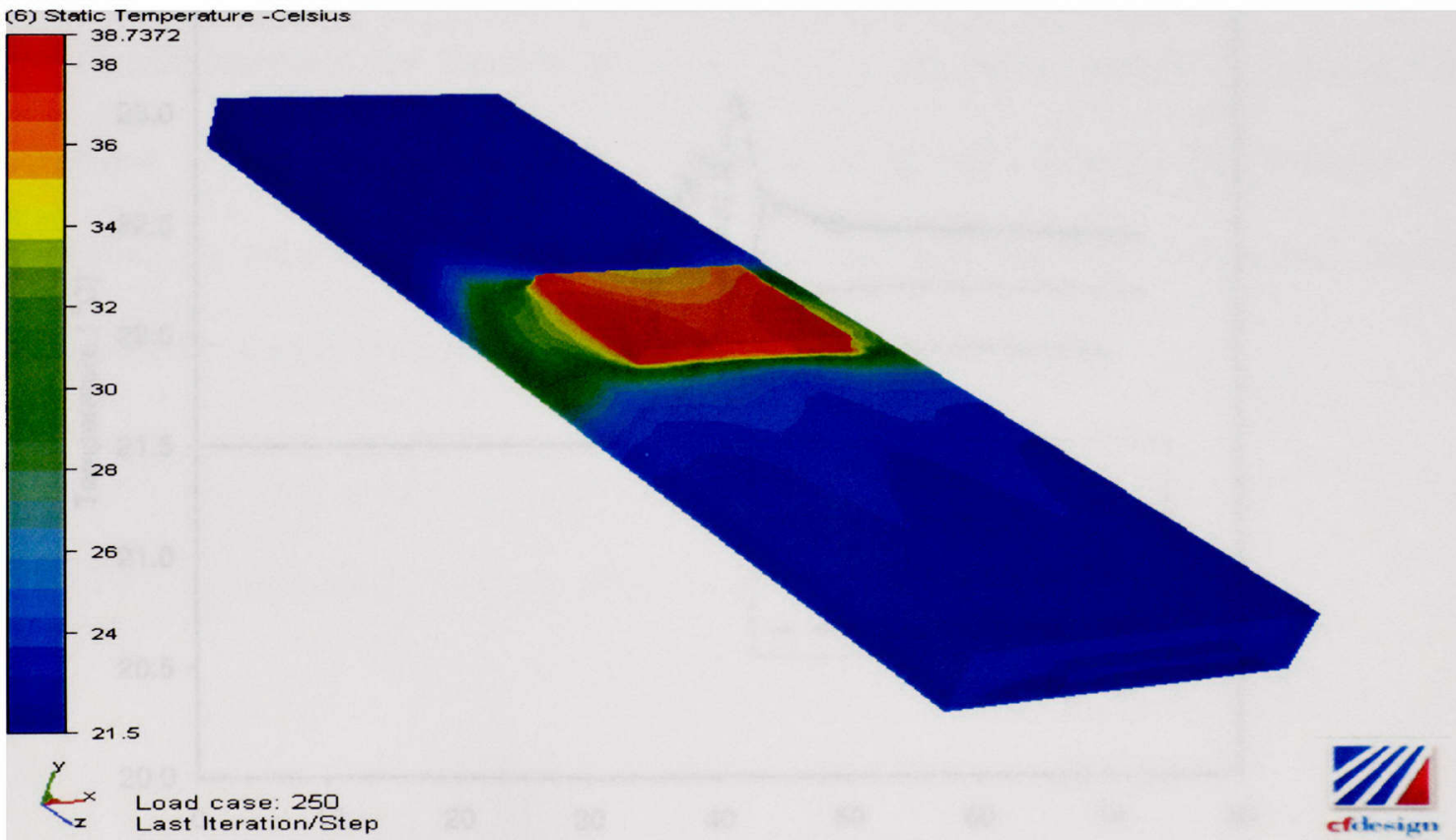

Figure 5-25 Isotherms for Sample2 at $1230 \mathrm{~mL} / \mathrm{min}$ flow rate and $50 \mathrm{~W}$ power input (shows full model including Cu shim). 


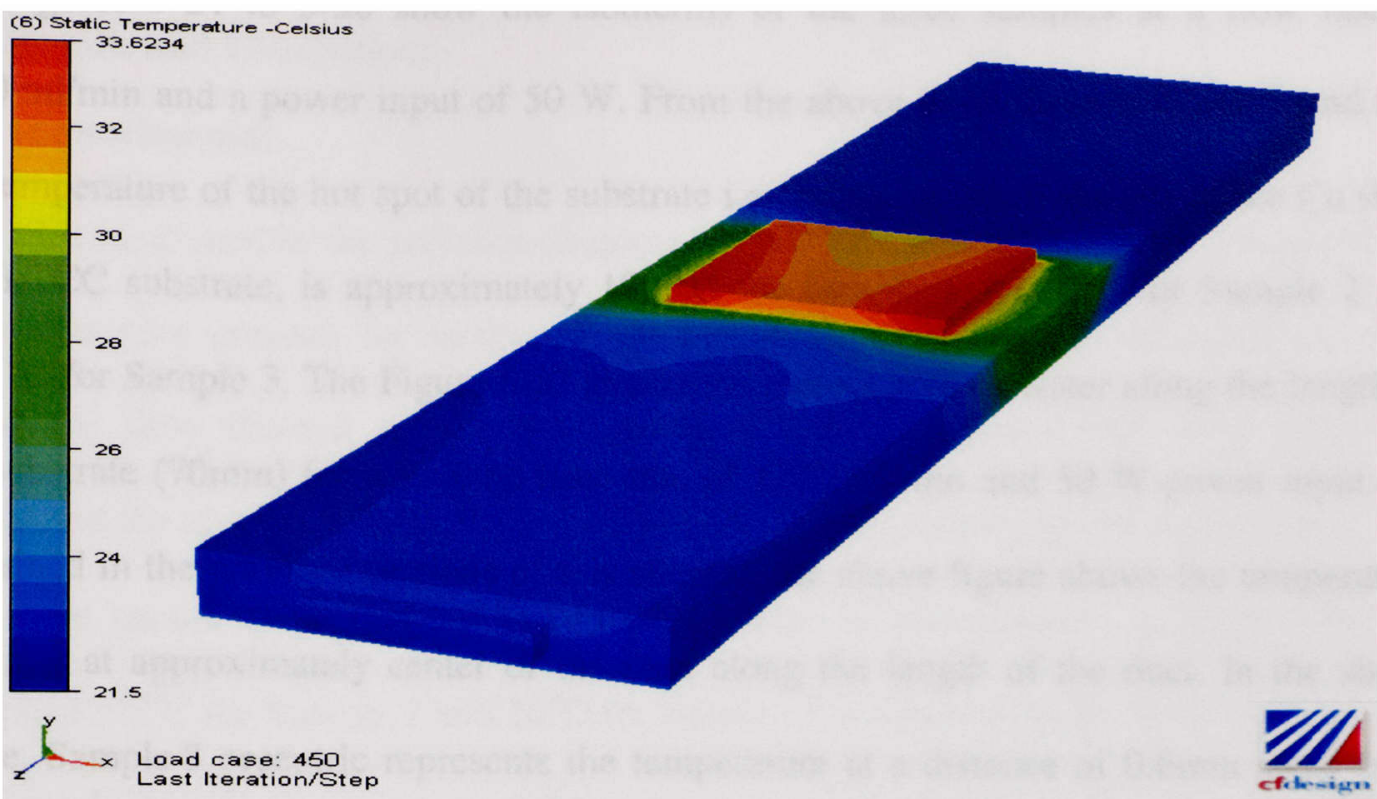

Figure 5-26 Isotherms for Sample3 at $1230 \mathrm{~mL} / \mathrm{min}$ flow rate and $50 \mathrm{~W}$ power input (shows full model including $\mathrm{Cu}$ shim).

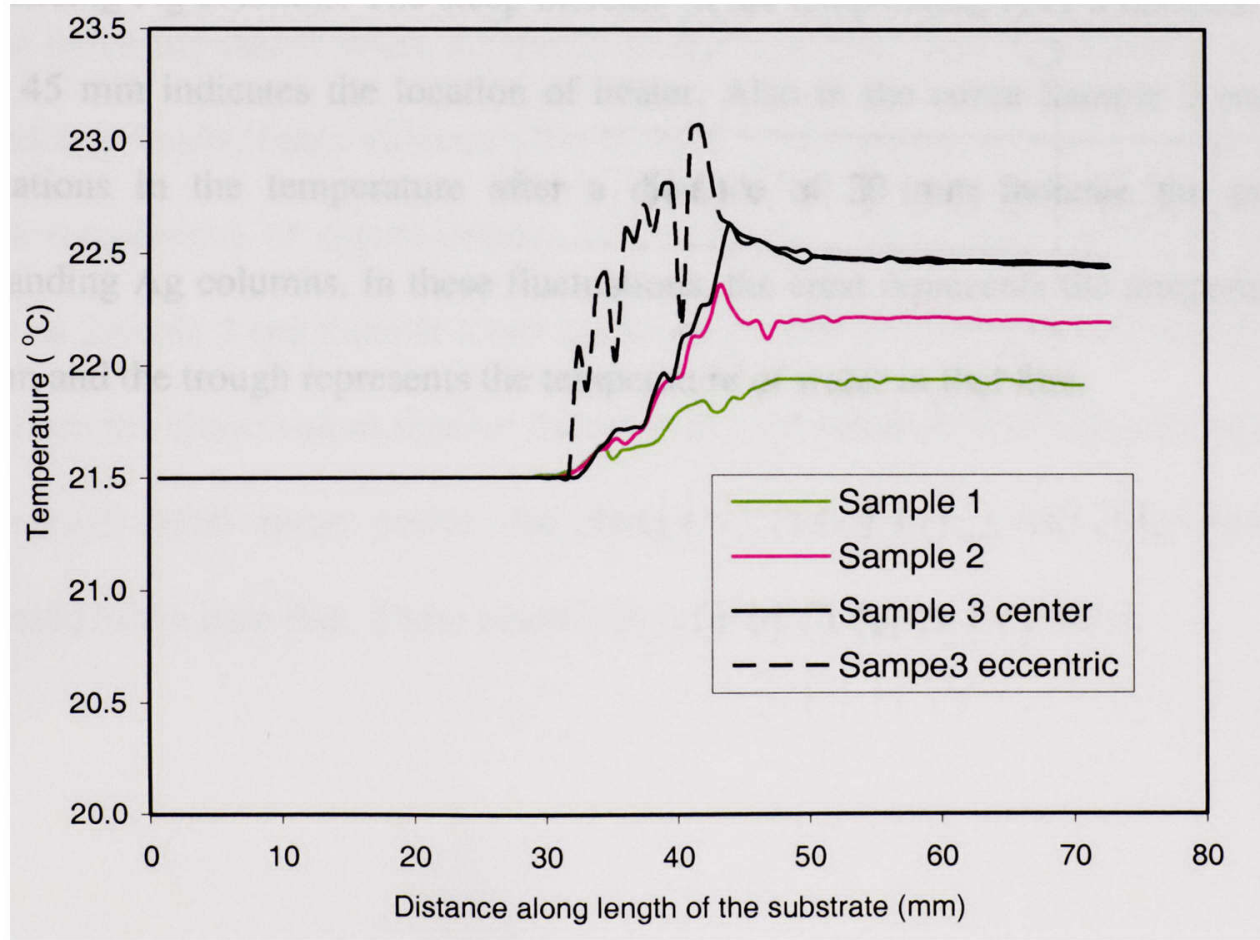

Figure 5-27 Temperature of water down-stream for Samples 1, 2 and 3 at $1230 \mathrm{ml} / \mathrm{min}$ flow rate and $50 \mathrm{~W}$ power input along the center and at a distance of $0.6 \mathrm{~mm}$ away from the center line of the duct. 
Figures 5-24 to 5-26 show the isotherms of the three samples at a flow rate of $1230 \mathrm{ml} / \mathrm{min}$ and a power input of $50 \mathrm{~W}$. From the above three figures, it was found that the temperature of the hot spot of the substrate i.e., at the interface surface of the $\mathrm{Cu}$ shim and LTCC substrate, is approximately $190{ }^{\circ} \mathrm{C}$ for Sample $1,38.7{ }^{\circ} \mathrm{C}$ for Sample 2 and $33.6{ }^{\circ} \mathrm{C}$ for Sample 3. The Figure 5-27 shows the temperature of water along the length of the substrate $(70 \mathrm{~mm})$ for a volume flow rate of $1230 \mathrm{ml} / \mathrm{min}$ and $50 \mathrm{~W}$ power input. As explained in the previous sections of this chapter, the above figure shows the temperature of water at approximately center of the duct along the length of the duct. In the above figure, Sample 3 eccentric represents the temperature at a distance of $0.6 \mathrm{~mm}$ away from the center of the duct and along the length of the duct. This line passes through the freestanding Ag columns. The steep increase in the temperature after a distance of $30 \mathrm{~mm}$ up to $45 \mathrm{~mm}$ indicates the location of heater. Also in the curve Sample 3 eccentric the fluctuations in the temperature after a distance of $30 \mathrm{~mm}$ indicate the presence of freestanding $\mathrm{Ag}$ columns. In these fluctuations, the crest represents the temperature of $\mathrm{Ag}$ column and the trough represents the temperature of water in that line. 


\section{Results and Conclusions}

\subsection{Experimental}

As mentioned in the previous chapters, three LTCC substrates were fabricated with internal cooing channel for enhanced thermal management. These substrates are then tested for their thermal performance. Sample 1, the substrate with only LTCC, is considered the baseline and the other two samples are compared with the former one.

The results show that the rise in temperature of the substrate in about $55^{\circ} \mathrm{C}$ for Sample $1,32^{\circ} \mathrm{C}$ for Sample 2 and $10^{\circ} \mathrm{C}$ for Sample 3 at approximately $10 \mathrm{~W}$ power input. For Sample 2 to rise temperature of this substrate to approximately $55^{\circ} \mathrm{C}$ (rise in Sample 1 for $10 \mathrm{~W}$ ) the input power should be more than $20 \mathrm{~W}$, which shows that Sample 2 alone can handle twice the power when compared to the base line. The experimental results show that adding fins/columns enhances the thermal performance beyond expectations. For a rise in temperature of approximately $24^{\circ} \mathrm{C}$, Sample 3 can handle power of up to $30 \mathrm{~W}$, where as Sample 2 and Sample 1 can handle only $10 \mathrm{~W}$ and $5 \mathrm{~W}$ of power respectively. It is clear from the above values that for the same rise in temperature of the substrate, Sample 2 can handle $100 \%$ more power and Sample 3 can handle $500 \%$ more power when compared to the base line. These results are justified in Figure 6-1 below. 


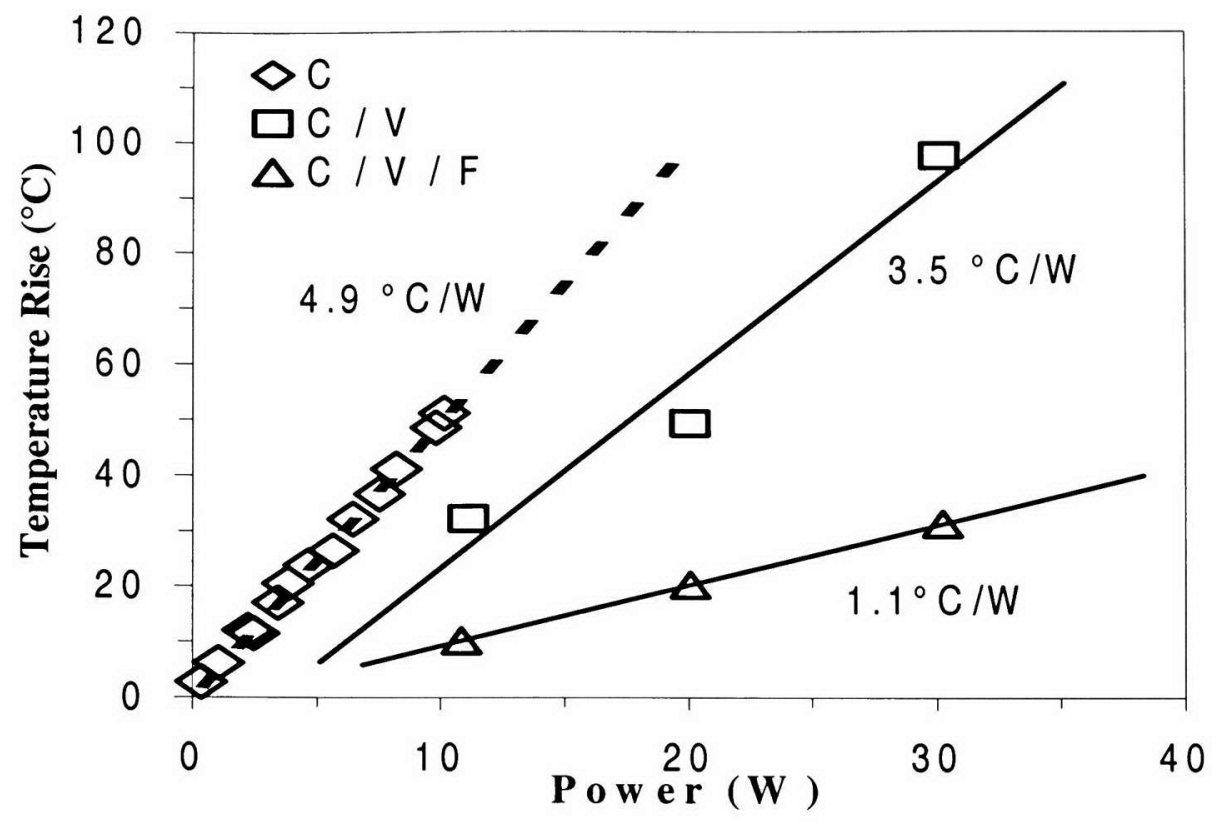

Figure 6-1 Substrate rise in temperature and effective overall thermal resistance of the system for all test configurations: $\mathrm{C}$ - channel; $\mathrm{V}$ - thermal vias; $\mathrm{F}$ - pin fins.

Also in heat transfer terms, the performance of the system is best determined by its thermal resistance. The above figure also gives an approximation of thermal resistance of the entire system at a flow rate of $300 \mathrm{ml} / \mathrm{min}$. The approximate overall effective thermal resistance for Sample 1 is $4.9^{\circ} \mathrm{C} / \mathrm{W}$, for Sample 2 is $3.5^{\circ} \mathrm{C} / \mathrm{W}$ and for Sample 3 is $1.1^{\circ} \mathrm{C} / \mathrm{W}$. This indicates a $28 \%$ reduction and a $78 \%$ reduction of overall thermal resistance when compared to the base line. 


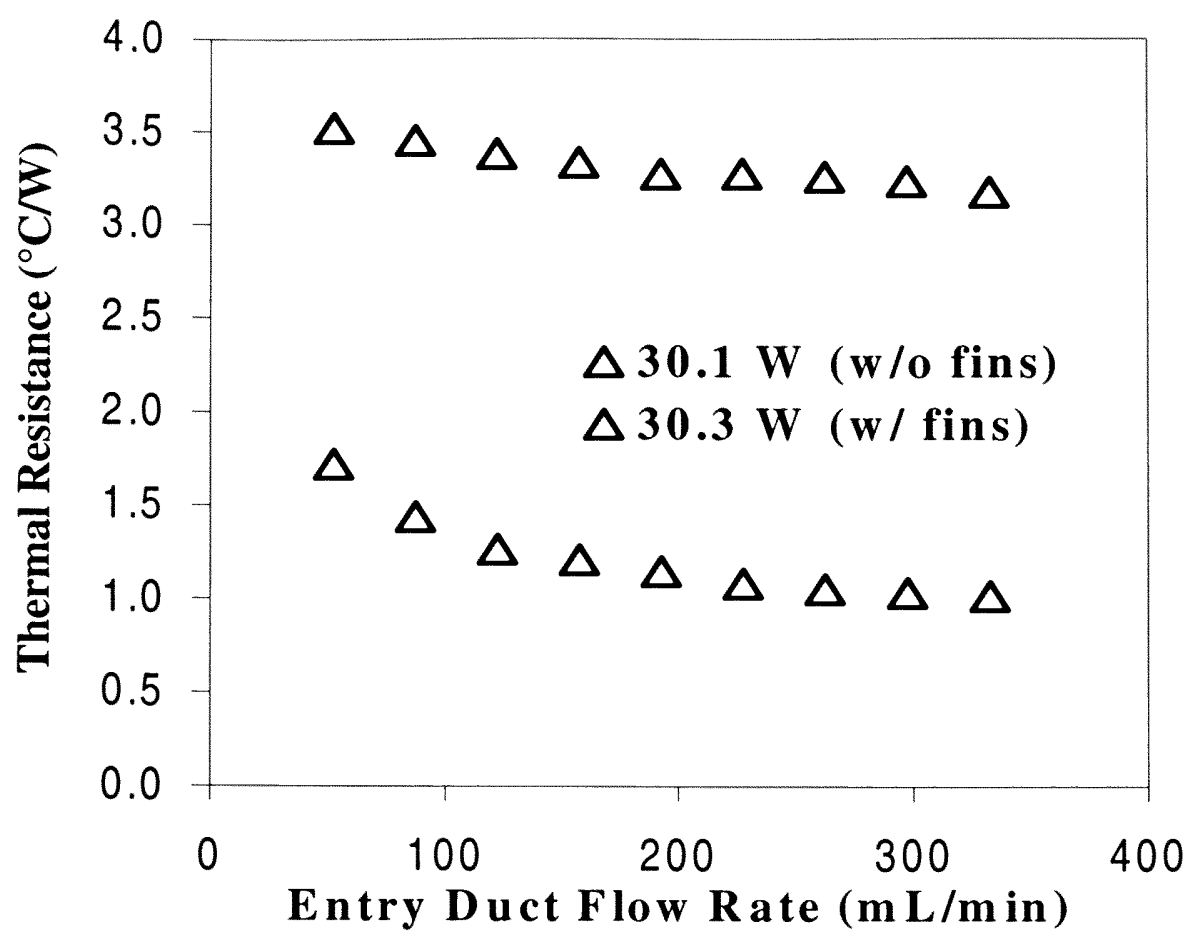

Figure 6-2 Effect of variation in flow rate and addition of pin fins in the duct on the system's thermal resistance.

The Figure 6-2 shows the trend of overall thermal resistance of the system with change in flow rate at $30 \mathrm{~W}$ power input for Sample 2 and 3. It is expected that flow rate should have some effect on the performance of the system, as it is the primary factor affecting convection heat transfer. It is clear from the figure that with increase in flow rate, there is a slight decrease in the system thermal resistance. The two curves in the above figure show that the effect of flow rate is roughly the same for both configurations.

\subsection{Analytical results}

One-dimensional analytical analyses for the three specifications were found using the basic laws of heat transfer. From this analysis, it was found that the overall thermal resistance of the system for Sample 1 is $4.25{ }^{\circ} \mathrm{C} / \mathrm{W}$ without considering the resistance of Copper shim and thermal epoxy; $4.62{ }^{\circ} \mathrm{C} / \mathrm{W}$ when it was considered. Similarly, the overall 
thermal resistance for Sample 2 is approximately $0.36{ }^{\circ} \mathrm{C} / \mathrm{W}$ without considering the copper shim resistance and $0.73{ }^{\circ} \mathrm{C} / \mathrm{W}$ when it is considered. It was also found that the resistance of the system is independent of flow rate and power input in Samples 1 and 2. And the overall thermal resistance for Sample 3 is approximately $0.12{ }^{\circ} \mathrm{C} / \mathrm{W}$ and $0.49{ }^{\circ} \mathrm{C} / \mathrm{W}$ at a flow rate of $293 \mathrm{ml} / \mathrm{min}$ the former without considering and the later considering the thermal resistance of copper shim and thermal epoxy and it is approximately $0.11^{\circ} \mathrm{C} / \mathrm{W}$ and $0.48^{\circ} \mathrm{C} / \mathrm{W}$ at a flow rate of $1230 \mathrm{ml} / \mathrm{min}$ the former without considering and the later considering the thermal resistance of copper shim and thermal epoxy.

\subsection{Computational analyses results}

Even for computational analysis, three samples were modeled and analyzed, to predict the behavior of these samples. The samples were tested for two different flow regimes and also tested at different power levels from $10 \mathrm{~W}$ to $50 \mathrm{~W}$ (constant power heat source) and $80^{\circ} \mathrm{C}$ of constant wall temperature.

From the results, it is determined that the overall thermal resistance for Sample 1 is in the range of 3.251 to $3.467^{\circ} \mathrm{C} / \mathrm{W}$ with an average value of $3.364^{\circ} \mathrm{C} / \mathrm{W}$. Similarly, the overall thermal resistance for Sample 2 and Sample 3 are in the range of 0.309 to $0.526^{\circ} \mathrm{C} / \mathrm{W}$ and 0.162 to $0.227^{\circ} \mathrm{C} / \mathrm{W}$ respectively with an average value of 0.418 and $0.195^{\circ} \mathrm{C} / \mathrm{W}$ in the same order. 


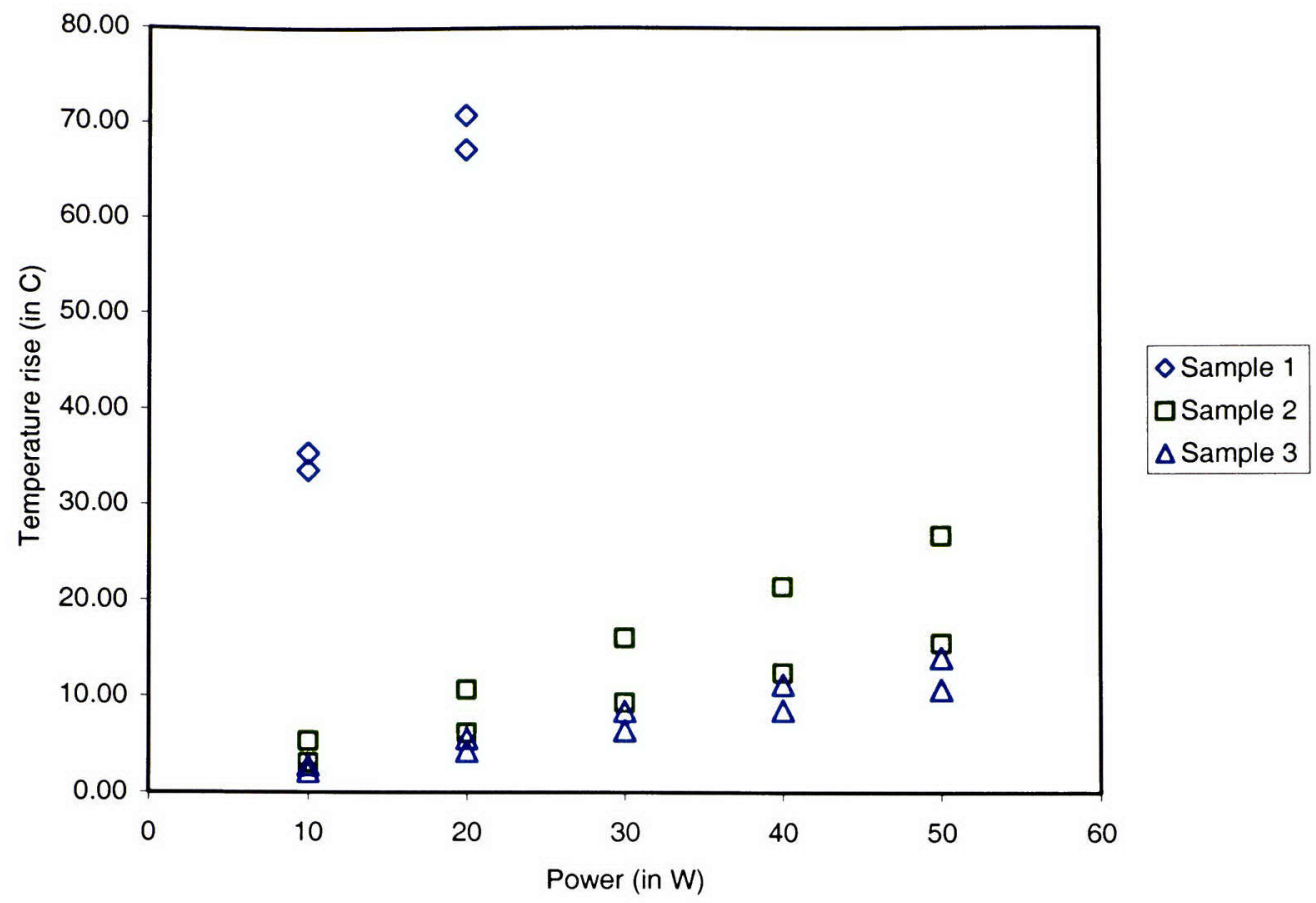

Figure 6-3 Substrate rise in temperature and effective overall thermal resistance of the system for all test configurations: $\mathrm{C}$ - channel; $\mathrm{V}$ - thermal vias; $\mathrm{F}$ - pin fins.

As discussed earlier in this chapter, it is expected that flow rate should have some effect on the performance of the system, as it is the primary factor affecting the convection heat transfer. The Figure 6-4 below shows that increase in flow rate decreases the system thermal resistance. 


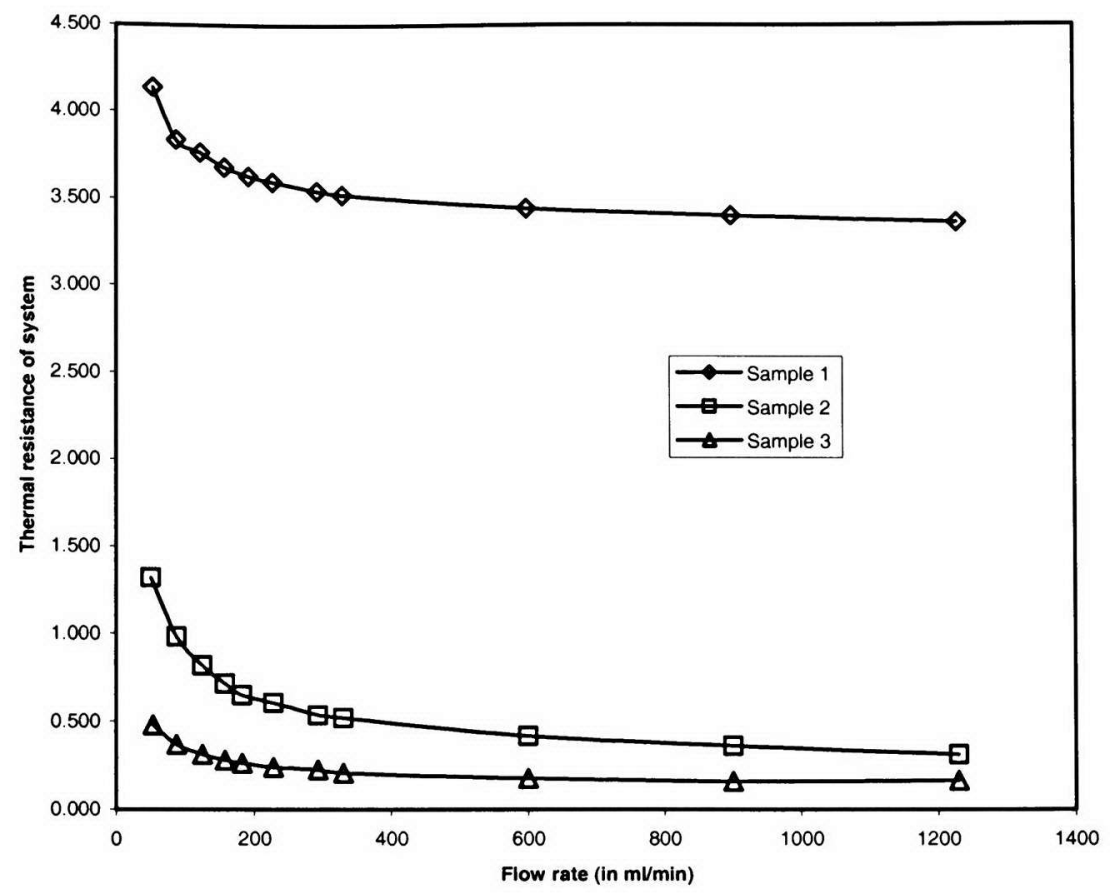

Figure 6-4 Effect of variation in flow rate on system's overall thermal resistance.

Unlike the experimental and analytical analysis, the resistance due to convection can be easily determined in computational analysis using resistance laws of heat transfer. The convective resistance for Sample 2 and 3 are plotted in the Figure 6-5 below with varying flow rates and at $30 \mathrm{~W}$ power input. 


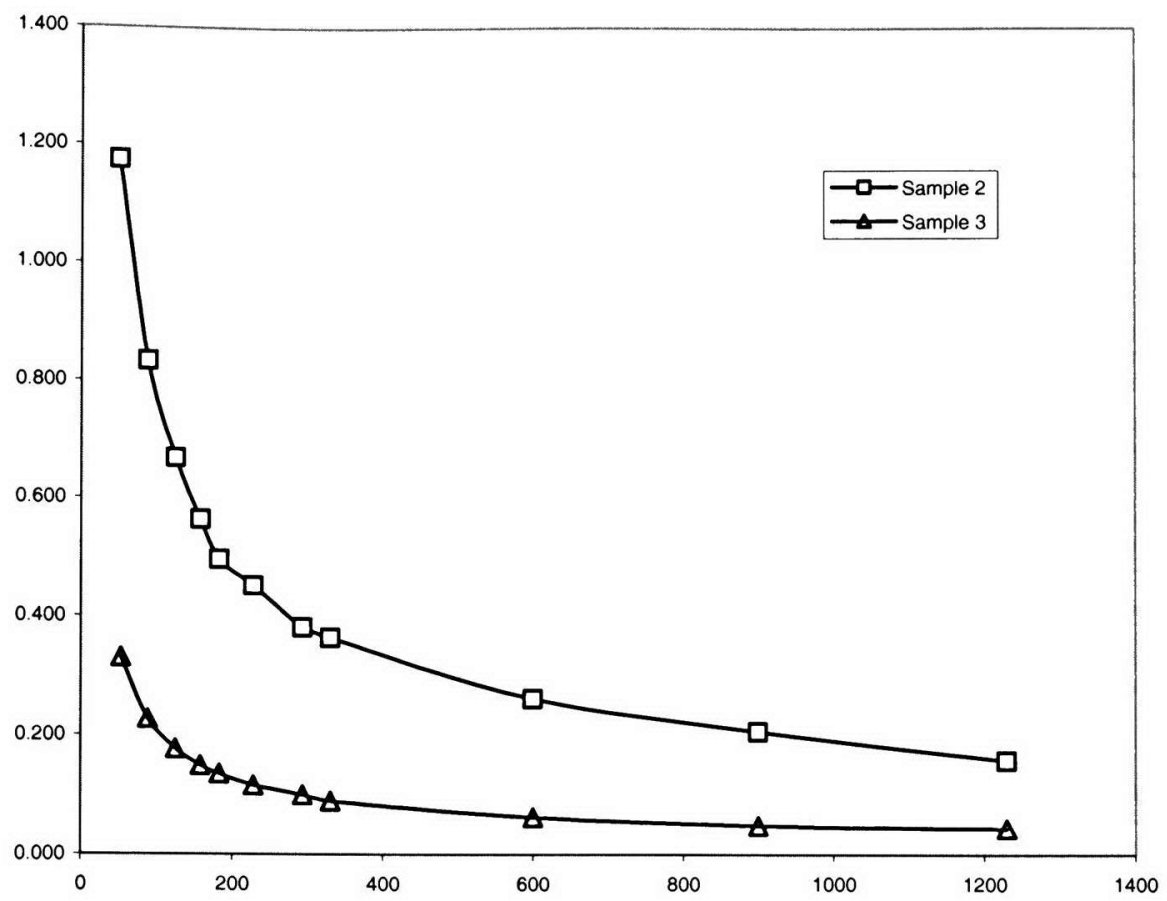

Figure 6-5 Effect of variation in flow rate on convective thermal resistance.

The results show that the convective resistance for Sample 1 and 2 is $0.375^{\circ} \mathrm{C} / \mathrm{W}$ $\mathrm{cm}^{2}$ (assuming similar cross-section of duct for both samples 1 and 2) and for Sample 3 it is $0.101^{\circ} \mathrm{C} / \mathrm{W}-\mathrm{cm}^{2}$ at a flow rate of $293 \mathrm{l} / \mathrm{min}$ and $0.157^{\circ} \mathrm{C} / \mathrm{W}-\mathrm{cm}^{2}$ for Sample 1 and 2 and $0.046^{\circ} \mathrm{C} / \mathrm{W}-\mathrm{cm}^{2}$ for Sample 3 at a flow rate of $1230 \mathrm{ml} / \mathrm{min}$. This shows a reduction of approximately $70 \%$ in the convective resistance due to the addition of the fins/columns in the duct area.

\subsection{Comparison and Conclusions}

The Table 6-1 below shows the effective overall thermal resistance of the three configurations. 


\begin{tabular}{|c|c|c|c|c|}
\hline \multirow{2}{*}{$\begin{array}{l}\text { At a flow rate } \\
\text { of } 293 \mathrm{ml} / \mathrm{min} \\
\text { and } 50 \mathrm{~W} \\
\text { power input }\end{array}$} & \multirow[t]{2}{*}{ Experimental } & \multicolumn{2}{|c|}{ Analytical } & \multirow[t]{2}{*}{ Computational } \\
\hline & & $\begin{array}{l}\text { Considering } \\
\text { resistance } \\
\text { due to } \\
\text { copper } \\
\text { shim and } \\
\text { epoxy }\end{array}$ & $\begin{array}{l}\text { Without } \\
\text { Considering } \\
\text { resistance } \\
\text { due to } \\
\text { copper } \\
\text { shim and } \\
\text { epoxy }\end{array}$ & \\
\hline Sample 1 & 4.9 & 4.25 & 4.62 & 3.364 \\
\hline Sample 2 & 3.5 & 0.36 & 0.73 & 0.418 \\
\hline Sample 3 & 1.1 & 0.11 & 0.49 & 0.195 \\
\hline
\end{tabular}

Table 6-1 Effective overall thermal resistance (in ${ }^{\circ} \mathrm{C} / \mathrm{W}-\mathrm{cm}^{2}$ ) using different techniques

From the above results it can be concluded that addition of thermal vias alone increases the thermal performance of the substrate. Further more, the addition of fins/columns increases its performance even more by drastically reducing the resistance of the system. The results from one dimensional analytical analysis and computational analysis agree with each other with minor errors, which might be due to the assumption of the system as one-dimensional. Even though the experimental results show that addition of columns, increases the performance of the system, the values doesn't match with that of computational results. In the later stages of the research, it was found that there was an anomaly in the fabrication as well as during the testing of the samples. The samples 2 and 3 had some leaks, which were unavoidable at that stage. Also while measuring the temperature on the surface of $\mathrm{Cu}$ shim, the bead of the thermo-couple generated some hot spots and apparently that temperature was measured, which further increased the thermal resistance of the system. Further more, when Sample 3 was cut to analyze the crosssection of the heat exchanger, it was found that few of the fins weren't in contact with the 
silver pad, which accounted for further increase in thermal resistance of that system. Taking into account these experimental errors, it can be justified that the results are in good agreement to each other.

\subsection{Future research}

Further research could be done in this field, which includes optimization of this system. In the present work, only an in-line array is presented. The study of fluid flow and heat transfer suggest that the more the turbulence in the flow, the more the heat transfer would be. This suggests that a staggered array pattern in the duct region would enhance the heat transfer rate.

The parameters, which could be considered for optimizing, are:

Inline/Staggered array.

Diameter of fin/themal vias.

Pitch of the fins.

Duct height.

Number of fins. 


\section{References}

[1] Barnwell P, Zhang W, Lebowitz J, Jones K, MacDonald N, Free C, Tian Z (2000), "An Investigation of the properties of LTCC Materials and Compatible Conductors for their use in Wireless Applications", Proc. International Symposium on Microelectronics, IMAPS, Boston, MA, USA, pp. 659-664.

[2] Wakino K, Nishikawa T, Tamura $\mathrm{H}$ and Sudo T (1987), "Dielectric Resonator Materials and their applications", Microwave Journal, 30(6) pp:133-159.

[3] Amey D I, Keating M Y, Smith M A, Horowitz S J, Donahue P C and Needes C R (2000), "Low Loss Tape Materials System for 10 to $40 \mathrm{GHz}$ Application" Proc. International Symposium on Microelectronics, IMAPS, Boston, MA, USA, pp: 654-658.

[4] Miyake H, Kitazawa S, Ishizaki T, Ogawa K, Awai I (1999), "A study of a Laminated Band Elimination Filter Comprising Coupled-Line Resonators Using Low Temperature Co-fired Ceramic", IEICE Transactions on Electronics, E82C(7): 1104-1109.

[5] Sheen J-W (1999), "LTCC_MLC Deplexer for DCS -1800", IEEE Transactions on Microwave Theory and Techniques, 47(9) pp: 1883-1890.

[6] Liang H, Sutono A, Lasker J and Smith W R (1999), "Material Parameter Characterization of Multilayer LTCC and Implementation of High Q Resonators", Proc. IEEE MMT-S International Microwave Symposium Digest, Anaheim, CA, USA, 4 pp: 1901-1904.

[7] Shutler W, Longworth H, Pennacchia J, Perfecto E and Shields R (1997), "A Family of High Performance MCM-C/D Packages Utilizing Cofired Alumina Multilayer Ceramic and a Shielded Thin Film Redistribution Structure", International Journal of Microcircuits and Electronic Packaging, 20(3) pp: 289296

[8] Embedded heat pipes in cofired ceramic substrates for enhanced thermal management of electronics - Dissertation for degree of Doctors of Philosophy by, Marc Anthony Zampino, Florida International University 2001.

[9] Huang C-Y and Lin M-H(2000), "Ceramic GPS Antenna for Remote Sensing", International Geoscience and Remote Sensing Symposium, IEEE, Piscataway, NJ, USA, 5 pp:2182-2184.

[10] Tummala R R (1991), "Ceramic and Glass-Ceramic Packaging in the 1990's", Journal of American Ceramic Society, 74(5) pp: 895-908. 
[11] Marc A. Zampino, Hari Adluru, Yanging Liu, W. Kinzy Jones, 2003, "LTCC substrates with internal cooling channel and Heat exchangers," Proceedings of 2003 of the $36^{\text {th }}$ International Symposium on Microelectronics, IMAPS, Boston, USA, pp: 505-510.

[12] Scrantom CQ and Gravier G J (1999), "LTCC Technology: Where we are and where we're going -IV" Proc. IEEE MTT-S International Topical Symposium on Technologies for Wireless Applications Digest, Vancouver, Bc., Canada, pp 193200

[13] Bailey A, Foley W, Hageman M, Murrey C, Piloto A, Sparks K and Zaki K (1997), "Miniature LTCC Filters for Digital Receivers", Proc. IEEE MTT-S International Microwave Symposium Digest, Denver, CO, USA, 2 pp:999-1002

[14] Jones W K, Liu Y, Larsen B, Wang P and Zampino M (2000), "Chemical, Structural and Mechanical Properties of the LTCC Tapes" Proc. International Symposium on Microelectronics, IMAPS, Boston, MA, USA, pp:669-704.

[15]R. Kandukari, M. Zampino, W.K. Jones, "High Performance Thermal Vias in LTCC substrates", Proc. 2002 Itherm, IEEE, San Diego, CA, pp. 179-185, 2002.

[16] http://microwave.ee.cuhk.edu.hk/microwave/www mwave/Research LTCC.html

[17] Kagata H, Inoue T, Kota J and Kameyama I (1992), "Low-fired Bismuth-based Dielectric Ceramics for Microwave Use", Japanese Journal of Applied Physics, part 1, 31(9B) pp:3152-3155.

[18] Computational Fluid Dynamics; The Basics with Applications by John D Anderson, Jr. McGraw-Hill Inc.

[19] Thermal Conductivity of High Density Thermal Vias in Low Temperature Cofired Ceramics (LTCC) - Master's Thesis by Ravindra Kandukuri, Florida International University 2002.

[20] CFDesign Technical Reference Manual by Blue Ridge Numerics Inc.

[21]D.Wilcox, R.F. Huang, D. Anderson, "The multiplayer Ceramic Integrated Circuit (MCIC) Technology: Opportunities and Challenges", Proc. $30^{\text {th }}$ International Symposium on Microelectronics, IMAPS, pgs. 17-23,1997.

[22] M. Zampino, W.K. Jones and Y. Cao, "Substrate embedded heat pipes compatible with ceramic co-fire processing," International of Microcircuits \& Electronic Packaging, Vol. 21, No.1, pp52-58, 1998. 
[23] Wang Y., Zhang G., Ma J., "Research of LTCC/Cu, Ag Multilayer Substrate in Microelectronics Packaging", Materials Science and Engineering B94, 2002, pp48-53

[24]P. Wang, W.K. Jones and Y. Liu, " Thick Silver tape in Low Temperature Cofire Ceramic (LTCC) for Thermal Management", Proc. 2001 International Microelectronics Conference, IMAPS, Baltimore, MD, 2001.

[25] A. Shakouri, D. Vashaee, J. Christofferson, X. Fan and C. Labounty, "Thin film solid state refrigerators for spot cooling of integrated circuits", Thermal Challenges in Next Generation Electronic Systems (THERMES 2002), Edited by Y.K. Joshi and S.V. Garimella, pp: 75-76, Jan 2002.

[26] O.G. Symko, E. Abdel-Rahman, Y.S. Kwon, M. Emmi, R. Behunin, "Design and development of high-frequency thermo-acoustic engines for thermal management in microelectronics", Microelectronics Journal 35 (2004), pp: 185-191.

[27] “ A mini-maze of Methanol pipes," part of the Defense Advanced Research Projects Agency's Heat Removal by Thermal Integrated Circuits project--a joint effort between Sandia and the Georgia Institute of Technology.

[28] Gao P., Le Person S., Favre-Marinet M., 2002, "Scale effects on hydrodynamics and heat transfer in two-dimensional mini and microchannels," International Journal of Thermal Sciences, V 41\#11, 1017-1027.

[29] M.L. Berre; S. Launay; V. Sartre; M. Lallemand, 2003, "Fabrication and experimental investigation of Silicon micro-heat pipes for cooling electronics," Journal of Micro-mechanics and Micro-engineering, V 13\#3, pp: 436-441

[30] Takuto Araki; Min Soo Kim; Hiroshi Iwai; Kenjiro Suzuki, 2001, "An experimental investigation of gaseous flow characteristics in Micro-channels," Microscale Thermophysical Engineering, V 6\#2, pp: 117-130

[31] C.B. Sobhan; Huang Xiaoyang; Liu Chang Yu, "Investigations on transient and steady-state performance of a micro-heat pipe," Journal of Thermophysics and Heat Transfer, V 14\#2, pp: 161-169

[32] C.P. Kothandaraman; S. Subramanyam, "Heat and Mass transfer Data Book," Fourth edition, pp: $13,97,111-114,122$

[33] CFDesign Technical Reference manual by Blue Ridge Numerics, Inc.,

[34] White, F.M., Viscous Fluid Flow, McGraw-Hill, New York, 1974 
[35] Schnike, R.J., "A Streamline Upwind Finite Element Method for Laminar and Turbulent Flow”, Ph.D. Dissertation, University of Virginia, May 1986.

[36] Weilin Qu, Issam Mudawar, "Analysis of three-dimensional heat transfer in micro-channel heat sinks", International Journal of Heat and Mass transfer 45 (2002), pp 3973-3985.

[37] Shung-Wen Kang, Sheng-Hong Tsai, Ming-Han Ko, "Metallic micro heat pipe heat spreader fabrication", Applied Thermal Engineering 24 (2004), pp 299-309.

[38] S. Belhardj, S. Mimouni, A. Saidane, M. Benzohra, "Using micro-channels to cool microprocessors: a transmission-line-matrix study", Microelectronics Journal 34 (2003), pp. 247-253.

[39]E. W. Kreutz, N. Pirch, T. Ebert, R. Wester, B. Ollier, P. Loosen, R. Poprawe, "Simulation of micro-channel heat sinks for optoelectronic Microsystems", Microelectronics Journal 31 (2000), pp 787-790.

[40] Seok Pil Jang, Sung Jin Kim, Kyung Wook Paik, "Experimental investigation of thermal characteristics for a micro-channel heat sink subject to an impinging jet, using a micro-thermal sensor array”, Sensors and Actuators A 105 (2003), pp 211-224. 


\section{Appendix 1 Tables from experimental tests}

\begin{tabular}{|c|c|c|c|c|c|c|c|c|c|c|c|c|c|c|}
\hline Sample & $\begin{array}{l}\text { Flow rate } \\
\mathrm{mL} / \mathrm{min}\end{array}$ & Voltage V & $\begin{array}{c}\text { Current } \\
\text { Amp }\end{array}$ & $\begin{array}{c}\mathrm{T}_{\text {inlet }} \\
{ }^{\circ} \mathrm{C} \\
\end{array}$ & $\begin{array}{c}T_{\text {outlet }} \\
{ }^{\circ} \mathrm{C} \\
\end{array}$ & $\begin{array}{c}\mathrm{T}_{\text {Itce }} \\
{ }^{\circ} \mathrm{C} \\
\end{array}$ & $\begin{array}{c}\text { Power } \\
\text { input W }\end{array}$ & $\begin{array}{l}\mathrm{dT} \text { coolant } \\
{ }^{\circ} \mathrm{C} \\
\end{array}$ & $\begin{array}{c}\mathrm{dm} / \mathrm{dt} \\
\mathrm{kg} / \mathrm{s}\end{array}$ & $\mathbf{Q}_{\text {gain }} \mathbf{W}$ & $V \mathrm{~m} / \mathrm{s}$ & $\begin{array}{l}\text { Reynolds } \\
\text { Number }\end{array}$ & dT sub ${ }^{\circ} \mathrm{C}$ & $\begin{array}{c}\mathbf{R}_{\text {th }} \\
{ }^{\circ} \mathrm{C} / \mathrm{W} \\
\end{array}$ \\
\hline \multirow{7}{*}{$\begin{array}{l}\text { No vias } \\
\text { No } \\
\text { Columns } \\
\text { Constant } \\
\text { flowrate }\end{array}$} & 294 & 2.026 & 0.17 & 21.6 & 21.7 & 24.4 & 0.34 & 0.1 & 0.004895 & 2.05 & 0.3403 & 993.46 & 2.8 & 8.13 \\
\hline & 294 & 3.38 & 0.3 & 21.6 & 21.7 & 27.8 & 1.01 & 0.1 & 0.004895 & 2.05 & 0.3403 & 993.46 & 6.2 & 6.11 \\
\hline & 294 & 5.01 & 0.44 & 21.6 & 21.8 & 33.7 & 2.20 & 0.2 & 0.004895 & 4.09 & 0.3403 & 993.46 & 12.1 & 5.49 \\
\hline & 294 & 6.58 & 0.58 & 21.6 & 21.9 & 42.1 & 3.82 & 0.3 & 0.004895 & 6.14 & 0.3403 & 993.46 & 20.5 & 5.37 \\
\hline & 294 & 8.53 & 0.66 & 21.6 & 21.9 & 48.1 & 5.63 & 0.3 & 0.004895 & 6.14 & 0.3403 & 993.46 & 26.5 & 4.71 \\
\hline & 294 & 9.66 & 0.78 & 21.6 & 22.1 & 58.2 & 7.53 & 0.5 & 0.004895 & 10.23 & 0.3403 & 993.46 & 36.6 & 4.86 \\
\hline & 294 & 10.92 & 0.9 & 21.7 & 22.1 & 70.3 & 9.83 & 0.4 & 0.004895 & 8.18 & 0.3403 & 993.46 & 48.6 & 4.95 \\
\hline \multirow{6}{*}{\begin{tabular}{l}
\multicolumn{1}{c}{1} \\
No vias \\
No \\
Columns \\
Constant \\
flowrate
\end{tabular}} & 158 & 6.09 & 0.4 & 21.9 & 22.1 & 33.4 & 2.44 & 0.2 & 0.002631 & 2.1982 & 0.1829 & 533.90 & 11.5 & 4.72 \\
\hline & 158 & 6.9 & 0.5 & 21.9 & 22.3 & 39.1 & 3.45 & 0.4 & 0.002631 & 4.3964 & 0.1829 & 533.90 & 17.2 & 4.99 \\
\hline & 158 & 7.81 & 0.6 & 21.9 & 22.4 & 45.8 & 4.69 & 0.5 & 0.002631 & 5.4955 & 0.1829 & 533.90 & 23.9 & 5.10 \\
\hline & 158 & 9.24 & 0.7 & 21.9 & 22.6 & 54.1 & 6.47 & 0.7 & 0.002631 & 7.6937 & 0.1829 & 533.90 & 32.2 & 4.98 \\
\hline & 158 & 10.29 & 0.8 & 21.9 & 22.8 & 63.1 & 8.23 & 0.9 & 0.002631 & 9.892 & 0.1829 & 533.90 & 41.2 & 5.00 \\
\hline & 158 & 11.28 & 0.9 & 21.9 & 23 & 73 & 10.15 & 1.1 & 0.002631 & 12.09 & 0.1829 & 533.90 & 51.1 & 5.03 \\
\hline \multirow{7}{*}{\begin{tabular}{l}
\multicolumn{1}{c}{2} \\
Vias only \\
No \\
Columns \\
Constant \\
flowrate
\end{tabular}} & 294 & 5.21 & 0.18 & 21.4 & 21.45 & 25.2 & 0.94 & 0.05 & 0.004895 & 1.0226 & 0.3403 & 993.46 & 3.8 & 4.05 \\
\hline & 294 & 8.14 & 0.28 & 21.4 & 21.5 & 28.6 & 2.28 & 0.1 & 0.004895 & 2.0452 & 0.3403 & 993.46 & 7.2 & 3.16 \\
\hline & 294 & 10.89 & 0.37 & 21.4 & 21.6 & 32.9 & 4.03 & 0.2 & 0.004895 & 4.0903 & 0.3403 & 993.46 & 11.5 & 2.85 \\
\hline & 294 & 14.31 & 0.49 & 21.4 & 21.7 & 40.5 & 7.01 & 0.3 & 0.004895 & 6.1355 & 0.3403 & 993.46 & 19.1 & 2.72 \\
\hline & 294 & 17.1 & 0.59 & 21.4 & 21.7 & 47.3 & 10.09 & 0.3 & 0.004895 & 6.1355 & 0.3403 & 993.46 & 25.9 & 2.57 \\
\hline & 294 & 20.28 & 0.7 & 21.4 & 21.9 & 57.5 & 14.20 & 0.5 & 0.004895 & 10.226 & 0.3403 & 993.46 & 36.1 & 2.54 \\
\hline & 294 & 23.52 & 0.81 & 21.4 & 22.1 & 68.5 & 19.05 & 0.7 & 0.004895 & 14.316 & 0.3403 & 993.46 & 47.1 & 2.47 \\
\hline
\end{tabular}




\begin{tabular}{|c|c|c|c|c|c|c|c|c|c|c|c|c|c|c|}
\hline Sample & $\begin{array}{c}\text { Flow rate } \\
\mathrm{mL} / \mathrm{min}\end{array}$ & Voltage V & $\begin{array}{c}\text { Current } \\
\text { Amp }\end{array}$ & $\begin{array}{c}T_{\text {inlet }} \\
{ }^{\circ} \mathrm{C} \\
\end{array}$ & $\begin{array}{c}\mathrm{T}_{\text {outlet }} \\
{ }^{\circ} \mathrm{C}\end{array}$ & $\begin{array}{l}\mathrm{T}_{\text {Hec }} \\
{ }^{\circ} \mathrm{C} \\
\end{array}$ & $\begin{array}{c}\text { Power } \\
\text { input W }\end{array}$ & $\begin{array}{c}\mathrm{dT} \\
\text { coolant } \\
{ }^{\circ} \mathrm{C}\end{array}$ & $\begin{array}{c}\mathrm{dm} / \mathrm{dt} \\
\mathrm{kg} / \mathrm{s}\end{array}$ & $\mathbf{Q}_{\text {gain }} \mathbf{W}$ & $\mathrm{V} \mathrm{m} / \mathrm{s}$ & $\begin{array}{c}\text { Reynolds } \\
\text { Number }\end{array}$ & dT sub ${ }^{\circ} \mathrm{C}$ & $\begin{array}{c}R_{\text {th }} \\
{ }^{\circ} \mathrm{C} / \mathrm{W}\end{array}$ \\
\hline & 294 & 26.38 & 0.91 & 21.4 & 22.3 & 76 & 24.01 & 0.9 & 0.004895 & 18.407 & 0.3403 & 993.46 & 54.6 & 2.27 \\
\hline & 294 & 29.42 & 1.01 & 21.4 & 22.4 & 83.9 & 29.71 & 1 & 0.004895 & 20.452 & 0.3403 & 993.46 & 62.5 & 2.10 \\
\hline \multirow{7}{*}{$\begin{array}{l}\text { Vias only } \\
\text { No } \\
\text { Columns } \\
\text { Constant } \\
\text { flowrate }\end{array}$} & 158 & 11.64 & 0.4 & 21.4 & 21.8 & 35.4 & 4.66 & 0.4 & 0.002631 & 4.40 & 0.1829 & 533.90 & 14 & 3.01 \\
\hline & 158 & 14.54 & 0.5 & 21.5 & 22.15 & 42.5 & 7.27 & 0.65 & 0.002631 & 7.14 & 0.1829 & 533.90 & 21 & 2.89 \\
\hline & 158 & 17.28 & 0.6 & 21.5 & 22.5 & 50.5 & 10.37 & 1 & 0.002631 & 10.99 & 0.1829 & 533.90 & 29 & 2.80 \\
\hline & 158 & 20.44 & 0.7 & 21.6 & 22.85 & 63.5 & 14.31 & 1.25 & 0.002631 & 13.74 & 0.1829 & 533.90 & 41.9 & 2.93 \\
\hline & 158 & 23.17 & 0.8 & 21.6 & 23 & 72.9 & 18.54 & 1.4 & 0.002631 & 15.39 & 0.1829 & 533.90 & 51.3 & 2.77 \\
\hline & 158 & 26.14 & 0.9 & 21.6 & 23.7 & 79.3 & 23.53 & 2.1 & 0.002631 & 23.08 & 0.1829 & 533.90 & 57.7 & 2.45 \\
\hline & 158 & 29.46 & 1.01 & 21.6 & 24.5 & 87.1 & 29.75 & 2.9 & 0.002631 & 31.87 & 0.1829 & 533.90 & 65.5 & 2.20 \\
\hline \multirow{7}{*}{$\begin{array}{l}\text { Vias only } \\
\text { No } \\
\text { Columns } \\
\text { Constant } \\
\text { flowrate }\end{array}$} & 88 & 11.64 & 0.4 & 21.6 & 22.35 & 37.1 & 4.66 & 0.75 & 0.001465 & 4.59 & 0.1019 & 297.36 & 15.5 & 3.33 \\
\hline & 88 & 14.5 & 0.5 & 21.7 & 22.8 & 44.6 & 7.25 & 1.1 & 0.001465 & 6.73 & 0.1019 & 297.36 & 22.9 & 3.16 \\
\hline & 88 & 17.23 & 0.59 & 21.7 & 23.4 & 52.7 & 10.17 & 1.7 & 0.001465 & 10.41 & 0.1019 & 297.36 & 31 & 3.05 \\
\hline & 88 & 20.37 & 0.7 & 21.7 & 24 & 63.9 & 14.26 & 2.3 & 0.001465 & 14.08 & 0.1019 & 297.36 & 42.2 & 2.96 \\
\hline & 88 & 23.29 & 0.8 & 21.7 & 24.6 & 72.4 & 18.63 & 2.9 & 0.001465 & 17.75 & 0.1019 & 297.36 & 50.7 & 2.72 \\
\hline & 88 & 26 & 0.89 & 21.7 & 25.6 & 77.3 & 23.14 & 3.9 & 0.001465 & 23.87 & 0.1019 & 297.36 & 55.6 & 2.40 \\
\hline & 88 & 29.2 & 1 & 21.7 & 26.9 & 83 & 29.20 & 5.2 & 0.001465 & 31.83 & 0.1019 & 297.36 & 61.3 & 2.10 \\
\hline & 294 & 5.14 & 0.17 & 21.4 & 21.6 & 34.6 & 0.87 & 0.2 & 0.004895 & 4.09 & 0.3403 & 993.46 & 13.2 & 15.11 \\
\hline & 294 & 8.25 & 0.28 & 21.4 & 21.7 & 35.1 & 2.31 & 0.3 & 0.004895 & 6.14 & 0.3403 & 993.46 & 13.7 & 5.93 \\
\hline 3 & 294 & 11.59 & 0.4 & 21.4 & 21.8 & 35.8 & 4.64 & 0.4 & 0.004895 & 8.18 & 0.3403 & 993.46 & 14.4 & 3.11 \\
\hline With vias & 294 & 14.43 & 0.5 & 21.4 & 21.9 & 43.3 & 7.22 & 0.5 & 0.004895 & 10.23 & 0.3403 & 993.46 & 21.9 & 3.04 \\
\hline
\end{tabular}




\begin{tabular}{|c|c|c|c|c|c|c|c|c|c|c|c|c|c|c|}
\hline Sample & $\begin{array}{c}\text { Flow rate } \\
\mathrm{mL} / \mathrm{min}\end{array}$ & Voltage V & $\begin{array}{c}\text { Current } \\
\text { Amp }\end{array}$ & $\begin{array}{c}\mathrm{T}_{\text {inlet }} \\
{ }^{\circ} \mathrm{C}\end{array}$ & $\begin{array}{c}\mathrm{T}_{\text {Outlet }} \\
{ }^{\mathrm{O}} \mathrm{C}\end{array}$ & $\begin{array}{l}\mathrm{T}_{\text {itce }} \\
{ }^{\circ} \mathrm{C}\end{array}$ & $\begin{array}{l}\text { Power } \\
\text { input W }\end{array}$ & 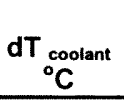 & $\begin{array}{c}\mathrm{dm} / \mathrm{dt} \\
\mathrm{kg} / \mathrm{s}\end{array}$ & $\mathbf{Q}_{\text {gain }} \mathbf{W}$ & $\mathrm{V} \mathrm{m} / \mathrm{s}$ & $\begin{array}{c}\text { Reynolds } \\
\text { Number } \\
\end{array}$ & dT ${ }_{\text {sub }}{ }^{\circ} \mathrm{C}$ & $\begin{array}{c}\mathbf{R}_{\mathrm{th}} \\
{ }^{\circ} \mathrm{C} / \mathrm{W}\end{array}$ \\
\hline \multirow{4}{*}{$\begin{array}{l}\text { With } \\
\text { columns } \\
\text { Constant } \\
\text { flowrate }\end{array}$} & 294 & 17.13 & 0.59 & 21.5 & 22.1 & 51.6 & 10.11 & 0.6 & 0.004895 & 12.27 & 0.3403 & 993.46 & 30.1 & 2.98 \\
\hline & 294 & 19.66 & 0.68 & 21.5 & 22.3 & 61.5 & 13.37 & 0.8 & 0.004895 & 16.36 & 0.3403 & 993.46 & 40 & 2.99 \\
\hline & 294 & 21.68 & 0.75 & 21.5 & 22.4 & 70 & 16.26 & 0.9 & 0.004895 & 18.41 & 0.3403 & 993.46 & 48.5 & 2.98 \\
\hline & 294 & 25.53 & 0.88 & 21.6 & 22.8 & 90.4 & 22.47 & 1.2 & 0.004895 & 24.54 & 0.3403 & 993.46 & 68.8 & 3.06 \\
\hline \multirow{8}{*}{$\begin{array}{l}\text { With vias } \\
\text { With } \\
\text { columns } \\
\text { Constant } \\
\text { flowrate }\end{array}$} & 158 & 5.11 & 0.17 & 21.7 & 21.9 & 24.8 & 0.87 & 0.2 & 0.002631 & 2.20 & 0.1829 & 533.90 & 3.1 & 3.57 \\
\hline & 158 & 8.18 & 0.28 & 21.7 & 22.1 & 28.8 & 2.29 & 0.4 & 0.002631 & 4.40 & 0.1829 & 533.90 & 7.1 & 3.10 \\
\hline & 158 & 11.6 & 0.4 & 21.8 & 22.4 & 36 & 4.64 & 0.6 & 0.002631 & 6.59 & 0.1829 & 533.90 & 14.2 & 3.06 \\
\hline & 158 & 14.25 & 0.49 & 21.8 & 22.6 & 43.3 & 6.98 & 0.8 & 0.002631 & 8.79 & 0.1829 & 533.90 & 21.5 & 3.08 \\
\hline & 158 & 17.74 & 0.61 & 21.7 & 22.9 & 54.6 & 10.82 & 1.2 & 0.002631 & 13.19 & 0.1829 & 533.90 & 32.9 & 3.04 \\
\hline & 158 & 20.32 & 0.7 & 21.7 & 23.2 & 65 & 14.22 & 1.5 & 0.002631 & 16.49 & 0.1829 & 533.90 & 43.3 & 3.04 \\
\hline & 158 & 23.34 & 0.8 & 21.7 & 23.7 & 77.4 & 18.67 & 2 & 0.002631 & 21.98 & 0.1829 & 533.90 & 55.7 & 2.98 \\
\hline & 158 & 27.34 & 0.94 & 21.6 & 24.3 & 91 & 25.70 & 2.7 & 0.002631 & 29.68 & 0.1829 & 533.90 & 69.4 & 2.70 \\
\hline \multirow{9}{*}{$\begin{array}{l}\text { With vias } \\
\text { With } \\
\text { columns } \\
\text { Constant } \\
\text { flowrate }\end{array}$} & 88 & 5.96 & 0.2 & 21.6 & 21.9 & 25.4 & 1.19 & 0.3 & 0.001465 & 1.84 & 0.1019 & 297.36 & 3.8 & 3.19 \\
\hline & 88 & 8.84 & 0.3 & 21.6 & 22.2 & 29.9 & 2.65 & 0.6 & 0.001465 & 3.67 & 0.1019 & 297.36 & 8.3 & 3.13 \\
\hline & 88 & 11.47 & 0.4 & 21.6 & 22.4 & 35.4 & 4.59 & 0.8 & 0.001465 & 4.90 & 0.1019 & 297.36 & 13.8 & 3.01 \\
\hline & 88 & 14.41 & 0.5 & 21.7 & 22.9 & 43.3 & 7.21 & 1.2 & 0.001465 & 7.35 & 0.1019 & 297.36 & 21.6 & 3.00 \\
\hline & 88 & 17.24 & 0.6 & 21.7 & 23.5 & 52.2 & 10.34 & 1.8 & 0.001465 & 11.02 & 0.1019 & 297.36 & 30.5 & 2.95 \\
\hline & 88 & 20.17 & 0.7 & 21.7 & 24.2 & 62.3 & 14.12 & 2.5 & 0.001465 & 15.30 & 0.1019 & 297.36 & 40.6 & 2.88 \\
\hline & 88 & 23.36 & 0.8 & 21.7 & 24.9 & 74.8 & 18.69 & 3.2 & 0.001465 & 19.59 & 0.1019 & 297.36 & 53.1 & 2.84 \\
\hline & 88 & 26.34 & 0.9 & 21.7 & 25.8 & 86.7 & 23.71 & 4.1 & 0.001465 & 25.10 & 0.1019 & 297.36 & 65 & 2.74 \\
\hline & 88 & 29.3 & 1 & 21.8 & 26.7 & 98.8 & 29.30 & 4.9 & 0.001465 & 30.00 & 0.1019 & 297.36 & 77 & 2.63 \\
\hline
\end{tabular}

Table 1 Observations and calculations of various test substrates at constant flow rate. 


\begin{tabular}{|c|c|c|c|c|c|c|c|c|c|c|c|c|c|c|}
\hline Sample & $\begin{array}{l}\text { Flow rate } \\
\mathrm{mL} / \mathrm{min}\end{array}$ & Voltage V & $\begin{array}{l}\text { Current } \\
\text { Amp }\end{array}$ & $\begin{array}{l}\text { Tinlet } \\
{ }^{\circ} \mathrm{C} \\
\end{array}$ & $\begin{array}{l}T_{\text {outiet }} \\
{ }^{\circ} \mathrm{C} \\
\end{array}$ & $\begin{array}{c}T_{\text {Itec }} \\
{ }^{\circ} \mathrm{C} \\
\end{array}$ & $\begin{array}{l}\text { Power } \\
\text { input W }\end{array}$ & $\begin{array}{c}d T_{\text {coolant }} \\
{ }^{\circ} \mathrm{C} \\
\end{array}$ & $\begin{array}{c}\mathrm{dm} / \mathrm{dt} \\
\mathrm{kg} / \mathrm{s}\end{array}$ & $\mathbf{Q}_{\text {gain }} \mathbf{W}$ & $\begin{array}{c}\begin{array}{c}\text { Velocity } \\
\mathrm{m} / \mathrm{s}\end{array} \\
\end{array}$ & $\begin{array}{l}\text { Reynolds } \\
\text { Number }\end{array}$ & $\mathrm{dT} \mathrm{sub}^{\circ} \mathrm{C}$ & $\begin{array}{c}R_{\text {th }} \\
{ }^{\circ} \mathrm{C} / W \\
\end{array}$ \\
\hline \multirow{5}{*}{\begin{tabular}{|l}
\multicolumn{1}{|c}{2} \\
Vias only \\
No \\
Columns \\
Constant \\
power
\end{tabular}} & 53 & 29.2 & 1 & 22.1 & 30.2 & 83.6 & 29.20 & 8.1 & 0.000882 & 29.86 & 0.0613 & 179.09 & 61.5 & 2.11 \\
\hline & 88 & 29.2 & 1 & 21.7 & 26.9 & 83 & 29.20 & 5.2 & 0.001465 & 31.83 & 0.1019 & 297.36 & 61.3 & 2.10 \\
\hline & 123 & 29.2 & 1 & 21.7 & 24.8 & 81.5 & 29.20 & 3.1 & 0.002048 & 26.52 & 0.1424 & 415.63 & 59.8 & 2.05 \\
\hline & 158 & 29.2 & 1 & 21.6 & 23.5 & 81.7 & 29.20 & 1.9 & 0.002631 & 20.88 & 0.1829 & 533.90 & 60.1 & 2.06 \\
\hline & 193 & 29.2 & 1 & 21.6 & 22.8 & 78 & 29.20 & 1.2 & 0.003213 & 16.11 & 0.2234 & 652.17 & 56.4 & 1.93 \\
\hline \multirow{5}{*}{\begin{tabular}{l}
\multicolumn{1}{c}{3} \\
With vias \\
With \\
columns \\
Constant \\
power
\end{tabular}} & 53 & 27.9 & 0.95 & 21.9 & 31.1 & 103.3 & 26.51 & 9.2 & 0.000882 & 33.92 & 0.0613 & 179.09 & 81.4 & 3.07 \\
\hline & 88 & 27.9 & 0.95 & 21.7 & 26.3 & 96.9 & 26.51 & 4.6 & 0.001465 & 28.16 & 0.1019 & 297.36 & 75.2 & 2.84 \\
\hline & 123 & 27.9 & 0.95 & 21.6 & 24.9 & 93.2 & 26.51 & 3.3 & 0.002048 & 28.24 & 0.1424 & 415.63 & 71.6 & 2.70 \\
\hline & 158 & 27.9 & 0.95 & 21.5 & 24 & 91.3 & 26.51 & 2.5 & 0.002631 & 27.48 & 0.1829 & 533.90 & 69.8 & 2.63 \\
\hline & 193 & 27.9 & 0.95 & 21.4 & 23.6 & 89.5 & 26.51 & 2.2 & 0.003213 & 29.54 & 0.2234 & 652.17 & 68.1 & 2.57 \\
\hline \multirow{6}{*}{\begin{tabular}{|l}
\multicolumn{1}{c}{3} \\
With vias \\
With \\
columns \\
Constant \\
power
\end{tabular}} & 53 & 25.06 & 0.86 & 21.6 & 30 & 106.8 & 21.55 & 8.4 & 0.000882 & 30.97 & 0.0613 & 179.09 & 85.2 & 3.95 \\
\hline & 88 & 25.06 & 0.86 & 21.8 & 25.7 & 98.8 & 21.55 & 3.9 & 0.001465 & 23.87 & 0.1019 & 297.36 & 77 & 3.57 \\
\hline & 123 & 25.06 & 0.86 & 21.7 & 24.4 & 96.2 & 21.55 & 2.7 & 0.002048 & 23.10 & 0.1424 & 415.63 & 74.5 & 3.46 \\
\hline & 158 & 25.06 & 0.86 & 21.6 & 23.7 & 94.4 & 21.55 & 2.1 & 0.002631 & 23.08 & 0.1829 & 533.90 & 72.8 & 3.38 \\
\hline & 193 & 25.06 & 0.86 & 21.6 & 23.3 & 93.6 & 21.55 & 1.7 & 0.003213 & 22.82 & 0.2234 & 652.17 & 72 & 3.34 \\
\hline & 228 & 25.06 & 0.86 & 21.5 & 22.9 & 92.4 & 21.55 & 1.4 & 0.003796 & 22.20 & 0.2639 & 770.43 & 70.9 & 3.29 \\
\hline
\end{tabular}

Table 2 Observations and Calculations of various test substrates at constant power.

\begin{tabular}{|c|c|c|c|c|c|c|c|c|c|c|c|c|}
\hline Sample & $\begin{array}{c}\mathbf{N} \\
\text { Rpm }\end{array}$ & $\begin{array}{c}\text { Flow } \\
\text { rate } \\
\text { mL/min }\end{array}$ & $\begin{array}{c}\mathrm{T}_{\text {inlet }} \\
{ }^{\circ} \mathrm{C} \\
\end{array}$ & $\begin{array}{r}T_{\text {outlet }} \\
{ }^{\circ} \mathrm{C}\end{array}$ & $\begin{array}{l}\mathrm{T}_{\text {Itcc }} \\
{ }^{\circ} \mathrm{C} \\
\end{array}$ & $\begin{array}{c}\mathbf{d} T_{\text {wate }} \\
{ }^{\circ} \mathrm{C} \\
\end{array}$ & $\begin{array}{c}\mathrm{dm} / \mathrm{dt} \\
\mathrm{kg} / \mathrm{s} \\
\end{array}$ & $\begin{array}{c}\mathbf{Q}_{\text {gain }} \\
\mathbf{W} \\
\end{array}$ & $\begin{array}{l}\text { Velocit } \\
\mathrm{m} / \mathrm{s} \\
\end{array}$ & $\operatorname{Re}$ & $\begin{array}{c}\text { dT } \\
\text { substrate } \\
{ }^{\circ} \mathrm{C} \\
\end{array}$ & $\begin{array}{l}\mathbf{R}_{\text {th }} \\
{ }^{\circ} \mathrm{C} / \mathrm{W}\end{array}$ \\
\hline & 50 & 53.01 & 21.9 & 35.8 & 128.1 & 13.9 & 0.000883 & 51.25 & 0.0614 & 179.12 & 106.2 & 3.52 \\
\hline & 100 & 87.98 & 21.7 & 29.2 & 125.9 & 7.5 & 0.001465 & 45.90 & 0.1018 & 297.30 & 104.2 & 3.46 \\
\hline
\end{tabular}




\begin{tabular}{|c|c|c|c|c|c|c|c|c|c|c|c|c|c|}
\hline Sample & & $\begin{array}{c}\mathrm{N} \\
\mathrm{Rpm}\end{array}$ & $\begin{array}{c}\text { Flow } \\
\text { rate } \\
\text { mL/min }\end{array}$ & $\begin{array}{c}T_{\text {inlet }} \\
{ }^{\circ} \mathrm{C} \\
\end{array}$ & $\begin{array}{r}T_{\text {outlet }} \\
{ }^{\circ} \mathrm{C} \\
\end{array}$ & $\begin{array}{l}\mathrm{T}_{\text {Itcc }} \\
{ }^{\circ} \mathrm{C} \\
\end{array}$ & $\begin{array}{c}\mathbf{d T} T_{\text {wate }} \\
{ }^{\circ} \mathrm{C} \\
\end{array}$ & $\begin{array}{c}\mathrm{dm} / \mathrm{dt} \\
\mathrm{kg} / \mathrm{s}\end{array}$ & $\begin{array}{c}\mathbf{Q}_{\text {gain }} \\
\mathbf{W} \\
\end{array}$ & $\begin{array}{c}\text { Velocit } \\
\mathrm{m} / \mathrm{s} \\
\end{array}$ & $\mathbf{R e}$ & $\begin{array}{c}d T \\
\text { substrate } \\
{ }^{\circ} \mathrm{C} \\
\end{array}$ & $\begin{array}{l}R_{\text {th }} \\
{ }^{\circ} \mathrm{C} / \mathrm{W} \\
\end{array}$ \\
\hline 2 & & 150 & 122.96 & 21.5 & 27.9 & 123.4 & 6.4 & 0.002047 & 54.74 & 0.1423 & 415.48 & 101.9 & 3.38 \\
\hline $\begin{array}{l}\text { Vias } \\
\text { only }\end{array}$ & & 200 & 157.93 & 21.5 & 24.9 & 122.1 & 3.4 & 0.002630 & 37.35 & 0.1828 & 533.67 & 100.6 & 3.34 \\
\hline $\begin{array}{l}\text { No } \\
\text { Column }\end{array}$ & & 250 & 192.91 & 21.4 & 24.5 & 120.2 & 3.1 & 0.003212 & 41.60 & 0.2233 & 651.85 & 98.8 & 3.28 \\
\hline $\begin{array}{l}\text { Voltage } \\
\text { (V) }\end{array}$ & 30.13 & 300 & 227.88 & 21.4 & 23.5 & 120.2 & 2.1 & 0.003794 & 33.29 & 0.2638 & 770.04 & 98.8 & 3.28 \\
\hline $\begin{array}{l}\text { Current } \\
\text { (amp) }\end{array}$ & 1 & 350 & 262.86 & 21.4 & 23.2 & 119.6 & 1.8 & 0.004377 & 32.91 & 0.3042 & 888.22 & 98.2 & 3.26 \\
\hline $\begin{array}{l}\text { Power } \\
\text { (W) }\end{array}$ & 30.13 & 400 & 297.83 & 21.4 & 22.9 & 118.9 & 1.5 & 0.004959 & 31.08 & 0.3447 & 1006.40 & 97.5 & 3.24 \\
\hline $\begin{array}{l}\text { Small } \\
\text { tube }\end{array}$ & & 450 & 332.81 & 21.4 & 22.6 & 117.1 & 1.2 & 0.005541 & 27.78 & 0.3852 & 1124.59 & 95.7 & 3.18 \\
\hline & & 50 & 53.01 & 23.3 & 31.6 & 85.8 & 8.3 & 0.000883 & 30.61 & 0.0614 & 179.12 & 62.5 & 3.11 \\
\hline & & 100 & 87.98 & 22.4 & 26.8 & 78.4 & 4.4 & 0.001465 & 26.93 & 0.1018 & 297.30 & 56 & 2.79 \\
\hline 2 & & 150 & 122.96 & 22.1 & 24.6 & 74.7 & 2.5 & 0.002047 & 21.38 & 0.1423 & 415.48 & 52.6 & 2.62 \\
\hline $\begin{array}{l}\text { Vias } \\
\text { only }\end{array}$ & & 200 & 157.93 & 21.9 & 24 & 73.4 & 2.1 & 0.002630 & 23.07 & 0.1828 & 533.67 & 51.5 & 2.56 \\
\hline $\begin{array}{l}\text { No } \\
\text { Column }\end{array}$ & & 250 & 192.91 & 21.8 & 23.7 & 72.8 & 1.9 & 0.003212 & 25.50 & 0.2233 & 651.85 & 51 & 2.54 \\
\hline $\begin{array}{l}\text { Voltage } \\
\text { (V) }\end{array}$ & 24.49 & 300 & 227.88 & 21.7 & 23.2 & 71.7 & 1.5 & 0.003794 & 23.78 & 0.2638 & 770.04 & 50 & 2.49 \\
\hline $\begin{array}{l}\text { Current } \\
\text { (amp) }\end{array}$ & 0.82 & 350 & 262.86 & 21.7 & 22.9 & 71.4 & 1.2 & 0.004377 & 21.94 & 0.3042 & 888.22 & 49.7 & 2.47 \\
\hline $\begin{array}{l}\text { Power } \\
\text { (W) }\end{array}$ & 20.08 & 400 & 297.83 & 21.6 & 22.6 & 70.9 & 1 & 0.004959 & 20.72 & 0.3447 & 1006.40 & 49.3 & 2.45 \\
\hline $\begin{array}{l}\text { Small } \\
\text { tube }\end{array}$ & & 450 & 332.81 & 21.4 & 22.1 & 77.7 & 0.7 & 0.005541 & 16.21 & 0.3852 & 1124.59 & 56.3 & 2.80 \\
\hline
\end{tabular}




\begin{tabular}{|c|c|c|c|c|c|c|c|c|c|c|c|c|c|}
\hline Sample & & $\begin{array}{c}N \\
\text { Rpm }\end{array}$ & $\begin{array}{c}\text { Flow } \\
\text { rate } \\
\mathrm{mL} / \mathrm{min}\end{array}$ & $\begin{array}{c}T_{\text {inlet }} \\
{ }^{\circ} \mathrm{C} \\
\end{array}$ & $\begin{array}{r}T_{\text {outlet }} \\
{ }^{\circ} \mathrm{C} \\
\end{array}$ & $\begin{array}{l}\mathrm{T}_{\text {Itce }} \\
{ }^{\circ} \mathrm{C}\end{array}$ & $\begin{array}{c}d T_{\text {wate }} \\
{ }^{\circ} \mathrm{C} \\
\end{array}$ & $\begin{array}{c}\mathrm{dm} / \mathrm{dt} \\
\mathrm{kg} / \mathrm{s} \\
\end{array}$ & $\begin{array}{c}\mathbf{Q}_{\text {gain }} \\
\mathbf{W} \\
\end{array}$ & $\begin{array}{c}\text { Velocit } \\
\mathrm{m} / \mathrm{s} \\
\end{array}$ & $\operatorname{Re}$ & $\begin{array}{c}\mathrm{dT} \\
\text { substrate } \\
{ }^{\circ} \mathrm{C}\end{array}$ & $\begin{array}{l}R_{\text {th }} \\
{ }^{\circ} \mathrm{C} / \mathrm{W}\end{array}$ \\
\hline & & 100 & 87.98 & 22.4 & 25.1 & 60.6 & 2.7 & 0.001465 & 16.52 & 0.1018 & 297.30 & 38.2 & 3.43 \\
\hline 2 & & 150 & 122.96 & 22.1 & 23.2 & 60.4 & 1.1 & 0.002047 & 9.41 & 0.1423 & 415.48 & 38.3 & 3.44 \\
\hline $\begin{array}{l}\text { Vias } \\
\text { only }\end{array}$ & & 200 & 157.93 & 21.9 & 22.9 & 58.3 & 1 & 0.002630 & 10.99 & 0.1828 & 533.67 & 36.4 & 3.27 \\
\hline $\begin{array}{l}\text { No } \\
\text { Column }\end{array}$ & & 250 & 192.91 & 21.8 & 22.6 & 57.1 & 0.8 & 0.003212 & 10.74 & 0.2233 & 651.85 & 35.3 & 3.17 \\
\hline $\begin{array}{l}\text { Voltage } \\
\text { (V) }\end{array}$ & 18.56 & 300 & 227.88 & 21.6 & 22.2 & 55 & 0.6 & 0.003794 & 9.51 & 0.2638 & 770.04 & 33.4 & 3.00 \\
\hline $\begin{array}{l}\text { Current } \\
\text { (amp) }\end{array}$ & 0.6 & 350 & 262.86 & 21.5 & 22.1 & 54.6 & 0.6 & 0.004377 & 10.97 & 0.3042 & 888.22 & 33.1 & 2.97 \\
\hline $\begin{array}{l}\text { Power } \\
\text { (W) }\end{array}$ & 11.13 & 400 & 297.83 & 21.4 & 22.1 & 53.5 & 0.7 & 0.004959 & 14.50 & 0.3447 & 1006.40 & 32.1 & 2.88 \\
\hline $\begin{array}{l}\text { Small } \\
\text { tube }\end{array}$ & & 450 & 332.81 & 21.4 & 21.8 & 52.6 & 0.4 & 0.005541 & 9.26 & 0.3852 & 1124.59 & 31.2 & 2.80 \\
\hline & & 50 & 53.01 & 21.9 & 34.3 & 74 & 12.4 & 0.000883 & 45.72 & 0.0614 & 179.12 & 52.1 & 1.72 \\
\hline & & 100 & 87.98 & 21.7 & 28.2 & 65.3 & 6.5 & 0.001465 & 39.78 & 0.1018 & 297.30 & 43.6 & 1.44 \\
\hline 3 & & 150 & 122.96 & 21.6 & 25.8 & 59.9 & 4.2 & 0.002047 & 35.92 & 0.1423 & 415.48 & 38.3 & 1.27 \\
\hline $\begin{array}{l}\text { With } \\
\text { vias }\end{array}$ & & 200 & 157.93 & 21.4 & 24.7 & 57.8 & 3.3 & 0.002630 & 36.25 & 0.1828 & 533.67 & 36.4 & 1.20 \\
\hline $\begin{array}{l}\text { With } \\
\text { column }\end{array}$ & & 250 & 192.91 & 21.4 & 24.1 & 56.1 & 2.7 & 0.003212 & 36.23 & 0.2233 & 651.85 & 34.7 & 1.15 \\
\hline $\begin{array}{l}\text { Voltage } \\
\text { (V) }\end{array}$ & 29.97 & 300 & 227.88 & 21.4 & 23.7 & 54.2 & 2.3 & 0.003794 & 36.46 & 0.2638 & 770.04 & 32.8 & 1.08 \\
\hline $\begin{array}{l}\text { Current } \\
\text { (amp) }\end{array}$ & 1.01 & 350 & 262.86 & 21.4 & 23.4 & 53.3 & 2 & 0.004377 & 36.57 & 0.3042 & 888.22 & 31.9 & 1.05 \\
\hline $\begin{array}{l}\text { Power } \\
\text { (W) }\end{array}$ & 30.27 & 400 & 297.83 & 21.4 & 23.1 & 52.7 & 1.7 & 0.004959 & 35.22 & 0.3447 & 1006.40 & 31.3 & 1.03 \\
\hline
\end{tabular}




\begin{tabular}{|c|c|c|c|c|c|c|c|c|c|c|c|c|c|}
\hline Sample & & $\begin{array}{c}\mathrm{N} \\
\mathrm{Rpm} \\
\end{array}$ & $\begin{array}{c}\text { Flow } \\
\text { rate } \\
\text { mL/min }\end{array}$ & $\begin{array}{l}\mathrm{T}_{\text {inlet }} \\
{ }^{\circ} \mathrm{C} \\
\end{array}$ & $\begin{array}{r}\mathrm{T}_{\text {outlet }} \\
{ }^{\circ} \mathrm{C} \\
\end{array}$ & $\begin{array}{l}\mathrm{T}_{\text {ttec }} \\
{ }^{\circ} \mathrm{C} \\
\end{array}$ & $\begin{array}{c}\mathbf{d} T_{\text {wate }} \\
{ }^{\circ} \mathrm{C} \\
\end{array}$ & $\begin{array}{c}\mathrm{dm} / \mathrm{dt} \\
\mathrm{kg} / \mathrm{s} \\
\end{array}$ & $\begin{array}{c}Q_{\text {gain }} \\
W \\
\end{array}$ & $\begin{array}{c}\text { Velocit } \\
\mathrm{m} / \mathrm{s} \\
\end{array}$ & $\mathrm{Re}$ & $\begin{array}{c}\text { dT } \\
\text { substrate } \\
{ }^{\circ} \mathrm{C}\end{array}$ & $\begin{array}{l}R_{\text {th }} \\
{ }^{\circ} \mathrm{C} / \mathrm{W}\end{array}$ \\
\hline \multicolumn{2}{|l|}{$\begin{array}{l}\text { Small } \\
\text { tube }\end{array}$} & 450 & 332.81 & 21.3 & 22.9 & 52 & 1.6 & 0.005541 & 37.04 & 0.3852 & 1124.59 & 30.7 & 1.01 \\
\hline \multirow{9}{*}{$\begin{array}{l}\quad 3 \\
\text { With } \\
\text { vias } \\
\text { With } \\
\text { column } \\
\text { Voltage } \\
\text { (V) } \\
\text { Current } \\
\text { (amp) } \\
\text { Power } \\
\text { (W) } \\
\text { Small } \\
\text { tube } \\
\end{array}$} & \multirow{8}{*}{$\begin{array}{c}24.21 \\
0.83 \\
20.09\end{array}$} & 50 & 53.01 & 21.9 & 30.3 & 54.6 & 8.4 & 0.000883 & 30.97 & 0.0614 & 179.12 & 32.7 & 1.63 \\
\hline & & 100 & 87.98 & 21.6 & 26.1 & 49.4 & 4.5 & 0.001465 & 27.54 & 0.1018 & 297.30 & 27.8 & 1.38 \\
\hline & & 150 & 122.96 & 21.4 & 24.4 & 46.7 & 3 & 0.002047 & 25.66 & 0.1423 & 415.48 & 25.3 & 1.26 \\
\hline & & 200 & 157.93 & 21.4 & 23.6 & 44.4 & 2.2 & 0.002630 & 24.17 & 0.1828 & 533.67 & 23 & 1.14 \\
\hline & & 250 & 192.91 & 21.3 & 23.2 & 43.4 & 1.9 & 0.003212 & 25.50 & 0.2233 & 651.85 & 22.1 & 1.10 \\
\hline & & 300 & 227.88 & 21.4 & 23 & 42.7 & 1.6 & 0.003794 & 25.36 & 0.2638 & 770.04 & 21.3 & 1.06 \\
\hline & & 350 & 262.86 & 21.4 & 22.8 & 42.2 & 1.4 & 0.004377 & 25.60 & 0.3042 & 888.22 & 20.8 & 1.04 \\
\hline & & 400 & 297.83 & 21.4 & 22.7 & 41.6 & 1.3 & 0.004959 & 26.93 & 0.3447 & 1006.40 & 20.2 & 1.01 \\
\hline & & 450 & 332.81 & 21.5 & 22.6 & 41.3 & 1.1 & 0.005541 & 25.47 & 0.3852 & 1124.59 & 19.8 & 0.99 \\
\hline \multirow{9}{*}{$\begin{array}{l}\quad 3 \\
\text { With } \\
\text { vias } \\
\text { With } \\
\text { column } \\
\text { Voltage } \\
\text { (V) } \\
\text { Current } \\
\text { (amp) } \\
\text { Power } \\
\text { (W) } \\
\text { Small } \\
\text { tube }\end{array}$} & & 50 & 53.01 & 21.9 & 26.6 & 38.7 & 4.7 & 0.000883 & 17.33 & 0.0614 & 179.12 & 16.8 & 1.55 \\
\hline & & 100 & 87.98 & 21.5 & 23.8 & 35.4 & 2.3 & 0.001465 & 14.08 & 0.1018 & 297.30 & 13.9 & 1.28 \\
\hline & & 150 & 122.96 & 21.6 & 23.1 & 34.2 & 1.5 & 0.002047 & 12.83 & 0.1423 & 415.48 & 12.6 & 1.16 \\
\hline & & 200 & 157.93 & 21.4 & 22.6 & 33 & 1.2 & 0.002630 & 13.18 & 0.1828 & 533.67 & 11.6 & 1.07 \\
\hline & & 250 & 192.91 & 21.4 & 22.4 & 32.5 & 1 & 0.003212 & 13.42 & 0.2233 & 651.85 & 11.1 & 1.02 \\
\hline & 17.8 & 300 & 227.88 & 21.3 & 22.2 & 32 & 0.9 & 0.003794 & 14.27 & 0.2638 & 770.04 & 10.7 & 0.99 \\
\hline & 0.61 & 350 & 262.86 & 21.3 & 22.1 & 31.7 & 0.8 & 0.004377 & 14.63 & 0.3042 & 888.22 & 10.4 & 0.96 \\
\hline & 10.85 & 400 & 297.83 & 21.2 & 22.1 & 31.4 & 0.9 & 0.004959 & 18.65 & 0.3447 & 1006.40 & 10.2 & 0.94 \\
\hline & & 450 & 332.81 & 21.4 & 21.9 & 31.2 & 0.5 & 0.005541 & 11.58 & 0.3852 & 1124.59 & 9.8 & 0.90 \\
\hline
\end{tabular}

Table 3 Observations and Calculations of various test substrates at constant power. 
Correlations:

The following correlations are used in the above tables.

$\begin{array}{ll}\text { Power }(\mathrm{Q}) & =\text { Voltage }(\mathrm{V}) * \text { Current }(\mathrm{I}) \\ \text { Flow rate }(\mathrm{G} \text { in } \mathrm{mL} / \mathrm{min}) & =(0.6995 * \mathrm{~N})+18.032 \text { for } 1 / 4 \text { in ID tube } \\ & =(3.0048 * \mathrm{~N})+7.2398 \text { for } 3 / 4 \text { in ID tube } \\ \mathrm{dT}_{\text {coolant }} & =\mathrm{T}_{\text {in }}-\mathrm{T}_{\text {out }} \\ \mathrm{dm} / \mathrm{dt} & =\rho * \mathrm{G} * 10^{-6} / 60 \\ \mathrm{Q}_{\text {gain }} & =\mathrm{dm} / \mathrm{dt} * \mathrm{c}_{\mathrm{p}} * \mathrm{dT}_{\text {coolant }} \\ \mathrm{Re} & =\rho * \mathrm{v} * \mathrm{D}_{\mathrm{h}} / v, \text { where } \mathrm{D}_{\mathrm{h}}=\text { Area } / \text { Perimeter } \\ & \\ \mathrm{R}_{\text {system }} & =\mathrm{dT}_{\text {substrate }} / \mathrm{Q}_{\text {input }}\end{array}$









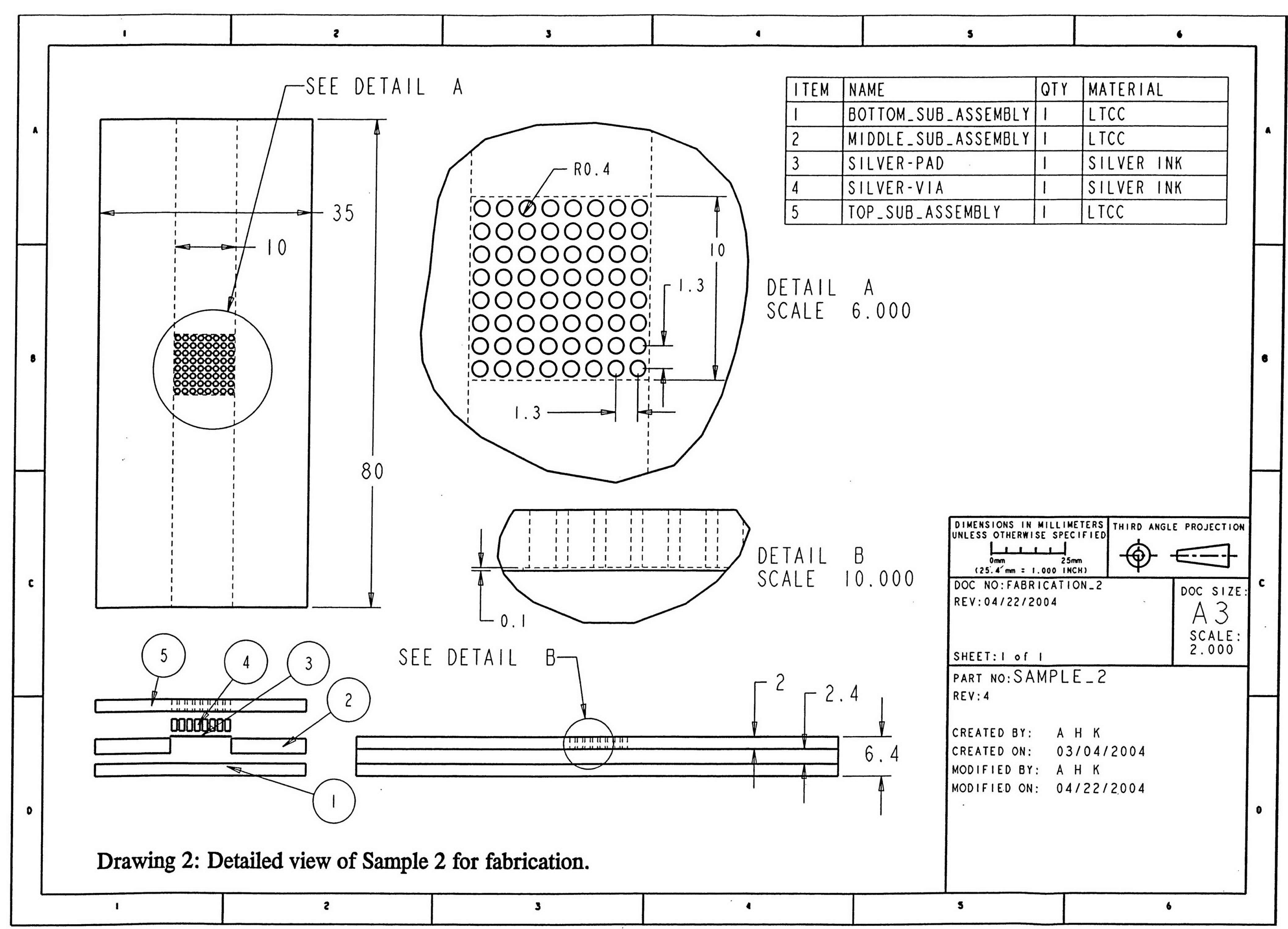




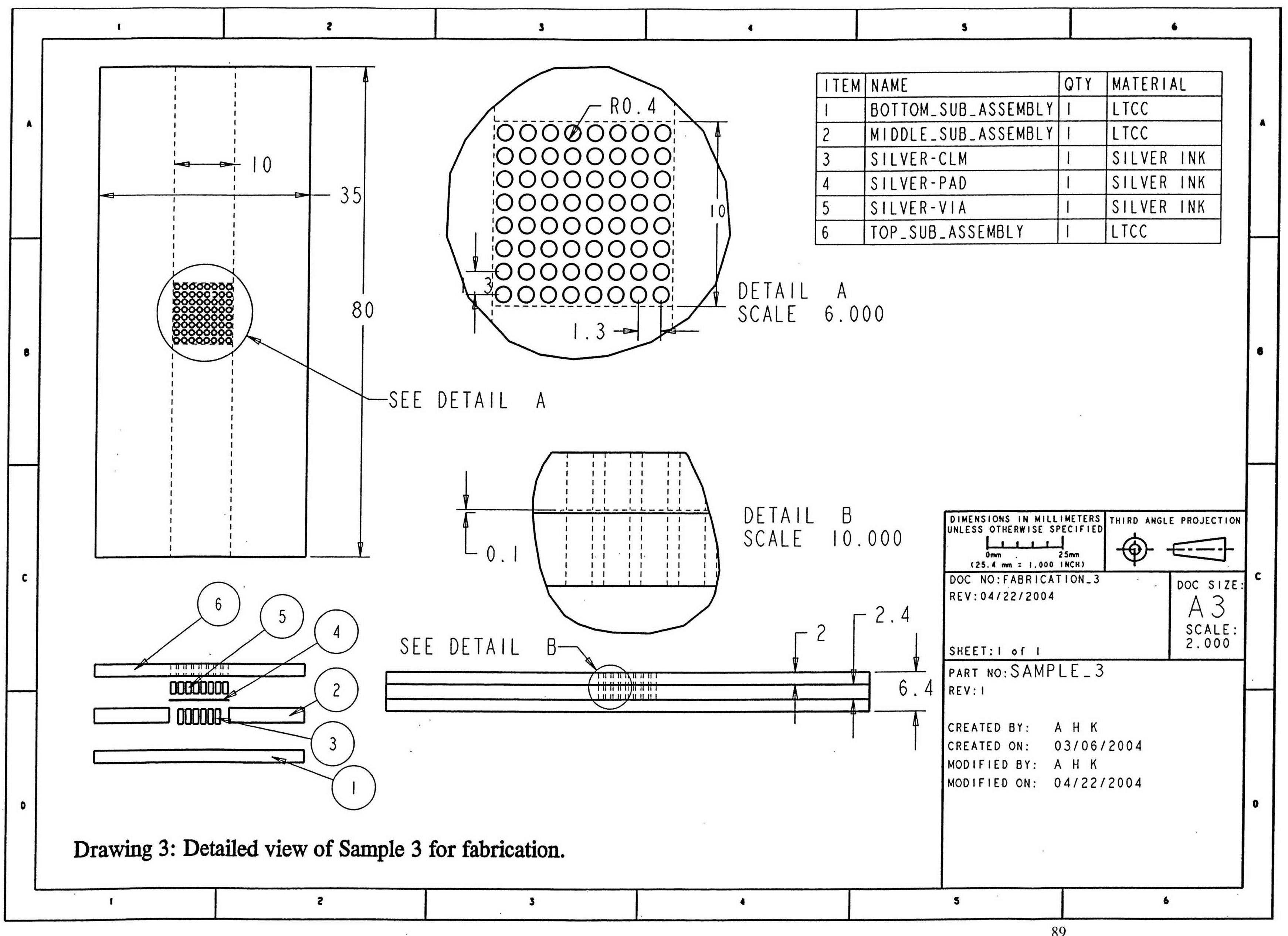




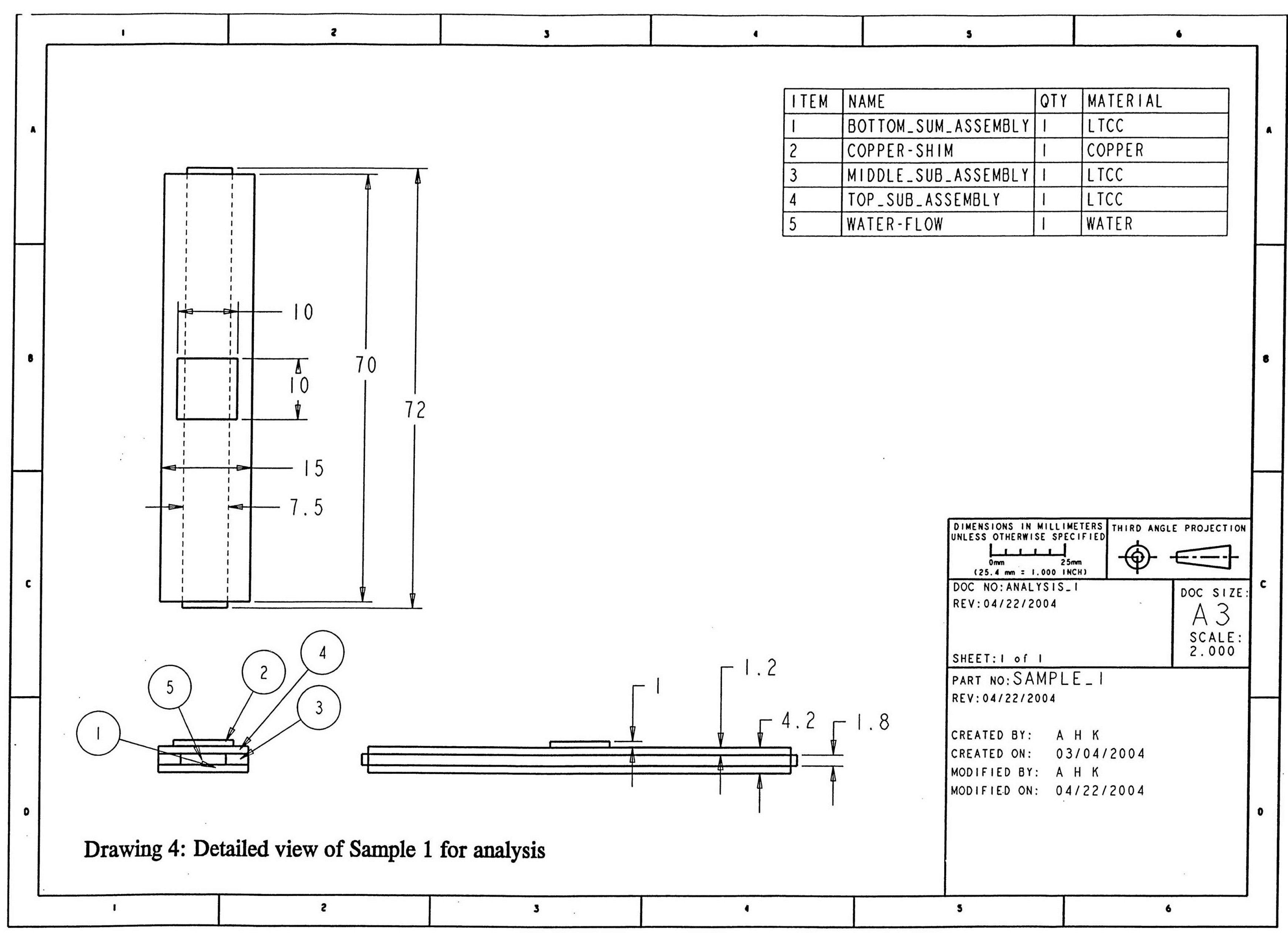




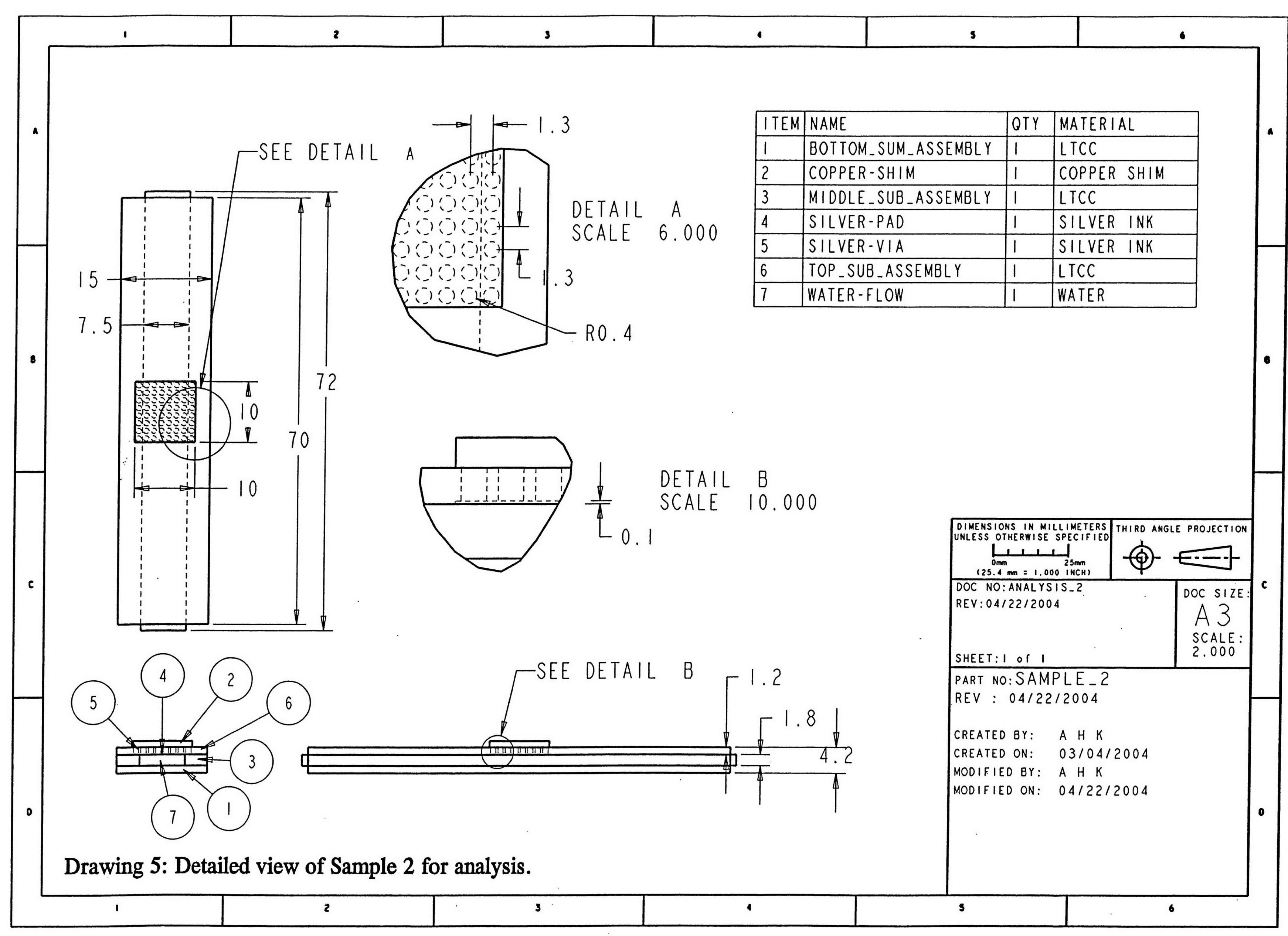

91 


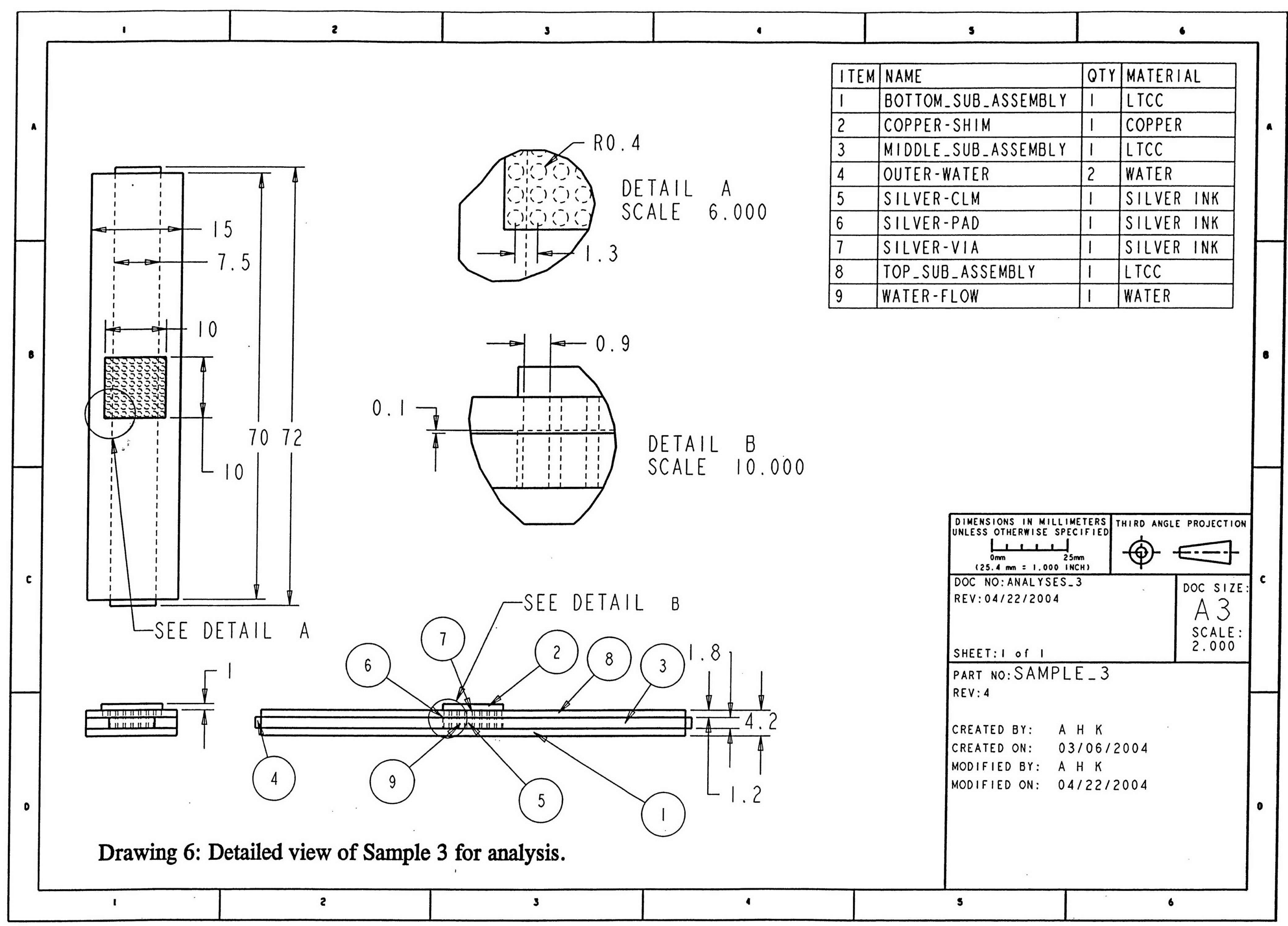

92 


\section{Appendix 3 Tables from CFDesign Analysis}

$\mathrm{T}_{\text {inlet }}=20^{\circ} \mathrm{C}, \mathrm{dm} / \mathrm{dt}$ for flow rate of $293 \mathrm{~mL} / \mathrm{min}$ is $4.87 \mathrm{e}-3 \mathrm{~kg} / \mathrm{s}$ and for $1230 \mathrm{~mL} / \mathrm{min}$ it is $2.05 \mathrm{e}-2 \mathrm{~kg} / \mathrm{s}$. Reynolds number is 1327 for $293 \mathrm{~mL} / \mathrm{min}$ flow rate and 5552 for $1230 \mathrm{~mL} / \mathrm{min}$ flow rate.

\begin{tabular}{|c|c|c|c|c|c|c|c|c|c|c|c|c|}
\hline $\begin{array}{l}\text { SI. } \\
\text { No }\end{array}$ & Description & $\begin{array}{l}\text { Flow } \\
\text { rate }\end{array}$ & $T_{\text {outlet }}$ & $T_{c u}$ & $Q_{\text {in }}$ & $\begin{array}{l}d T_{\text {coolan }} \\
t\end{array}$ & V & $\begin{array}{l}Q=m c_{p} d \\
T\end{array}$ & $Q_{\text {sum }}$ & $\begin{array}{l}\mathrm{dT}_{\text {sub }} \\
\text { strate }\end{array}$ & $\mathrm{R}_{\mathrm{sy}}$ & $\begin{array}{l}\% \\
\text { error } \\
\text { in Q }\end{array}$ \\
\hline & & $\mathrm{mL} / \mathrm{min}$ & ${ }^{\circ} \mathrm{C}$ & ${ }^{\circ} \mathrm{C}$ & W & ${ }^{\circ} \mathrm{C}$ & $\mathrm{m} / \mathrm{s}$ & W & W & ${ }^{\circ} \mathrm{C}$ & $\begin{array}{l}{ }^{\circ} \mathrm{Cl} \\
\mathrm{W}\end{array}$ & \\
\hline 1 & Analysis1a-1200mL-80T-A-02252004 & 1230 & 20.21 & 80.00 & & 0.212 & 1.51 & 18.17 & 17.8 & 60.00 & 3.3 & 2.0 \\
\hline 2 & Analysis 1a-1200mL-10W-A-02252004 & 1230 & 20.12 & 53.64 & 10 & 0.120 & 1.51 & 10.23 & 9.99 & 33.64 & 3.2 & 2.3 \\
\hline 3 & Analysis 1a-1200mL-20W-A-02252004 & 1230 & 20.25 & 87.28 & 20 & 0.246 & 1.51 & 21.06 & 19.9 & 67.28 & 3.1 & 5.3 \\
\hline 4 & Analysis1a-1200mL-30W-A-02252004 & 1230 & 20.36 & 120.92 & 30 & 0.365 & 1.51 & 31.19 & 30.0 & 100.9 & 3.2 & 3.9 \\
\hline 5 & Analysis1a-1200mL-40W-A-02252004 & 1230 & 20.49 & 154.56 & 40 & 0.490 & 1.51 & 41.90 & 39.8 & 134.5 & 3.2 & 4.7 \\
\hline 6 & Analysis1a-1200mL-50W-A-02252004 & 1230 & 20.60 & 188.21 & 50 & 0.600 & 1.51 & 51.31 & 49.9 & 168.2 & 3.2 & 2.6 \\
\hline 7 & Analysis 1a-300mL-80T-A-02252004 & 293 & 20.85 & 80.00 & & 0.847 & 0.36 & 17.27 & 16.8 & 60.00 & 3.4 & 2.2 \\
\hline 8 & Analysis1a-300mL-10W-A-02252004 & 293 & 20.50 & 55.43 & 10 & 0.502 & 0.36 & 10.23 & 9.99 & 35.43 & 3.4 & 2.2 \\
\hline 9 & Analysis $1 \mathrm{a}-300 \mathrm{~mL}-20 \mathrm{~W}-\mathrm{A}-02252004$ & 293 & 21.00 & 90.86 & 20 & 1.003 & 0.36 & 20.45 & 19.9 & 70.86 & 3.4 & 2.2 \\
\hline 10 & Analysis $1 \mathrm{a}-300 \mathrm{~mL}-30 \mathrm{~W}-\mathrm{A}-02252004$ & 293 & 21.50 & 126.30 & 30 & 1.505 & 0.36 & 30.67 & 29.9 & 106.3 & 3.4 & 2.2 \\
\hline 11 & Analysis1a-300mL-40W-A-02252004 & 293 & 22.01 & 161.74 & 40 & 2.005 & 0.36 & 40.87 & 39.9 & 141.7 & 3.4 & 2.1 \\
\hline 12 & Analysis1a-300mL-50W-A-02252004 & 293 & 22.51 & 197.17 & 50 & 2.508 & 0.36 & 51.12 & 49.9 & 177.1 & 3.4 & 2.2 \\
\hline
\end{tabular}

Table 4 Results for Sample1 at various flow rates and various power levels. 


\begin{tabular}{|c|c|c|c|c|c|c|c|c|c|c|c|c|c|c|c|}
\hline SI\# & Description & $\begin{array}{l}\text { Flow } \\
\text { rate }\end{array}$ & $T_{\text {outlet }}$ & $T_{c u}$ & $\mathrm{~T}_{\text {int }}$ & $Q_{\text {in }}$ & $\mathrm{dT}_{\text {coolant }}$ & V & $\mathrm{Q}=m c_{p} d T$ & $Q_{\text {sum }}$ & $d T_{\text {sub }}$ & $R_{\text {sys }}$ & $\mathrm{R}_{\text {cond }}$ & $\mathrm{R}_{\text {conv }}$ & $\begin{array}{l}\% \\
\text { erro } \\
r \text { in } \\
Q\end{array}$ \\
\hline & & $\begin{array}{l}\mathrm{mL} / \mathrm{mi} \\
\mathrm{n}\end{array}$ & & & & & & & & & & & & & \\
\hline 1 & $\begin{array}{l}\text { analysis } 2 \mathrm{c}- \\
1200 \mathrm{~mL}-10 \mathrm{~W}-\mathrm{A}- \\
\mathrm{Ag}-03042004\end{array}$ & 1230 & 21.62 & 24.61 & 23.09 & 10 & 0.118 & 1.518 & 10.12 & 9.96 & 3.11 & 0.30 & 0.151 & 0.157 & 1.2 \\
\hline 2 & $\begin{array}{l}\text { analysis2C- } \\
1200 \mathrm{~mL}-20 \mathrm{~W}-\mathrm{A}- \\
\mathrm{Ag}-03042004 \\
\end{array}$ & 1230 & 21.74 & 27.73 & 24.67 & 20 & 0.237 & 1.518 & 20.26 & 19.9 & 6.23 & 0.30 & 0.151 & 0.157 & 1.2 \\
\hline 3 & $\begin{array}{l}\text { analysis2C- } \\
1200 \mathrm{~mL}-30 \mathrm{~W}-\mathrm{A}- \\
\mathrm{Ag}-03042004\end{array}$ & 1230 & 21.85 & 30.84 & 26.26 & 30 & 0.354 & 1.518 & 30.28 & 29.9 & 9.34 & 0.30 & 0.151 & 0.157 & 0.9 \\
\hline 4 & $\begin{array}{l}\text { analysis } 2 \mathrm{C}- \\
1200 \mathrm{~mL}-40 \mathrm{~W}-\mathrm{A}- \\
\mathrm{Ag}-03042004\end{array}$ & 1230 & 21.97 & 33.96 & 27.85 & 40 & 0.474 & 1.518 & 40.53 & 39.8 & 12.46 & 0.30 & 0.151 & 0.157 & 1.3 \\
\hline 5 & $\begin{array}{l}\text { analysis2C- } \\
1200 \mathrm{~mL}-50 \mathrm{~W}-\mathrm{A}- \\
\mathrm{Ag}-03042004 \\
\end{array}$ & 1230 & 22.09 & 37.07 & 29.44 & 50 & 0.595 & 1.518 & 50.88 & 49.8 & 15.57 & 0.30 & 0.150 & 0.156 & 1.7 \\
\hline 6 & $\begin{array}{l}\text { analysis2c- } \\
1200 \mathrm{~mL}-80 \mathrm{~T}-\mathrm{A}- \\
\mathrm{Ag}-03042004 \\
\end{array}$ & 1230 & 23.64 & 80.00 & 50.41 & & 2.145 & 1.518 & 183.52 & 180. & 58.50 & 0.31 & 0.161 & 0.158 & 1.9 \\
\hline 7 & $\begin{array}{l}\text { analysis } 2 \mathrm{C}- \\
300 \mathrm{~mL}-10 \mathrm{~W}-\mathrm{A}- \\
\mathrm{Ag}-03042004\end{array}$ & 294 & 21.99 & 26.87 & 25.33 & 10 & 0.494 & 0.370 & 10.31 & 9.99 & 5.37 & 0.52 & 0.149 & 0.372 & 3.0 \\
\hline 8 & $\begin{array}{l}\text { analysis } 2 \mathrm{C}- \\
300 \mathrm{~mL}-20 \mathrm{~W}-\mathrm{A}- \\
\mathrm{Ag}-03042004\end{array}$ & 294 & 22.49 & 32.23 & 29.16 & 20 & 0.988 & 0.370 & 20.62 & 19.9 & 10.73 & 0.52 & 0.149 & 0.372 & 3.0 \\
\hline 9 & $\begin{array}{l}\text { analysis2c- } \\
300 \mathrm{~mL}-30 \mathrm{~W}-\mathrm{A}- \\
\mathrm{Ag}-03042004 \\
\end{array}$ & 294 & 22.98 & 37.60 & 32.99 & 30 & 1.482 & 0.370 & 30.93 & 29.9 & 16.10 & 0.52 & 0.149 & 0.372 & 3.1 \\
\hline 10 & $\begin{array}{l}\text { analysis2C- } \\
300 \mathrm{~mL}-40 \mathrm{~W}-\mathrm{A}- \\
\mathrm{Ag}-03042004\end{array}$ & 294 & 23.48 & 42.97 & 36.83 & 40 & 1.976 & 0.370 & 41.23 & $\begin{array}{c}39.9 \\
6\end{array}$ & 21.47 & $\begin{array}{c}0.52 \\
1\end{array}$ & 0.149 & 0.372 & $\begin{array}{c}3.0 \\
9\end{array}$ \\
\hline 11 & $\begin{array}{l}\text { analysis2c- } \\
300 \mathrm{~mL}-50 \mathrm{~W}-\mathrm{A}- \\
\mathrm{Ag}-03042004\end{array}$ & 294 & 23.97 & 48.34 & 40.65 & 50 & 2.470 & 0.363 & 50.53 & $\begin{array}{c}49.9 \\
8\end{array}$ & 26.84 & $\begin{array}{c}0.53 \\
1\end{array}$ & 0.152 & 0.379 & $\begin{array}{c}1.0 \\
6\end{array}$ \\
\hline 12 & $\begin{array}{l}\text { analysis2C- } \\
300 \mathrm{~mL}-80 \mathrm{~T}-\mathrm{A}- \\
\mathrm{Ag}-03042004 \\
\end{array}$ & 293 & 26.77 & 80.00 & 62.55 & & 5.271 & 0.361 & 107.45 & $\begin{array}{c}106 . \\
39\end{array}$ & 58.50 & $\begin{array}{c}0.54 \\
4\end{array}$ & 0.162 & 0.382 & $\begin{array}{c}0.9 \\
9\end{array}$ \\
\hline
\end{tabular}

Table 5 Results for sample 2 at various flow rates and various power levels. 


\begin{tabular}{|c|c|c|c|c|c|c|c|c|c|c|c|c|c|c|c|}
\hline SI. No & Description & $\begin{array}{l}\text { Flow } \\
\text { rate }\end{array}$ & $T_{\text {outlet }}$ & $T_{c u}$ & $\mathrm{~T}_{\text {inter }}$ & $Q_{\text {in }}$ & $\mathrm{dT}_{\text {coolant }}$ & V & $\begin{array}{l}\mathrm{Q}=m c_{p} \\
\mathrm{dT}\end{array}$ & $Q_{\text {sum }}$ & $\mathrm{dT}_{\text {sub }}$ & $R_{\text {sys }}$ & $\mathrm{R}_{\text {cond }}$ & $R_{\text {conv }}$ & $\begin{array}{l}\text { \%error } \\
\text { in Q }\end{array}$ \\
\hline & & $\mathrm{mL} / \mathrm{min}$ & & & & & & & & & & & & & \\
\hline 1 & $\begin{array}{l}\text { analysis3b- } \\
300 \mathrm{~mL}-80 \mathrm{~T}-\mathrm{A}- \\
\mathrm{Ag}-03062004 \\
\end{array}$ & 294 & 33.70 & 80.0 & 46.71 & & 12.200 & 0.363 & 249.54 & 200.4 & 58.50 & 0.23 & 0.133 & 0.101 & 19.68 \\
\hline 2 & $\begin{array}{l}\text { analysis } 3 b- \\
300 \mathrm{~mL}-10 \mathrm{~W}-\mathrm{A}- \\
\mathrm{Ag}-03062004 \\
\end{array}$ & 294 & 22.11 & 24.3 & 22.75 & 10 & 0.610 & 0.363 & 12.47 & 10.02 & 2.81 & 0.22 & 0.125 & 0.100 & 24.72 \\
\hline 3 & $\begin{array}{l}\text { analysis3b- } \\
300 \mathrm{~mL}-20 \mathrm{~W}-\mathrm{A}- \\
\mathrm{Ag}-03062004\end{array}$ & 294 & 22.72 & 27.1 & 24.01 & 20 & 1.220 & 0.363 & 24.96 & 20.04 & 5.63 & 0.22 & 0.125 & 0.100 & 24.81 \\
\hline 4 & $\begin{array}{l}\text { analysis } 3 \mathrm{~b}- \\
300 \mathrm{~mL}-30 \mathrm{~W}-\mathrm{A}- \\
\mathrm{Ag}-03062004 \\
\end{array}$ & 294 & 23.33 & 29.9 & 25.26 & 30 & 1.834 & 0.363 & 37.52 & 29.92 & 8.44 & 0.22 & 0.125 & 0.100 & 25.06 \\
\hline 5 & $\begin{array}{l}\text { analysis } 3 b- \\
300 \mathrm{~mL}-40 \mathrm{~W}-\mathrm{A}- \\
\mathrm{Ag}-03062004 \\
\end{array}$ & 294 & 23.93 & 32.7 & 26.51 & 40 & 2.429 & 0.363 & 49.68 & 40.05 & 11.26 & 0.22 & 0.126 & 0.101 & 24.19 \\
\hline 6 & $\begin{array}{l}\text { analysis } 3 \mathrm{~b}- \\
300 \mathrm{~mL}-50 \mathrm{~W}-\mathrm{A}- \\
\mathrm{Ag}-03062004 \\
\end{array}$ & 294 & 24.55 & 35.5 & 27.77 & 50 & 3.050 & 0.363 & 62.39 & 50.09 & 14.07 & 0.22 & 0.125 & 0.100 & 24.79 \\
\hline 7 & $\begin{array}{l}\text { analysis } 3 \mathrm{~b}- \\
1200 \mathrm{~mL}-80 \mathrm{~T}-\mathrm{A}- \\
\mathrm{Ag}-03062004\end{array}$ & 1230 & 25.85 & 80.0 & 36.67 & & 4.349 & 1.518 & 372.21 & 261.6 & 58.50 & 0.15 & 0.116 & 0.041 & 29.72 \\
\hline 8 & $\begin{array}{l}\text { analysis } 3 b- \\
1200 \mathrm{~mL}-10 \mathrm{~W}-\mathrm{A}- \\
\mathrm{Ag}-03062004\end{array}$ & 1230 & 21.65 & 23.6 & 22.08 & 10 & 0.154 & 1.518 & 13.20 & 10.04 & 2.14 & 0.16 & 0.118 & 0.044 & 32.04 \\
\hline 9 & $\begin{array}{l}\text { analysis } 3 \mathrm{~b}- \\
1200 \mathrm{~mL}-20 \mathrm{~W}-\mathrm{A}- \\
\mathrm{Ag}-03062004\end{array}$ & 1230 & 21.81 & 25.7 & 22.67 & 20 & 0.313 & 1.518 & 26.77 & 20.09 & 4.28 & 0.16 & 0.116 & 0.044 & 33.86 \\
\hline 10 & $\begin{array}{l}\text { analysis } 3 \mathrm{~b}- \\
1200 \mathrm{~mL}-30 \mathrm{~W}-\mathrm{A}- \\
\mathrm{Ag}-03062004\end{array}$ & 1230 & 21.96 & 27.9 & 23.25 & 30 & 0.461 & 1.518 & 39.43 & 30.14 & 6.42 & 0.16 & 0.118 & 0.045 & 31.42 \\
\hline 11 & $\begin{array}{l}\text { analysis } 3 \mathrm{~b}- \\
1200 \mathrm{~mL}-40 \mathrm{~W}-\mathrm{A}- \\
\mathrm{Ag}-03062004\end{array}$ & 1230 & 22.13 & 30.0 & 23.84 & 40 & 0.626 & 1.518 & 53.55 & 30.14 & 8.55 & 0.16 & 0.116 & 0.044 & 33.88 \\
\hline 12 & $\begin{array}{l}\text { analysis } 3 \mathrm{~b}- \\
1200 \mathrm{~mL}-50 \mathrm{~W}-\mathrm{A}- \\
\mathrm{Ag}-03062004\end{array}$ & 1230 & 22.22 & 32.2 & 24.42 & 50 & 0.724 & 1.518 & 61.93 & 50.24 & 10.71 & 0.17 & 0.126 & 0.047 & 23.86 \\
\hline
\end{tabular}

Table 6 Results for sample 3 at various flow rates and various power levels. 


\section{Appendix 4 Theory behind CFDesign solver}

In this section, I will discuss the partial differential equations governing the fluid flow and heat transfer. The laws, which govern the fluid and heat transfer, are continuity equation, Navier-stokes equation and the energy equation. These equations are intimately coupled and non-linear making a general analytic solution impossible except for a limited number of special problems, where the equations can be reduced to yield analytic solutions. Because most practical problems of interest do not fall into this limited category, approximate methods are used to determine the solution of these equations.

For the analyses, I used incompressible, Newtonian fluid with conduction and forced convection for heat transfer. I will be discussing the governing equations in these cases and not the entire general governing equations, which become more robust in discussion. An incompressible fluid means change in the fluid pressure doesn't affect its density. For incompressible flow, downstream effects are felt everywhere immediately and the pressure equation are mathematically elliptic, requiring down stream boundary conditions. Downstream boundaries must be left free of pressure constraints. Before discussing about the Newtonian fluid, it is worth to describe about boundary layer formation. When a fluid flows over a rigid surface, a boundary layer is formed. This boundary layer grows s we move along the surface. Fluid shear is largely contained in the boundary layer. Boundary layer flow refers to a class of fluid flow problems, which are primarily concerned, with the growth of this shear layer. A Newtonian fluid is one, which exhibits a linear relationship between fluid shear and strain.

$$
\tau_{\mathrm{xy}}=\mu * \partial \mathrm{u} / \partial \mathrm{y}
$$


Where $\tau$ is the fluid shear stress, the velocity gradient represents one component of the strain rate tensor and $\mu$ is the coefficient of viscosity. For Newtonian fluids, the viscosity is either constant or a function of temperature. Most engineering flows are Newtonian ( air, water, oil, steam,..) including this one.

\section{Heat transfer}

There are three modes by which heat can be transferred- conduction, convection and radiation. In conduction, heat is transferred via molecular motion. The heat transfer rate is dependent upon the thermal conductivity. Convection heat transfer refers to heat being transported by fluid motion. Radiation heat transfer is an electromagnetic phenomenon, which is dependent upon the optical conditions of the radiating media. Conjugate heat transfer refers to the combination of two or all three of these modes of heat transfer. In the present analyses uses conduction and forced convection. In forced convection flow, the temperature is dominated by fluid motion and buoyancy or gravity has little or no effect. Forced convection always has inlet region(s) and outlet region(s)

Convection problems may also be laminar or turbulent. For forced convection, the Reynolds number is the measure for determining the flow regimes. The Reynolds number is defined as the ratio of inertia force and viscous force.

$$
\mathrm{Re}=\mathrm{u}^{*} \mathrm{~L}_{\mathrm{eff}} / \mathrm{v}
$$

Where, $u$ is flow velocity, $L_{\text {eff }}$ is effective length, $v$ is the kinematic viscosity.

The other non-dimensional number, which is referenced with forced convection, is Prandtl number. The Prandtl number is defined as the ratio of molecular diffusivity of momentum and molecular diffusivity of heat. 


$$
\operatorname{Pr}=\mathrm{c}_{\mathrm{p}} * \mu / \mathrm{k}
$$

Where, $c_{p}$ is the specific heat of fluid; $\mu$ is the co-efficient of viscosity; $k$ is the thermal conductivity.

\section{Film coefficients}

CFDesign will calculate convection or film coefficients in one of the two ways. The first way is to calculate the heat transfer residual. The heat transfer residual is calculated by forming the energy equation and substituting the last temperature (or enthalpy values) solution into the formed equations. The residual is the amount of heat required to maintain the solution temperature.

The heat transfer residual is used to determine the film coefficient from the relation:

$$
\mathrm{h}=\mathrm{q}_{\mathrm{residual}} / \Delta \mathrm{T}
$$

Where, the temperature difference is that between the wall value and a near wall value.

The second method is to use an empirical correlation based on the Reynolds number the empirical correlation requires the calculation of the Nusselt number, which is defined as ratio of temperature gradients by conduction and convection at the surface.

$$
\mathrm{Nu}=\mathrm{h} * \mathrm{~L} / \mathrm{k}
$$

Where, $\mathrm{h}$ is the film coefficient, $\mathrm{L}$ is a characteristic length and $\mathrm{k}$ is the thermal conductivity of fluid. The correlation that is used to calculate the Nusselt number is:

$$
\mathrm{Nu}=\mathrm{C} * \operatorname{Re}^{\mathrm{a}} * \operatorname{Pr}^{\mathrm{b}}
$$

Where $\operatorname{Pr}$ is the Prandtl number, Re is the Reynolds number and $\mathrm{a}, \mathrm{b}$ and $\mathrm{C}$ are constants. Note that both Nusselt number and Reynolds number are dependent on a length. These lengths are not necessarily the same and are frequently different. The Reynolds number is 
usually an opening length, a cylinder diameter or step height. The Nusselt number length is generally the length along the surface for which film coefficients are being calculated.

\section{Governing equations}

The governing equations for fluid flow and heat transfer are Navier-Stokes or momentum equations and the First Law of Thermodynamics or energy equation. The governing partial differential equations can be written as:

$$
\begin{aligned}
& (\partial \rho / \partial \mathrm{t})+(\partial \rho \mathrm{u} / \partial \mathrm{x})+(\partial \rho v / \partial \mathrm{y})+(\partial \rho \mathrm{w} / \partial \mathrm{z})=0 \quad \text { continuity equation } \\
& \rho(\partial \mathrm{u} / \partial \mathrm{t})+\rho \mathrm{u}(\partial \mathrm{u} / \partial \mathrm{x})+\rho \mathrm{v}(\partial \mathrm{u} / \partial \mathrm{y})+\rho \mathrm{w}(\partial \mathrm{u} / \partial \mathrm{z})=\rho \mathrm{g}_{\mathrm{x}}-\partial \mathrm{p} / \partial \mathrm{x}+\partial[2 \mu(\partial \mathrm{u} / \partial \mathrm{x})] / \partial \mathrm{x}+ \\
& \partial[\mu(\partial \mathrm{u} / \partial \mathrm{y}+\partial \mathrm{v} / \partial \mathrm{x})] / \partial \mathrm{y}+\partial[\mu(\partial \mathrm{u} / \partial \mathrm{z}+\partial \mathrm{w} / \partial \mathrm{x})] / \partial \mathrm{z}+\mathrm{S}_{\omega}+\mathrm{S}_{\mathrm{DR}} \quad \mathrm{x}- \\
& \text { momentum equation } \\
& \rho(\partial v / \partial t)+\rho u(\partial v / \partial x)+\rho v(\partial v / \partial y)+\rho w(\partial v / \partial z)=\rho g_{y}-\partial p / \partial y+\partial[\mu(\partial u / \partial y+\partial v / \partial x)] / \partial x+ \\
& \partial[2 \mu(\partial v / \partial y)] / \partial y+\partial[\mu(\partial v / \partial z+\partial w / \partial y)] / \partial z+S_{\omega}+S_{D R} \quad y-\text { momentum } \\
& \text { equation } \\
& \rho(\partial w / \partial t)+\rho u(\partial w / \partial x)+\rho v(\partial w / \partial y)+\rho w(\partial w / \partial z)=\rho g_{z}-\partial p / \partial z+\partial[\mu(\partial u / \partial z+\partial w / \partial x)] / \partial x \\
& +\partial[\mu(\partial \mathrm{v} / \partial \mathrm{z}+\partial \mathrm{w} / \partial \mathrm{y})] / \partial \mathrm{y}+\partial[2 \mu(\partial \mathrm{v} / \partial \mathrm{z})] / \partial \mathrm{z}+\mathrm{S}_{\omega}+\mathrm{S}_{\mathrm{DR}} \mathrm{z}-\text { momentum } \\
& \text { equation }
\end{aligned}
$$

The two source terms in the momentum equations are for distributed resistances and rotating coordinates, respectively. The distributed resistance term can be written in general as:

$$
S_{D R}=-\left[\left(K_{i}+f / D_{h}\right) \rho V_{i}^{2} / 2\right]-C \mu V_{i}
$$

Where i refers to the global coordinate direction ( $\mathrm{u}, \mathrm{v}, \mathrm{w}$ momentum equation), $\mathrm{K}$-factor can be determined from measurements of pressure drop versus flow rate, $\mathrm{f}$ is the friction 
factor, $D_{h}$ is the hydraulic diameter. The friction factor is calculated using the Moody relation, $\mathrm{C}$ is permeability and $\mu$ is the fluid viscosity. Note that the $\mathrm{K}$-factor term can operate on a single momentum equation at a time because each has its own unique $\mathrm{K}$ factor. The other two resistance types operate equally on each momentum equation. The other source term is for rotating flow. This term can be written in general as:

$$
S_{\omega}=-2 \rho \omega_{i} \times V_{i}-\rho \omega_{i} \times \omega_{i} \times r_{i}
$$

Where $\mathrm{i}$ refers to the global coordinate direction, $\omega$ is the rotational speed and $\mathrm{r}$ is the distance from the axis of rotation.

For incompressible and subsonic compressible flow, the energy equation is written in terms of static temperature:

$$
\begin{gathered}
\rho \mathrm{C}_{\mathrm{p}} \partial \mathrm{T} / \partial \mathrm{t}+\rho \mathrm{C}_{\mathrm{p}} \mathrm{u}(\partial \mathrm{T} / \partial \mathrm{x})+\rho \mathrm{C}_{\mathrm{p}} \mathrm{v}(\partial \mathrm{T} / \partial \mathrm{y})+\rho \mathrm{C}_{\mathrm{p}} \mathrm{w}(\partial \mathrm{T} / \partial \mathrm{z})=\partial[\mathrm{k}(\partial \mathrm{T} / \partial \mathrm{x})] / \partial \mathrm{x}+ \\
\partial[\mathrm{k}(\partial \mathrm{T} / \partial \mathrm{y})] / \partial \mathrm{y}+\partial[\mathrm{k}(\partial \mathrm{T} / \partial \mathrm{z})] / \partial \mathrm{z}+\mathrm{q}_{\mathrm{v}}
\end{gathered}
$$

\section{Segregated Solver}

The sequence of operations in CFDesign segregated solver is shown in the figure below. The governing equations are solved separately. Also, if the analysis is isothermal, the energy equation solution is skipped. Likewise if the analysis is laminar, the turbulence equations are skipped.

1. Read in geometry, boundary conditions and control data.

2. Create data structures.

3. Solve x-momentum equation.

4. Solve y-momentum equation.

5. Solve z-momentum equation. 
6. Solve pressure equation and correct velocities.

7. Solve energy equations.

8. Solve turbulent kinetic energy equations.

9. Solve turbulent energy dissipation equation.

10. Check convergence. Goto 3

11. Perform output calculations.

12. Write out data.

\section{Exit}

As the governing equations are non-linear, they must be solved iteratively. A picard or successive substitution method is used. In this method, estimates of the solution variables $(\mathrm{U}, \mathrm{V}, \mathrm{W}, \mathrm{P}, \mathrm{T}, \mathrm{K}, \varepsilon)$ are substituted into the governing equations. The equations are solved for new values, which are then used as estimates for the next pass. The global iteration is shown in the above figure. CFDesign will either perform a fixed number of these global iterations, or it will check for the convergence criterion, or it will stop when either is reached. The convergence criterion is the level at which the specified variable's residual norm must reach. Residual norm is the parameter, which yields the most information for the widest range of problems.

First, the residual must be defined. After the governing equations have been discretized, they will become a set of algebraic equations for the dependent variables: $U$, $\mathrm{V}, \mathrm{W}, \mathrm{P}, \mathrm{T}, \mathrm{K}, \varepsilon$. For each of these variables, there will be an equation for each finite element node in the analysis model. A typical algebraic equation for variable $\varphi$ at node I can be written as:

$$
A_{i i} \varphi_{i}+\sum A_{i j} \varphi_{j}=F_{i} ; j \neq i
$$


Where $A_{i j}$ is the algebraic coefficients resulting from discretizing the advection and diffusion terms in the governing equation and $F_{i}$ are the discretized source terms. The residual of this equation is defined as:

$$
R_{\varphi i}=F_{i}-A_{i i} \varphi_{i}-\Sigma A_{i j} \varphi_{j}
$$

where $R_{\varphi i}$ is the nodal residual for $\varphi$ at node $i$.

With each pass through the segregated solver or global iteration, these residuals should become smaller if the solution is converging. Rather than plotting each nodal residual after every global iteration, the norm of the nodal residuals is calculated. The norm effectively combines all of the nodal residuals into a single number:

$$
\sqrt{ }\left(\Sigma \mathrm{R}_{\mathrm{i}}{ }^{2}\right)
$$

As with the nodal residuals, the norms of the residuals should also get smaller as the solution converges. The norm of the nodal residual is what CFDesign prints in the status file and plots in the convergence monitor window to indicate convergence.

Other indicators of convergence include looking at the minimum, maximum and average values of the dependent variables. All of these parameters should asymptote to a single value. When this happens, the solver is no longer significantly changing these values and the solution can be considered converged. The ultimate test of convergence is to look at the results of the analysis in the post-processor at different global iterations. If the results do not change appreciably between the two runs, the solution may be converged enough for your purpose. 


\section{Matrix solvers}

As shown in the above equations, the discretization process produces algebraic equations at every node. These equations form a matrix, $\mathrm{A}_{\mathrm{ij}}$ that has as many rows as there are finite element nodes and columns enough to contain the non-zero coefficients for nodal $\varphi$ values.

The classical method for solving the matrix equation is Gaussian elimination. This is a rather expensive way to get a solution because the elimination process requires at least a banded matrix for the fill produced during decomposition. The $\mathrm{A}_{\mathrm{ij}}$ stored by CFDesign is much smaller than a banded matrix. Also, the elimination process is fairly computeintensive. Since we are solving these equations repeatedly, this expensive elimination procedure would be prohibitively slow and arduous.

The simplest iterative matrix solver is the Gauss-Seidel procedure where the $\varphi$ values are determined:

$$
\Phi_{i}=\left(F_{i}-\Sigma A_{i j} \varphi_{j}\right) / A_{i i}, j \neq i
$$

The $\varphi_{\mathrm{j}}$ values in this equation are the most recently available values. Effectively, what this does is transfer all of the off-diagonal terms to the right-hand-side of the equation. Because the number of Gauss-Seidel iterations it takes to get a decent solution is quite large, this method is not often used.

Another iterative matrix solver, which gives a considerably better solution than Gauss-Seidel particularly for transport problems, is the Tri-Diagonal Matrix Algorithm (TDMA). In this method, a tri-diagonal matrix equation is constructed. Here, the two columns adjacent to the diagonal of the coefficient matrix are kept and the other terms are 
transferred to the right-hand-side of the equations where old values of values of $i$ are used. The matrix equation for TDMA can be written as:

$$
A_{i-1, j} \varphi_{i-1}+A_{i, j} \varphi_{i-1}+A_{i+1, j} \varphi_{i+1}=\sum A_{i, j} \varphi_{j}+F_{i}, j \neq i-1, j \neq i, j \neq i+1
$$

The TDMA algorithm effectively solves 1-dimensional planes of nodes simultaneously. In the transport equations, information passes from the inlet plane on to each successive plane. Hence, using the TDMA algorithm to solve the transport equations mimics this physical information flow process.

There are several iterative matrix solvers, which are variants of the conjugate gradient method. Some methods are applicable only to symmetric matrices; others apply to nonsymmetric matrices. All of these variants use the similar techniques to solve the matrix equation. Namely, they use a searching technique to direct the solution of the matrix equations and converge faster. They are frequently referred to as semi-direct matrix solvers because they yield highly accurate solutions. In CFDesign, the conjugate gradient solvers will iterate through the elimination process until the convergence criterion is met or the number of iterations set by the user is exceeded.

\section{Relaxation}

As we solve the non-linear governing equation approximately, during the segregated solver passes or global iterations, the resulting new solution variables may well over-shoot or under-shoot their correct values. These over-shoots and under-shoots can easily cause divergence. To prevent the solution from going to far off the mark, we slow the changes made to the solution variables using relaxation techniques. 
The first technique is called under-relaxation. In this form, the new solution is weighted by the old solution using the formula:

$$
\Phi=\alpha \varphi_{\text {new }}+(1-\alpha) \varphi_{\text {old }}
$$

Where $\varphi_{\text {new }}$ is the current solution, $\varphi_{\text {old }}$ is the previous value and $\alpha$ is the relaxation value. This value should be in the range of 0.0 to 1.0 . if a value of 0.0 is used, the new solution is ignored. If 1.0 is used, the previous value is ignored. For most situations, the value of 0.5 is best. If convergence difficulties occur, lowering the pressure relaxation to a value of 0.1 to 0.3 may solve the problem.

The second form of relaxation is called inertial relaxation, where under-relaxation is typically applied to the solution variables themselves, inertial relaxation is used in the governing equations to slow the solution down in the same manner as the transient terms for non-steady problems. So, the inertial relaxation term is added to the governing equations in the following manner:

$$
\left[\mathrm{A}_{\mathrm{i}, \mathrm{I}}+\rho_{\mathrm{i}} \mathrm{Nd} \Omega / \Delta \mathrm{t}_{\text {inertia }}\right] \varphi_{\mathrm{i}}+\Sigma \mathrm{A}_{\mathrm{i}, \mathrm{j}} \varphi_{\mathrm{j}}=\mathrm{F}_{\mathrm{i}}+\left(\rho_{\mathrm{i}} \mathrm{Nd} \Omega / \Delta \mathrm{t}_{\text {inertia }}\right) \varphi_{\mathrm{i}}{ }^{\text {old }}
$$

The second term within the parentheses and the last term on the right hand side of this equation are the inertial relaxation terms. The $\Delta \mathrm{t}_{\text {inertia }}$ can be adjusted to affect the influence of inertia. A value of $1 e+15$ is the default, which effectively eliminates any inertial influence. For analyses with convergence difficulties, this term should be lowered. Values on the order of 1e-4 to $1 \mathrm{e}-1$ are recommended. For incompressible flows, inertia should only be applied to the momentum equations (velocities). For compressible flows, using inertial relaxation on pressure frequently aids solution progress. 